Universidad de Lima

Facultad de Economía

Carrera de Contabilidad

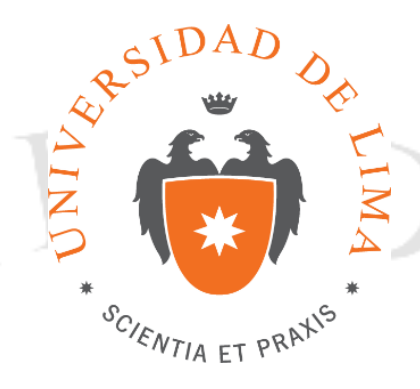

\title{
PROCESO DE COSTEO DE UNA EMPRESA DE SERVICIOS DE INGENIERÍA Y CONSTRUCCIÓN DEL SECTOR MINERO
}

Trabajo profesional teóricamente fundamentado (Proyecto profesional) para optar el título de Contador Público

\section{Oscar Eduardo Torres Torreblanca \\ Código 19882629}

\author{
Asesor \\ Julio Segundo Catacora Díaz.
}

Lima - Perú

Enero de 2017 


\section{DEDICATORIA}

A mi querido y recordado papá, mi amigo, mi vida: Mario Gregorio Torres Heredia, por todo lo que hiciste por mi en vida y aún sigues haciendo desde la gloria de nuestro Señor Dios. Sé que estás ausente físicamente, pero siempre estás en mi corazón, mis pensamientos, mi vida, hasta el día que Dios me permita volverte a encontrar.

Asimismo, a mi mamá: Rosa, tía Yolanda, mis hermanos y mis hermosos sobrinos, por apoyarme en los buenos y más aún, en los momentos difíciles, sin cuyo soporte y aliento, no hubiera sido posible realizar este pequeño proyecto. 


\section{PROCESO DE COSTEO DE UNA EMPRESA DE SERVICIOS DE INGENIERÍA Y CONSTRUCCIÓN DEL SECTOR MINERO}




\section{TABLA DE CONTENIDO}

CAPITULO I: PRESENTACIÓN, CARACTERÍSTICAS Y ACTIVIDADES DE LA

EMPRESA

1.1 Análisis y Características de la Empresa....................................................................... 3

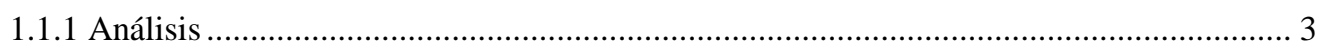

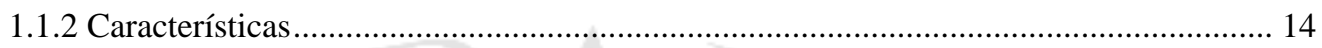

1.1.3 Técnicas de Gestión y Control en un proyecto EPCM ............................................ 17

1.1.3.1 Gestión y Control de Proyectos ................................................................................ 18

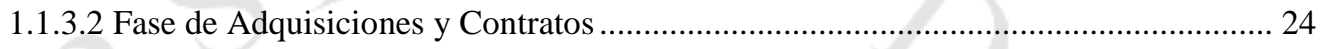

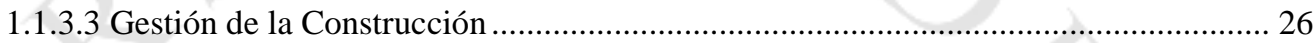

1.2 La Empresa y la Problemática Actual del Sector ............................................... 31

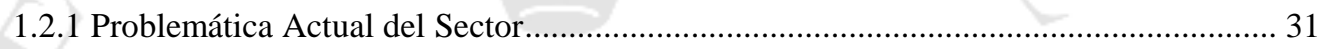

1.2.2 La Empresa en el Contexto Minero .............................................................. 40

1.3 Objetivo y Alcance del Proceso de Costeo............................................................................. 48

CAPITULO 2: ENFOQUE Y DESARROLLO DEL INFORME ...............................50

2.1 Otorgamiento y tipos de Contrato en una empresa EPCM ............................... 50

2.1.1 Otorgamiento del Contrato de Construcción ............................................................. 50

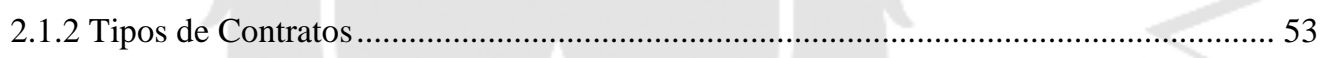

2.1.2.1 Contratos a Suma Alzada o Llave en Mano................................................................ 56

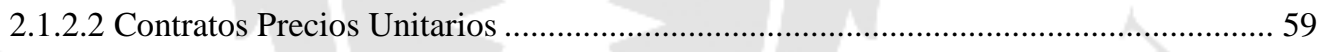

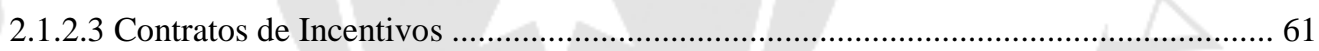

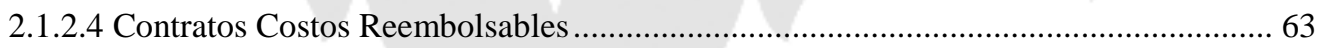

2.2 Roles y Responsabilidades de las áreas dentro de la empresa ............................ 68

2.3 Aspectos Contables y Tributarios del proceso de facturación.............................. 80

CAPITULO 3: COSTEO Y ELEMENTOS DEL COSTEO ........................................97

3.1 Centros y Elementos del Costeo ....................................................................... 98

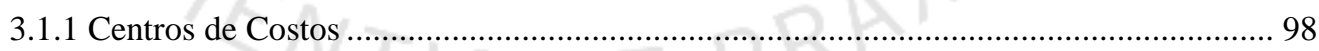

3.2 Recopilación de datos, preparación y presentación de la factura.................... 103

3.3 Documentos soporte y/o entregables para afectos tributarios......................... 108

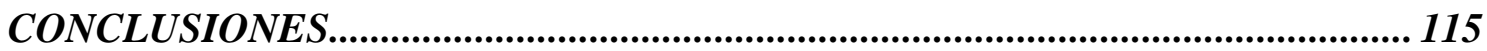

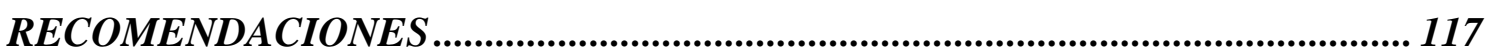

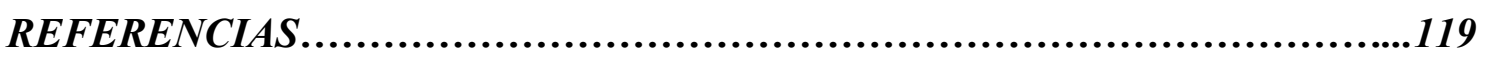

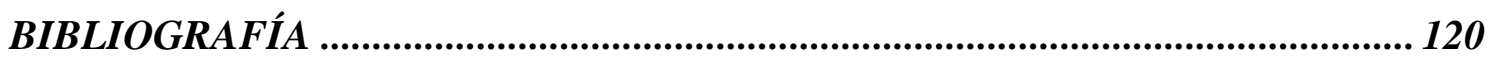

ANEXOS 


\section{ÍNDICE DE TABLAS}

Tabla 1.1: Estado Consolidado de Situación Financiera .............................................. 9

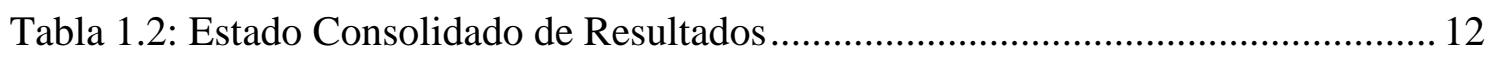

Tabla 1.3: Ganancia por Unidades de Negocio ......................................................... 14

Tabla 1.4: Recaudación del Estado por Actividades del Sector Minero ........................ 35

Tabla 1.5: Recaudación del Impuesto a la Renta de 3ra. Categoría Por Sectores .......... 37

Tabla 2.1: Método de Asignación de Determinación del Ingreso Neto.......................... 88

Tabla 3.1: Cálculo de Ingresos y Costos del Servicio ................................................. 97

Tabla 3.2: Grado de Avance Estimado por Mes ............................................................ 98

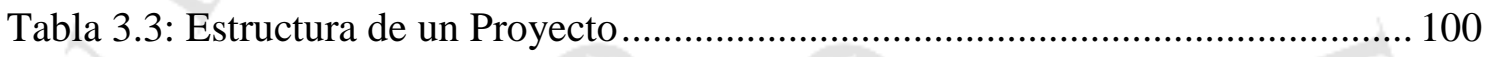




\section{ÍNDICE DE FIGURAS}

Figura 1.1: Esquema De Funcionamiento Contrato De Construcción EPCM.................. 5

Figura 1.2: Carga Total De Tributos y Aportes Del Sector Minero. .............................. 34

Figura 1.3: Producción Nacional de Oro .................................................................... 44

Figura 1.4: Producción Nacional de Plata .................................................................. 45

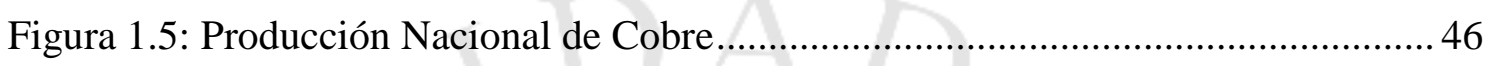

Figura 1.6: Producción Nacional de Plomo .................................................................... 47

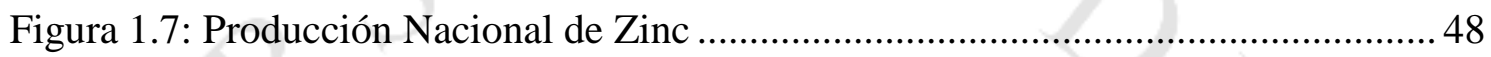

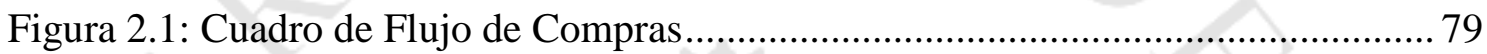




\section{ÍNDICE DE ANEXOS}

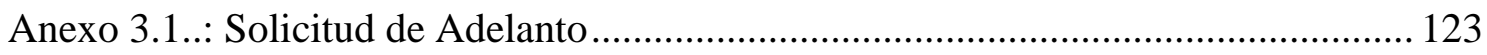

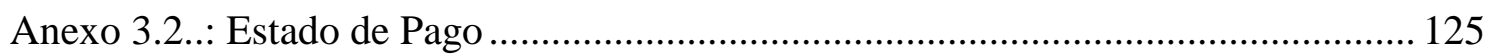

Anexo 3.3..: Lista Autorización de Firmas ................................................................... 130

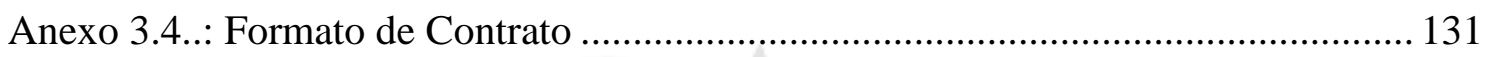

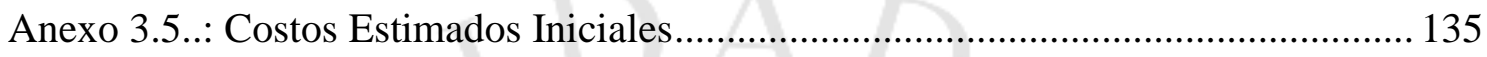

Anexo 3.6..: Formato Presentación y Solicitud de Pago de Edp's ................................ 136

Anexo 3.7..: Relación de Gastos Aceptados .................................................................... 137

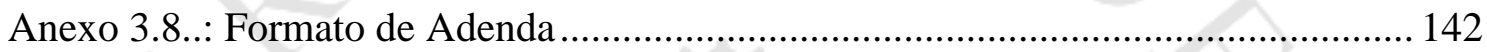

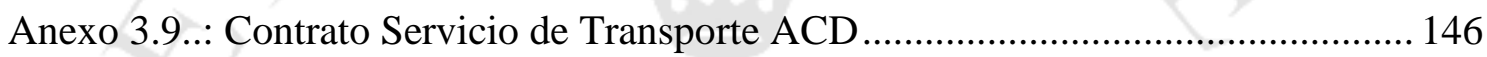

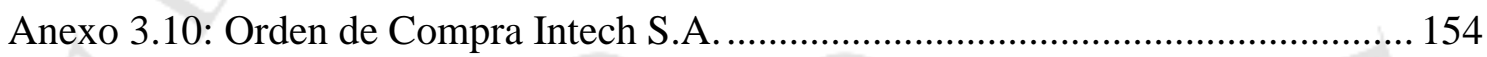

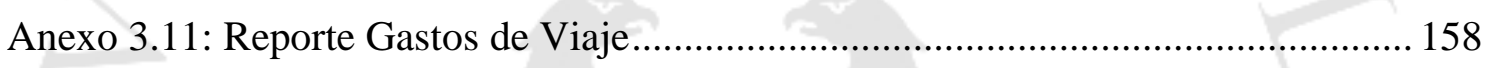

Anexo 3.12: Documentación para Presentación de Valorizaciones Contratistas .......... 159 


\section{INTRODUCCIÓN}

El presente proyecto profesional tiene por finalidad, mostrar el planteamiento de desarrollo de un proceso de costeo en una empresa que brinda servicios de ingeniería y construcción a través de sus servicios de Ingeniería, Procura, Construcción y Gerenciamiento o Administración (EPCM, por sus siglas en inglés). Este es un modelo muy particular de costeo y posterior facturación a sus clientes, ya que se realiza a través de los Estados de Pago o Valorizaciones, los cuales incluyen información relevante de todos los costos y gastos en los cuales la empresa incurre, por lo general, por periodos mensuales, costos y gastos que son trasladados a su(s) cliente(s), en cuanto sean aceptados y de acuerdo a lo estipulado en los contratos acordados para la realización de sus proyectos u obras.

Si bien es cierto, los proyectos que realiza son completos, EPCM y cuyo proceso es desarrollado y explicado en su totalidad en este trabajo profesional, en este caso enfocaremos el plan de las etapas de Construcción y Gerenciamiento o Administración de la obra, ya que por tratarse de una empresa transnacional, que desarrolla sus etapas de Ingeniería y Procura en su casa matriz, por decisiones corporativas, no destina infraestructura, medios económicos y personal especializado permanente para realizarlos en cada país donde tiene operaciones. Estas dos etapas finales, son desarrolladas en el país y más específicamente en la locación donde finalmente se ejecuta la obra o proyecto.

Se apreciará la íntima relación que existe, tanto entre cliente, quien contrata los servicios de la empresa y contratista quien desarrolla la obra, como la relación de las áreas de la empresa involucradas en la ejecución de los proyectos, la cual debe ser muy activa y de mucha comunicación, ya que de ello dependerá la ejecución exitosa de sus obras, con índices de tiempo en la medida de lo acordado, márgenes aceptables de desviaciones en los presupuestos planificados, no menos importante en este tipo de empresas, pocas probabilidades de ocurrencias de accidentes en los colaboradores, es decir, alto grado de seguridad, entre otros aspectos, lo que redundará en la satisfacción del cliente y mantener o incrementar el prestigio de la empresa en el sector en los países donde ofrezca sus servicios. 
Se plantea en términos generales, el desarrollo del sector minero durante el transcurso de los años en el país, pro y contras con la evolución del sector en aspectos económicos, sociales, culturales y los aportes de personalidades ligadas al rubro, tanto nacionales, como extranjeros.

El presente proyecto se enfocará en la forma de recolección de información para aplicar el cálculo de los valores y determinar los costos de sus servicios, proceso en el que no sólo tiene que medir sus propios valores agregados, como el costo de la mano de obra de su propio personal asignado, que es el más importante, ya que la empresa tiene por política contar con colaboradores altamente calificados, las mejores relaciones con sus proveedores para la consecución de los mejores valores de los materiales a usar en la obra, cartera de sub-contratistas con altos estándares en la prestación de sus servicios. Además la empresa cuenta con conocimiento de más de 100 años de creación y alrededor de 40 años desarrollando proyectos en el país, tiempo en el cual ha aplicado el conocimiento adquirido con la experiencia en la ejecución de proyectos EPCM y que le ha permitido generar e implementar políticas específicas y muy claras para cada área de la empresa, las que le han permitido ganarse un lugar y prestigio dentro de sus clientes, los cuales por lo general, recurren a ella para el desarrollo de sus obras o proyectos.

Finalmente, la idea primordial con el desarrollo de la estructura de este trabajo, es poder colaborar con información, que en adelante, ayude a los interesados en el desarrollo este tipo de proyectos de servicios de ingeniería y construcción denominados EPCM. 


\section{CAPITULO I: PRESENTACION, CARACTERISTICAS Y ACTIVIDADES DE LA EMPRESA}

\subsection{Análisis y Características de la Empresa}

\subsubsection{Análisis}

La Empresa con más de 100 años aceptando grandes desafíos en su rubro es el líder mundial en ingeniería, adquisiciones, construcción, mantenimiento y gestión de proyectos, con presencia en los 5 continentes, trabajando con gobiernos y empresas multinacionales para diseñar, construir y mantener muchos de los proyectos de inversión más complejos y desafiantes en el mundo. Cabe mencionar que cuenta con cinco unidades de negocio para el desarrollo de su negocio global que son en los sectores: Petróleo y Gas, Gobierno, Energía, Servicios Globales y finalmente Industria e Infraestructura, que es la unidad de negocios en el que está incluido el sector de servicios de gerenciamiento de ingeniería y construcción, el cual es objeto del desarrollo de este proyecto.

La Empresa ha contribuido activamente en el desarrollo de diversos proyectos de cobre, oro, plata y molibdeno. Sus expertos son reconocidos globalmente y la compañía cuenta con equipos especializados en disciplinas claves tales como manejo de materiales, concentrados y tecnologías de proceso, además ofrece un amplio rango de servicios a los proyectos que realiza, los que incluyen estudios de pre-factibilidad y factibilidad y brindando servicios de Ingeniería, Adquisiciones, Construcción y Administración de Proyectos (EPCM: Engineering, Procurement, Construction and Management, por sus siglas en inglés), los cuales se desarrollarán brevemente:

Ingeniería: cuenta con vasta experiencia en la realización de estudios conceptuales, estudios de pre-factibilidad e ingeniería conceptual o básica y detallada. La ingeniería conceptual, sirve para identificar la viabilidad técnica y económica del proyecto y marcará la pauta para el desarrollo de la ingeniería básica y de detalle. Es la primera fase o etapa de un proyecto de ingeniería, en la cual se fijan los objetivos deseados por el cliente, se establece el tipo de tecnologías a aplicar, se define el marco de las normas técnicas que regularán los diseños, se establecen los criterios de evaluación económica y de cálculo de la rentabilidad. Una vez definidos éstos, se procede a conciliar las bases o criterios de norma de las entidades financieras o crediticias establecidas por el cliente, con la finalidad de elegir la opción con la cual se procederá a desarrollar la siguiente fase o se define la cancelación del proyecto por baja rentabilidad. 
La ingeniería de detalle, consiste en interconectar cada uno de los equipos e instrumentos de la ingeniería conceptual o básica para que el proceso cumpla su objetivo. Con las memorias de cálculo de diseño se podrá detallar la construcción, por ejemplo, de la cimentación, columnas o marcos de un edificio completo. Se pueden elaborar planos de detalle del montaje, general, sub-montajes de mecanismos y piezas de una determinada maquinaria. Se pueden elaborar los de detalle de la ingeniería eléctrica, subestación eléctrica, hasta la instalación de un motor o una lámpara en la edificación.

Adquisiciones o Procura: en este aspecto la organización proporciona fuentes estratégicas de aprovisionamiento y servicios tácticos de compras de bienes y servicios para apoyar a sus proyectos en el mundo. Cuenta con una importante cantidad de especialistas en su equipo de colaboradores, quienes seleccionan los materiales y equipos adquiridos para dar soporte a sus proyectos. Cuenta con proveedores en todo el mundo, con lo cual asegura el abastecimiento a todos sus proyectos cuando alguno de ellos no encuentra proveedores locales.

Construcción: la empresa ofrece un enfoque totalmente integrado para este rubro. La constructibilidad es una parte clave en la planeación de la ejecución de los proyectos. Los esfuerzos en la construcción, empiezan temprano en el desarrollo del proyecto y son impulsados por el total de trabajadores del proyecto y apoyados por el grupo de construcción. Todas las áreas del proyecto son investigadas en la búsqueda de oportunidades de modularización, prefabricación e instalación que ahorrarán tiempo y dinero al proyecto. Todas las oportunidades son exploradas por los equipos de ingeniería, adquisiciones, control de proyectos, construcción y seguridad industrial para asegurar que se tome una decisión que cumpla con los requisitos del proyecto y proporcione valor agregado de manera segura y rentable.

Administración o Gerenciamiento del Proyecto: la empresa tiene entendido que la entrega exitosa de un proyecto no se logra por una casualidad, sino, gracias a una cuidadosa planeación y organización. Cuenta con experiencia en la preparación de estrategias de ejecución de proyectos que combina las mejores prácticas, las lecciones aprendidas y los requisitos y procedimientos que sus clientes desean obtener. Su capacidad para la administración de proyectos abarca diferentes industrias, así como también tiene la capacidad para servir como administrador de mega-proyectos complejos. Como empresa global y con altos estándares en uso de tecnología, todas las oficinas tienen acceso a la información y al conocimiento compartido establecido y 
herramientas, procedimientos y procesos de administración de proyectos que se utilizan en todos los proyectos. Los documentos que usa como soporte, son de alta calidad técnica para asegurar una consistente y exitosa entrega de los proyectos desde todas las ubicaciones donde opera. Así como también tiene la capacidad de combinar sus conocimientos y experiencia en la industria para desarrollar consistentemente soluciones de administración para la entrega de los proyectos con seguridad, a tiempo y dentro del presupuesto acordado.

El siguiente es un sencillo esquema del funcionamiento de un contrato de construcción EPCM, en cuanto a sus participantes y responsabilidades:

Figura 1.1: Esquema De Funcionamiento Contrato De Construcción EPCM

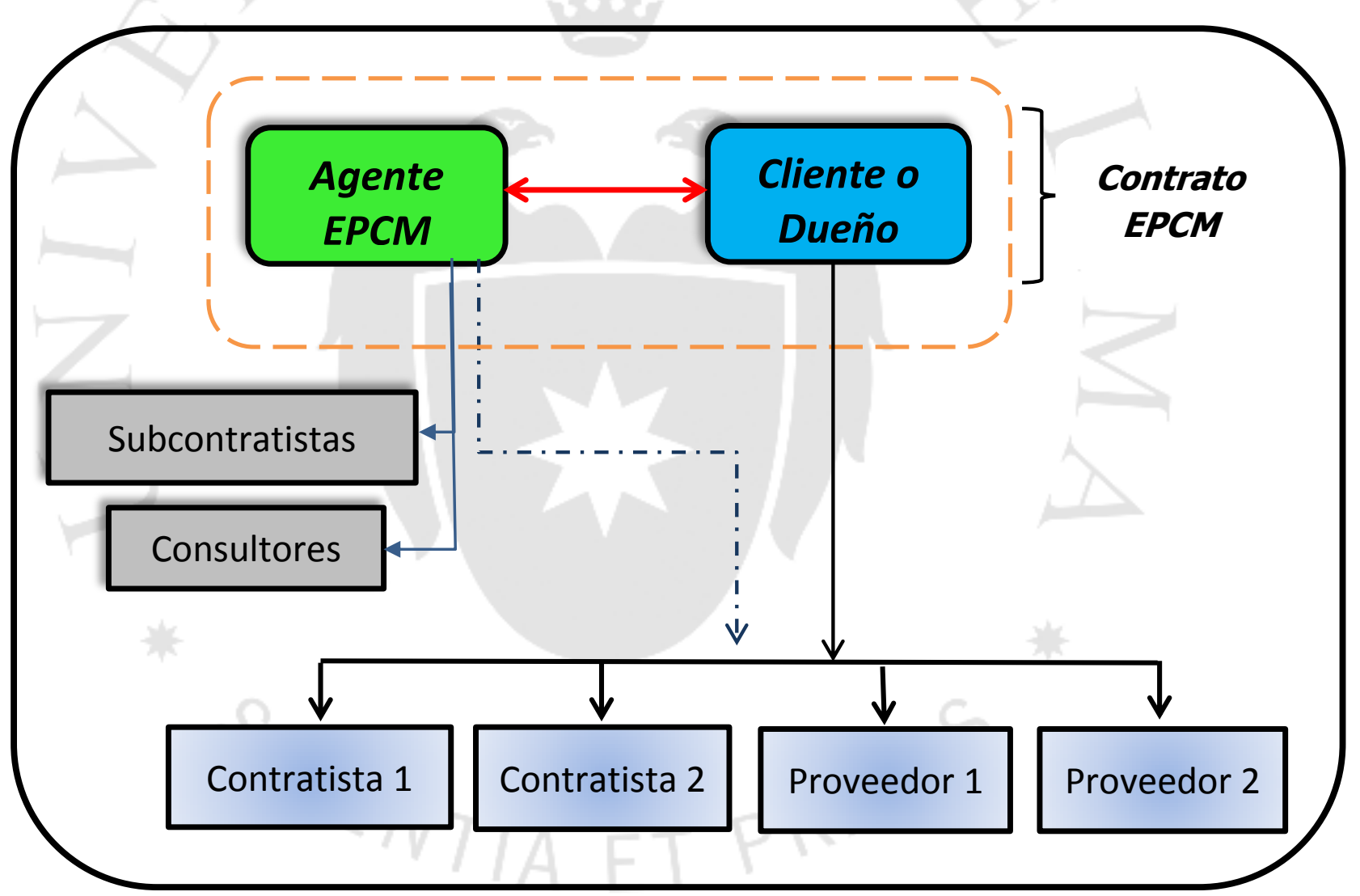

Fuente:http://www.indemipe.com/indemipe/Antonio-Pinilla.pdf 
La Empresa, es una empresa basada en soluciones, que cuenta con la capacidad técnica y financiera necesarias para abordar las tareas más difíciles. La Empresa es reconocida como una empresa confiable, que realiza sus proyectos a tiempo y dentro del presupuesto, que posee un excelente historial de seguridad y que cumple con los más altos estándares éticos. Su comprobada capacidad para resolver desafíos de ingeniería y medioambientales la ha hecho merecedora de una gran reputación por ser confiables, lo cual ha dado como resultado excelentes relaciones con sus clientes. El aporte y logros estimulan la expansión económica y mejoran la calidad de vida de millones de personas en todo el mundo.

Los clientes confían en la Empresa para la provisión de servicios que optimicen sus activos, mejoren su posición competitiva y aumenten su éxito comercial a largo plazo. La Empresa es clasificada constantemente como uno de los contratistas más seguros del mundo ya que uno de sus objetivos principales consiste en desarrollar, ejecutar y mantener proyectos con excelencia operativa, además de ofrecer el espectro completo de servicios del ciclo de vida para apoyar las inversiones de capital de sus clientes.

La Empresa es líder de la industria en:

- La ejecución de proyectos complejos en ubicaciones desafiantes.

- La movilización de fuerzas laborales diversificadas.

- La vinculación de recursos de ingeniería global a través de centros de ejecución situados estratégicamente.

- El abastecimiento de materiales utilizando su propia red de contratación global y también de proveedores locales.

- El cumplimiento con cronogramas ajustados.

- Desarrollar financiamientos de proyectos innovadores y rentables.

- La optimización de los bienes durante el ciclo de vida de una instalación, desde el concepto hasta las operaciones y el mantenimiento.

- El uso de técnicas de fabricación y construcción de modulares.

La experiencia adquirida por sus expertos le permite desarrollar soluciones técnicas que aportan un valor estratégico a los proyectos de capital de sus clientes en todo el mundo, ofreciendo soluciones que resuelven los retos más complejos que les toca enfrentar. Sus programas de Catedráticos y Catedráticos Principales reconocen y promueven a los empleados que se capaciten en las áreas de especialidades técnicas, 
incluyendo, por ejemplo, la ingeniería, construcción, petróleo y gas, energía, tecnología off shore y el cumplimiento de normas gubernamentales. Para ello cuenta con su galardonado sistema de gestión: Conocimiento en Línea (Knowlodge on Line), su plataforma de intranet, que permite a sus empleados tener acceso a la información y a los expertos técnicos para solucionar problemas desde cualquier lugar del mundo a cualquier hora del día, desde procedimientos aplicables por la empresa, hasta educación en línea.

La Empresa tiene como valores fundamentales: la Salud, Seguridad y Protección Ambiental, considerando como uno de sus pilares el bienestar de las personas, los empleados, sus clientes y muy importante las comunidades en las que trabaja y cuyo personal está totalmente involucrado en los proyectos que le son encargados. La ejecución exitosa de proyectos complejos entregados de una manera segura y ambientalmente racional es una prioridad máxima para la empresa. Cada día, de la mano de sus clientes, la Empresa, ayuda a proteger el medio ambiente, a ahorrar energía, a proteger vidas y a fortalecer las economías y estructuras sociales de las comunidades en las que trabaja y viven sus mismos empleados. Otro de los pilares y orgullo de la empresa, es su reconocimiento dentro de la industria y también de los gobiernos del mundo por su excelencia aplicada a la seguridad.

La Empresa se esfuerza por ser considerada como un empleador preferido a nivel global, enfocándose en atender las demandas empresariales: contratando, desarrollando y conservando el mejor talento para sus proyectos, ofreciéndoles a las personas oportunidades para desarrollar sólidas habilidades técnicas y empresariales, sustentando un flujo de talento mediante una sólida planificación de las carreras y manteniendo un ambiente laboral de inclusión, en el que los empleados de todos los lugares puedan contribuir con sus ideas y habilidades.

Dentro de su rol inclusivo, en lo referente a las comunidades donde desarrolla actividades, tiene por misión, brindar a sus habitantes bienestar social creando puestos de trabajo, otorgando educación y materiales educativos a los que necesiten y en ocasiones, cuando la situación lo amerita, construyendo viviendas, redes de electricidad y servicio de agua potable, con trabajos voluntarios de parte de sus mismos empleados para tener un impacto positivo y sustentable en la calidad de vida de dichas comunidades.

Personalmente puedo dar fe de todas éstas metas y contribuciones de La Empresa, ya que tuve oportunidad de cubrir una asignación por alrededor de un año de 
labores, en uno de sus proyectos en el departamento de Cajamarca, en la cual pude apreciar la participación de pobladores trabajando en obras de mejoramiento, como sembríos y canalización de redes de agua que eran re-direccionadas para el regadío de sus propias tierras, así como también, de la organización de actividades recreacionales y educativas de libre participación para las personas de las comunidades cercanas al proyecto, entre otros servicios de apoyo.

A continuación, y para tener una idea del posicionamiento de la empresa, se muestran los Estados de: Situación Financiera, de Resultados y un reporte de Ganancias por Segmentos, por los años terminados el 31 de Diciembre del 2013 y 2014, respectivamente: 
Tabla 1.1: Estado Consolidado De Situación Financiera

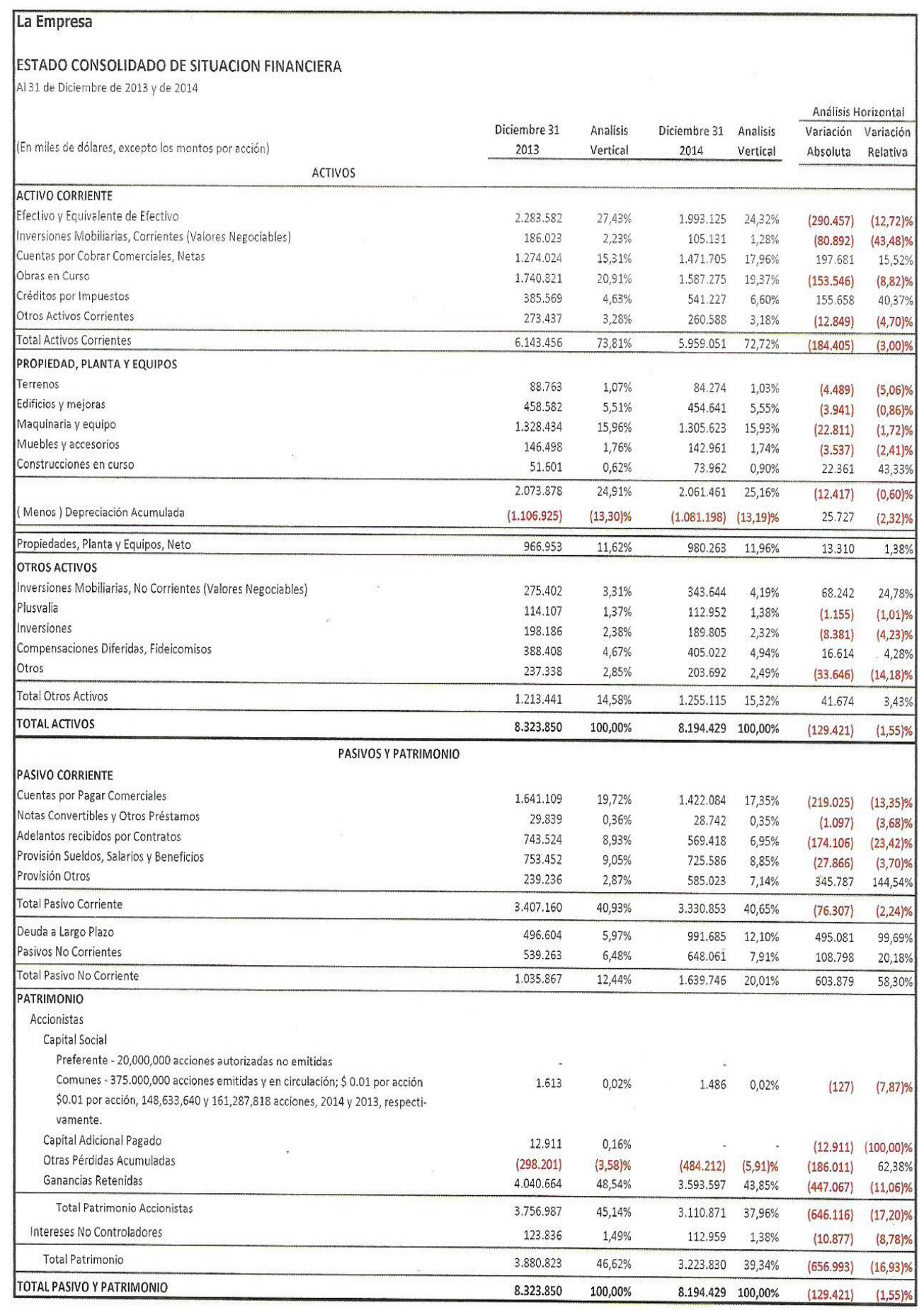

De acuerdo a las cifras mostradas en el Estado Consolidado de Situación Financiera, se puede apreciar una disminución considerable en las Inversiones Mobiliarias Corrientes (Valores Negociables Corrientes), de $43.48 \%$, lo cual se explica a que, como parte de política de la empresa, éstas se reclasifican a Inversiones Mobiliarias No Corrientes, aquellos documentos con una antigüedad mayor a 3 meses, lo que también da como resultado, en parte, el aumento de ésta última cuenta en 
24.78\%. Así mismo, se observa que las Cuentas por Cobrar Comerciales han tenido un incremento considerable de $15.52 \%$, lo que es indicador de un incremento en la facturación de los servicios que brinda y que están relacionados con el grado de avance aprobados por sus clientes, pero que aún están pendientes de cobro. Sin embargo, este aumento, conlleva a una disminución de la rotación de las cobranzas, tal como lo demuestra la ratio a continuación:

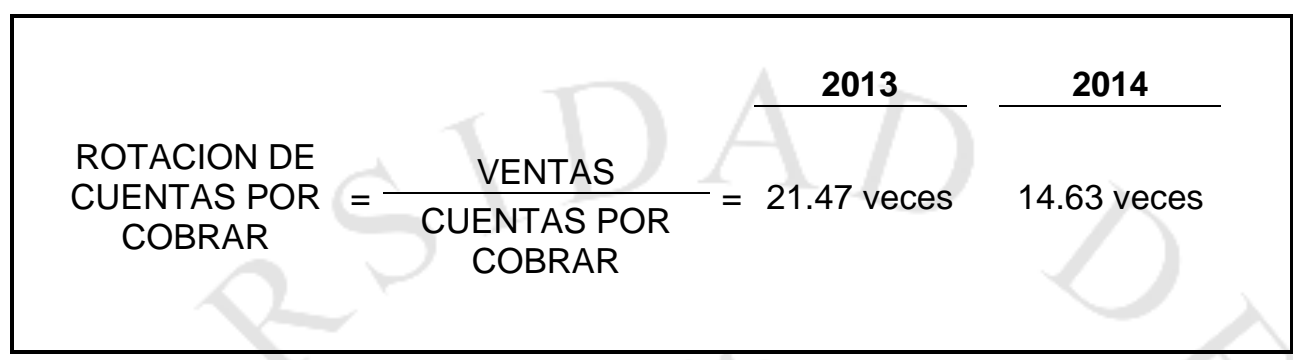

Otro aumento considerable dentro de los activos corrientes, se aprecia en los Créditos por Impuestos $(40.37 \%)$, lo cual se puede relacionar al reconocimiento contable de pagos a cuenta del impuesto a la renta y también a diferencias temporales reconocidas y por pagar en el corto plazo. Para finalizar con el rubro de los activos, la cuenta Construcciones en Curso han tenido un crecimiento considerable (43.33\%), producto de inversiones en mejoras de propiedades de la propia empresa.

Del análisis vertical de los rubros del activo, se puede apreciar que su composición, así como el mayor porcentaje de participación en su estructura, recaen en las cuentas: Efectivo y Equivalente de Efectivo, Cuentas por Cobrar Comerciales, Obras en Curso, éstas dos últimas directamente relacionadas, ya que como se puede observar, la disminución de las Obras en Curso, han generado un aumento de las Cuentas por Cobrar Comerciales, como consecuencia de la facturación de los servicios prestados. Finalmente, otra de las cuentas con mayor participación porcentual es la de Maquinaria y Equipo.

En el Pasivo Corriente se puede apreciar que la Empresa está cumpliendo con los pagos a sus proveedores y compromisos de deuda, que se reflejan en una conveniente disminución de las Cuentas por Pagar Comerciales (lo que también sería un reflejo de la disminución de la cuenta de Efectivo y Equivalente de Efectivo). También se ve una caída importante en la cuenta de Adelantos recibidos por Contratos (23.42\%), lo cual indica que se han hecho cobranzas a los clientes por los adelantos solicitados para financiar los avances de obra y que hasta que no son totalmente facturados, para el 
caso de la Empresa, mensualmente, permanecen registrados en ésta cuenta. También existe un incremento importante en la cuenta Provisión Otros (144.54\%), esto producido generalmente debido a las provisiones de cierre anuales producto de operaciones corrientes de la empresa a realizarse en fecha posterior a al periodo corriente anual.

En cuanto al aumento de la cuenta: Deudas a Largo Plazo (99.69\%), se puede concluir que la empresa a incurrido importantes financiamientos para el desarrollo de sus operaciones, lo cual también se puede apreciar en el aumento de la cuenta: Gastos por Intereses del Estado de Resultados.

Respecto al Patrimonio, el rubro Otras Pérdidas Acumuladas a mostrado un incremento considerable (62.38\%), debido al reconocimiento de pérdidas por efecto de traslación de la moneda extranjera y también al ajuste del plan de pensiones a sus empleados y en menor proporción, a pérdidas derivadas de contratos de servicios. 
Tabla 1.2: Estado Consolidado De Resultados

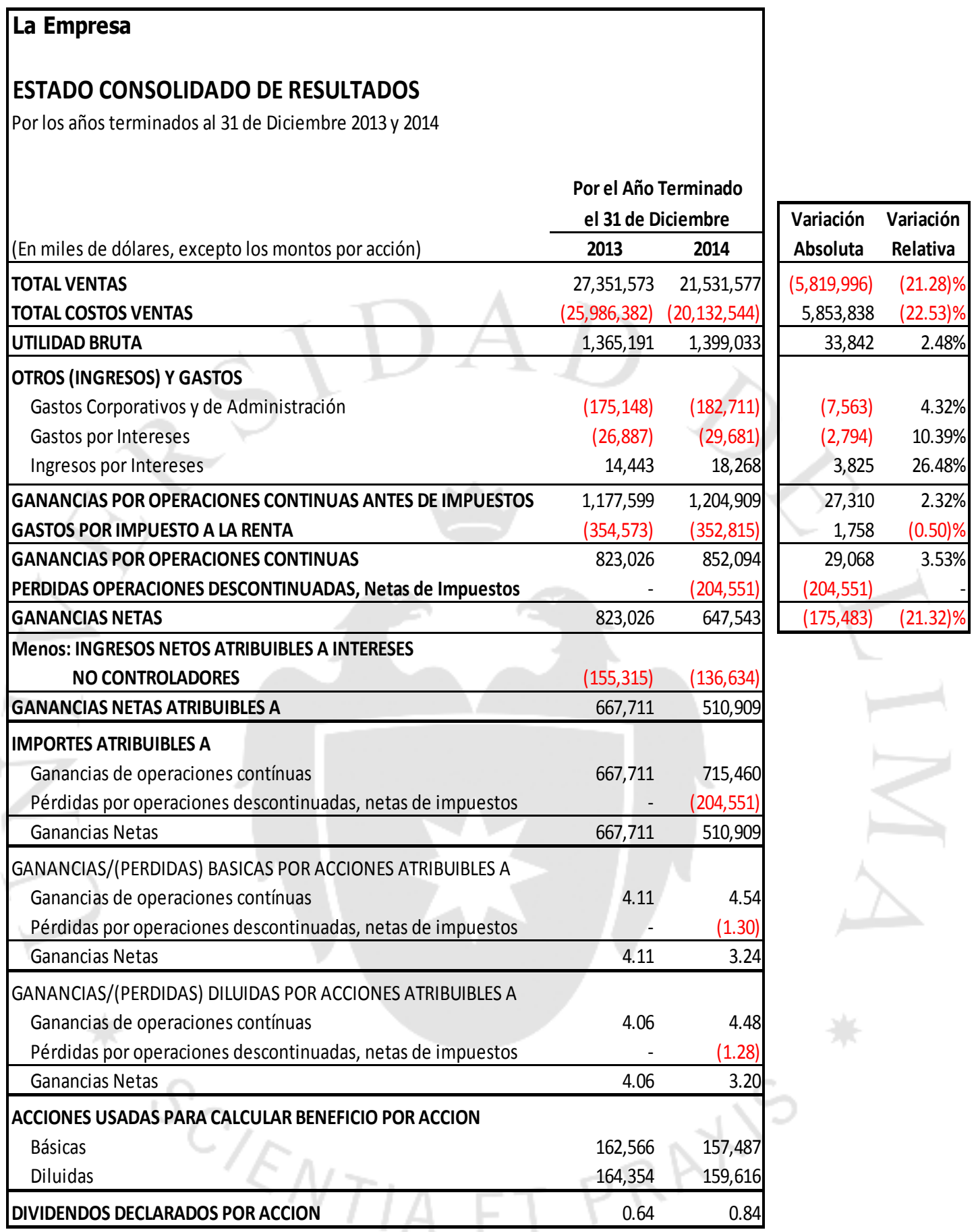

De la revisión del Estado Consolidado de Resultados de la Empresa, se puede una contracción en los ingresos (21.32\%), del año 2013 al 2014, situación que se refleja en la disminución en los Ingresos por Ventas (21.28\%), que como consecuencia, refleja una disminución en los Costos de Ventas que van en relación directa con la caída de las ventas, lo cual se justifica en la actual coyuntura, tanto nacional como internacional, motivado principalmente por la desaceleración del sector minero, a lo cual en el caso de 
nuestro país, se suman los conflictos sociales en contra de la actividad minera y la decisión de los inversionistas del sector de dejar o paralizar proyectos debido a que no se dan las condiciones políticas, jurídicas, económicas para la ejecución de los proyectos con las garantías adecuadas. Por otra parte, se puede apreciar un aumento (4.32\%) en las cuentas de Gastos Corporativos y de Administración y también en la cuenta de Gastos por Intereses (10.39\%), éste aumento debido al incremento de la cuenta Deudas a Largo Plazo, comentada líneas arriba. Otro dato resaltante de éste estado financiero, es el de la rentabilidad de la Empresa, se puede observar que tanto en los años 2013 y 2014, se mantiene en un nivel del 3\% aproximadamente, como se puede apreciar en la siguiente ratio:

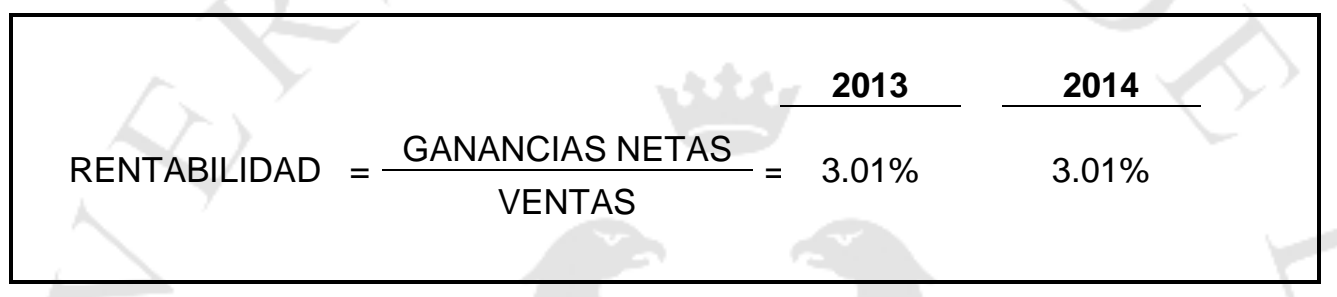

Generalmente, las empresas de éste rubro tienen cierto control en los márgenes de sus ingresos y costos, ya que, desde el inicio y fijación en las condiciones de sus contratos de servicios, tienen los estudios suficientes para programar sus flujos de ingresos y costos, de acuerdo a los grados de avance propuestos y aprobados por sus clientes, salvo hechos o acontecimientos fortuitos o externos, que puedan escapar al control de la empresa.

A continuación, se muestra reporte de Ganancias por Unidades de Negocios de la Empresa por los segmentos en los cuales se subdivide la empresa para el desarrollo de sus negocios. 
Tabla 1.3: Ganancia por Unidades de Negocio

\section{LA EMPRESA \\ GANANCIAS POR UNIDADES DE NEGOCIOS}

(En mllns. de dólares)

\begin{tabular}{|l|r|r|r|r|}
\hline \multicolumn{2}{|c|}{ Años Terminados el 31 de Diciembre } \\
\hline \multicolumn{1}{|c|}{ SEGMENTO } & $\mathbf{2 0 1 3}$ & $\mathbf{2 0 1 4}$ \\
\hline Petróleo y Gas & 11,520 & 11,369 \\
\hline Industria \& Infraest. & 11,082 & 6,062 \\
\hline Gobierno & 2,749 & 2,512 \\
\hline Energía & 1,389 & 1,004 \\
\hline Servicios Globales & 612 & 585 \\
\hline TOTALES & $\mathbf{2 7 , 3 5 2}$ & $\mathbf{2 1 , 5 3 2}$ & $\begin{array}{r}\text { Variación } \\
\text { Absoluta }\end{array}$ & $\begin{array}{c}\text { Variación } \\
\text { Relativa }\end{array}$ \\
\cline { 2 - 5 } & & $(151)$ & $(1.31) \%$ \\
$(5,020)$ & $(237)$ & $(8.63) \%$ \\
$(385)$ & $(27.72) \%$ \\
$(4.38) \%$ \\
\hline
\end{tabular}

En éste reporte se puede apreciar el detalle de los Ingresos por Ventas mostrado en el Estado Consolidado de Resultados de los años 2013 y 2014 y en él, una disminución en todos sus segmentos o líneas de negocios, pero la contracción más resaltante se puede observar justamente en el segmento: Industria e Infraestructura, línea de negocio de la cual forma parte el área que desarrolla los servicios de ingeniería y construcción, que como ya se mencionó, se debe a la coyuntura del sector minero a nivel global.

\subsubsection{Características}

La Empresa al ser una empresa que brinda servicios en los rubros de ingeniería y construcción, se caracteriza por brindar a sus clientes la mejor y más avanzada tecnología de la industria, reclutando en su plana a los mejores profesionales de todas las áreas en las que desarrolla su trabajo en cada uno de los proyectos que asume.

En general, a nivel global, la industria de la minería y la metalurgia es una de las actividades económicas más antiguas e importantes, debido a que ha sido fundamental para el desarrollo mundial a lo largo de la historia. En estas actividades se consigue una gran variedad de minerales y metales, que tienen múltiples aplicaciones en todos los procesos productivos existentes y en la gran mayoría de productos comercializados a nivel mundial.

Los proyectos mineros más importantes son construidos y gerenciados por grandes empresas, en su mayoría estatales o transnacionales privadas, que exploran e 
invierten considerables sumas de dinero en yacimientos de minerales en todos los continentes para atender la demanda mundial. Estas características de las empresas mineras se dan debido a las importantes inversiones requeridas para hacer realidad la infraestructura e instalaciones de tal envergadura que les permitan ser rentables. Además de ello, se tiene que sumar los riesgos inherentes a la exploración, investigación, construcción y explotación; y a los precios que pueden conseguir sus productos en los mercados internacionales donde son comercializados.

Debido a las grandes escalas de los proyectos y los riesgos asociados, la actividad minera requiere de considerables cantidades de recursos directos e indirectos, para desarrollar nuevas instalaciones o potenciarlas y mantener las ya existentes. Así se generan constantemente cantidades importantes de trabajo para muchas empresas y sectores especializados en la minería, relacionados principalmente a la ingeniería, la construcción, las maquinarias industriales, las ciencias y tecnología y servicios administrativos, comerciales, financieros, legales, educacionales, entre otros.

En nuestro país, el sector minero es uno de los más significativos, principalmente debido a las importantes reservas de cobre, plata y oro, entre otros minerales que posee el país, lo que a lo largo de su historia ha permitido desde épocas milenarias, como de los Incas, desarrollar esta industria a lo largo de todo el país y lo ha convertido en una de las bases de nuestra economía.

Volviendo al tema de las corporaciones que desarrollan proyectos de ingeniería y construcción, más conocidos como EPCM (Engineering, Procurement, Construction and Management), en las que la compañía Mandante o Cliente encarga a otra empresa contratista especializada, que desarrolle íntegramente el proyecto a materializar en base a estudios de factibilidad e ingenierías básicas generadas previamente, para lo cual se incluyen los siguientes procesos destacados:

Desarrollo de la ingeniería de detalle acordada para el proyecto, mediante la aplicación de recursos propios y/o subcontratando servicios del alcance total, dependiendo de la necesidad de conocimientos y experiencias adicionales en ciertas especialidades.

Manejo del proceso de adquisición de bienes, materiales, servicios y equipos y servicios necesarios para la materialización de las instalaciones e infraestructura que conforman el alcance del proyecto y la entrega de ellos en obra o donde sean requeridos, en representación del Cliente. Esto incluye los servicios a ser contratados para materializar los proyectos. 
Gerenciamiento de la construcción y administración de los contratos que el Cliente suscribe directamente con empresas especializadas en cada tipo de labores, incluyendo inspección, coordinación, control de avances, costos y programas.

Además de lo ya mencionado, la empresa contratista también realiza el gerenciamiento del proyecto completo, encargándose de las estimaciones del control de costos a lo largo del desarrollo, de la planificación y programación de las etapas y actividades, de la administración de documentos, asignación de recursos, controles de avances y gestión de la seguridad y calidad durante las distintas etapas del proyecto.

El formato de desarrollo de proyectos EPCM ha sido utilizado ampliamente en la industria de la minería a nivel global, llegando a ser uno de los métodos más utilizados en este tipo de proyectos. Esto debido a ciertas ventajas ofrecidas al Cliente frente a otras opciones que se le presentan al momento de promover una inversión de gran tamaño, lo cual es común en proyectos de inversión minera. Algunos de estos beneficios son:

El Cliente tiene la posibilidad de incorporar a un agente con trayectoria en el desarrollo de proyectos para el sector minero, ofreciendo su experiencia en diversas situaciones, ubicaciones y con otros clientes. Esto contribuye al aumento de la confiabilidad y credibilidad en la propuesta del proyecto frente a los posibles inversionistas.

Reduce el riesgo de la inversión para el Cliente ya que éste se traspasa en parte a la EPCM contratada al haber el compromiso de entregar el diseño final dentro del presupuesto, los plazos establecidos y con la calidad requerida. Además, durante la construcción, el Contratista defiende los intereses del Cliente frente a los sub contratistas y proveedores, fortaleciendo su posición.

Disminución del personal necesario del cliente, tanto para el desarrollo, como para la gestión de la obra. Esto permite enfocarse en temas prioritarios y en la supervisión de procesos críticos.

El Contratista EPCM, es responsable de coordinar y garantizar la seguridad en el proyecto, la disponibilidad de trabajo y suministros para los contratistas y sus labores en terreno, disminuyendo las opciones de accidentes, los tiempos muertos y posibles inconvenientes legales.

El Contratista es el encargado de realizar todo el proceso de precalificación, licitación y adjudicación de proveedores, equipos, contratistas y materiales, generando 
una opinión técnica y recomendación final para cada ocasión, dejando al Cliente la decisión final.

Brinda mayor integración entre los procesos de diseño, ingeniería, compras y construcción, aspecto crucial en casos con limitaciones de presupuesto, tiempos o con condiciones adversas. El resultado es un proyecto en la cual las fases se superponen, se organiza mejor la programación y anticipar posibles distorsiones, lo que puede reducir los plazos y los costos totales.

Finalmente, este procedimiento entrega la posibilidad de obtener mejores precios finales de propuesta y mayor eficiencia en las áreas de la especialidad donde existen pocas empresas constructoras con la capacidad de desarrollar grandes alcances de trabajo. Este punto es de suma importancia para la gran minería.

Los proyectos diseñados y construidos bajo la estructura EPCM, no deben confundirse con los proyectos EPC (Ingeniería, Adquisiciones y Construcción), cuya metodología de trabajo es diferente. En este segundo caso, el Contratista EPC ejecuta directamente todos los trabajos necesarios para el desarrollo del proyecto y asume los riesgos, plazos y costos, en coordinación a lo acordado con el Cliente. Durante este tipo de proyectos la participación del Cliente es reducida, sólo interactúa directamente con el Contratista general. Los Contratistas EPC son, por lo general, grandes constructoras que subcontratan el gerenciamiento y desarrollo de la ingeniería y ponen principal interés en la etapa de construcción.

\subsubsection{Técnicas de Gestión y Control en un proyecto EPCM}

Como parte de los proyectos EPCM también se pueden distinguir técnicas para el control de los procesos, que son conocidas o llamadas generalmente como: Gestión y Control de Proyecto, Adquisiciones y Contratos y Gestión de la Construcción. La primera fase se extiende a través de toda la etapa de vida del proyecto, en tanto las siguientes tres restantes, son generalmente secuenciales, aunque es bastante usual que estén programadas para superponerse, de forma tal que se puedan disminuir los plazos totales de ejecución del proyecto. A continuación, detalle de cada una de las fases: 


\subsubsection{Gestión y Control de Proyectos}

Se define la gestión de proyectos como la aplicación de conocimientos, destrezas, herramientas y técnicas a procesos y actividades del proyecto durante su ciclo de vida, con la finalidad de completarlo cumpliendo con los requisitos que le fueron encargados en un comienzo, mediante la programación, organización y asignación de recursos humanos y materiales, el control y supervisión de actividades a ejecutar mientras se desarrolle el proyecto. Los requerimientos por satisfacer son, principalmente, el cumplimiento de criterios de diseño y estándares de calidad respetando presupuestos, fechas y plazos determinados para la ejecución del proyecto.

Con este objetivo en curso, se define un plan de ejecución del proyecto, que busque terminarlo de forma exitosa, un programa que determine fechas claves, tiempos e hitos por cumplir de parte de la organización durante las actividades y también un presupuesto, estimado y administrado por el control de costos, para mantener actualizado el valor final de la inversión y poder hacer de conocimiento a los interesados.

Es responsabilidad de este grupo asegurar el funcionamiento eficiente de la organización del proyecto, por lo que se determinan los siguientes puntos como críticos al momento de desarrollar la administración del proyecto:

La definición de los objetivos del proyecto debe ser la tarea principal, de modo que queden definidos explícitamente y que sean informados a todos los integrantes relevantes de la organización, para mantener una sola línea.

Se deben determinar los riesgos que puedan aparecer durante la ejecución del proyecto, para que los hechos fortuitos no detengan su desarrollo. Esto permite tomar previsiones para ciertos casos o anticiparse a riesgos que pueden ser tanto internos del proyecto, como externos, tales como la economía, los mercados, la disponibilidad tecnológica o algún fenómeno de la naturaleza (tormentas, lluvias, desbordes de ríos, entre otros).

Tomar decisiones tempranas e invertir más en las fases iniciales del proyecto, ya que está comprobado que en la medida que se avanza en la ejecución de la obra, el costo de realizar cambios aumenta y al mismo tiempo la efectividad de éstos disminuye considerablemente.

La programación del proyecto debe tomar en cuenta todas aquellas actividades y procesos relevantes, con plazos precisos y fechas bien establecidas. Los cambios y las 
actualizaciones tienen que realizarse de forma fácil y rápida tratando de afectar al mínimo las actividades posibles.

La asignación adecuada de recursos y costos vinculados a las actividades para asegurar lo establecido en el programa y obtener flujos claros.

La responsabilidad de coordinar con las diferentes áreas y disciplinas del proyecto, promover la comunicación entre ellas y con ello mejorar el resultado final a obtener. Hacer participe en la toma de decisiones a todos aquellos que se vean involucrados por el cambio y que pueda sumar en la mejora de los rendimientos.

El control y supervisión de actividades es de mucha importancia para garantizar el correcto funcionamiento de la organización y realizar acciones correctivas a tiempo, complementando con una adecuada planificación y claridad en los objetivos y responsabilidades.

El establecimiento temprano de buenas estrategias de contratación y distribución de los alcances de trabajo, ayudan a obtener mejores resultados finales, relacionados a precios, puntualidad y calidad en las entregas de contratistas y proveedores.

Finalmente es importante definir da manera adecuada las necesidades de entrenamiento y capacitación con las cuales se deben contar para poder incluir nuevos integrantes al equipo, de forma rápida y eficiente.

Estos hitos pueden ser abordados de mejor manera si se hace referencia a proyectos realizados anteriormente, utilizando todo aquello aprendido de los problemas y cuáles fueron las soluciones más efectivas aplicadas.

A continuación, se presentan algunos de los procesos y actividades más relevantes a desarrollar durante la fase de gestión del proyecto:

\section{Plan de Ejecución del Proyecto}

Es la síntesis de todos los pasos y estudios a seguir para realizar exitosamente el proyecto a desarrollar. Determina aquello que se quiere ejecutar, cuándo se ejecutará y las definiciones básicas de los alcances de trabajo, en relación a las restricciones de costos, plazos y calidad a ser satisfechas, para todas las etapas y grupos involucrados. Para ello se debe tomar en cuenta estudios y documentos como organigramas relevantes, planes de contratación y movilización del personal, plan de calidad, manuales de procedimientos, asignación de recursos a áreas y disciplinas y 
estimaciones iniciales de presupuestos y programas, así como también, los objetivos establecidos para el proyecto, a ser informados y publicados.

\section{Planificación y Programación}

Grupo encargado de la gestión y los plazos del proyecto, estableciendo fechas, duraciones y secuencias establecidas para las actividades del proyecto, para que se cumplan con los objetivos establecidos. Esto involucra la planificación de la línea base o estimación original, seguimiento y actualización, para lo cual se hace uso del plan de ejecución de proyecto, junto a los alcances de ingeniería, el programa de adquisiciones y la estimación de recursos para la construcción, definir actividades a realizar, las relaciones de interdependencia y crear un programa maestro. Luego, en la medida que se desarrolla el proyecto, se reestructura para reflejar los cambios necesarios o acordados.

\section{Bases de Estimación}

El objetivo final de este proceso es generar la estimación de los Costos de Capital (Capital Expedintures o CAPEX por sus siglas en inglés). Este es un informe detallado de las partidas que se consideran para la construcción, junto con las cantidades de material, horas hombres y de costos que conlleva cada uno de los puntos establecidos. Se consideran también las estructuras de costos para los recursos enumerados, estimaciones y análisis de riesgos para el proyecto y condiciones y alcances especiales.

\section{Control de Costos}

Proceso cuyo objetivo final es la supervisar los flujos de costos incurridos, para cumplir con lo presupuestado y aprobado para el proyecto. Esto significa un seguimiento y registro de todas las órdenes de compra, las tendencias observadas en los presupuestos y los costos finales. La gestión de cambios, adicionalmente, supervisa y registra todos los posibles cambios de alcance, desviaciones y transferencias de costos que puedan aparecer entre actividades y partidas. Se determinan los estados de pagos, los compromisos de compras y también los de contratos de servicios, de manera de contar con los flujos financieros que se originen. Finalmente se hace una proyección de 
costos, basándose en las cantidades instaladas y las probabilidades de cambio previstas, formándose nuevas estimaciones de costos a término y planes de contingencia.

\section{Control de Avance de Ingeniería y de Construcción}

Este proceso gestiona el avance que presentan la Ingeniería y la Construcción, a través de la medición de los grados de avance en que se encuentran el diseño o progreso de las obras en terreno. Esto, para confirmar el cumplimiento de los tiempos establecidos, los presupuestos y manteniendo los niveles de desempeño y calidad definidos.

Los informes de avance son desarrollados en base a las emisiones y revisiones de los entregables o diseños y las horas de trabajo empleados hasta el momento de medición para la ingeniería. También son medidos a partir de los reportes periódicos de horas empleadas en construcción, sean directas o indirectas y de las cantidades instaladas por los contratistas.

Todas estas actividades son de suma importancia, ya que establecen el correcto funcionamiento de las demás fases y en base a las informaciones generadas de ellas se podrán determinar las acciones correctivas necesarias, en caso que se observen desviaciones relevantes al compararlas con la estimación y el programa originales del proyecto.

\section{Fase de Ingeniería de Detalle}

Los servicios completos de ingeniería para un proyecto industrial de minería están conformados, a grandes rasgos de cuatro etapas principales, pero en el caso de un proyecto EPCM se considera solamente la cuarta etapa, es decir, la ingeniería de detalle. Igualmente se deben considerar breves descripciones de las demás etapas, para ilustrar el proceso completo. Estas etapas de ingeniería se organizan generalmente en disciplinas o especialidades que en minería incluyen, pero no se limitan a: Acústica, Ambiental, Arquitectura, Eléctrica, Estructural, Geología, Geotecnia, Hidráulica, Instrumentación, Mecánica, Minería, Obras Civiles, Obras Marítimas, Químicas y Procesos, Tuberías y Gerencias de Ingeniería.

Para cada nivel de ejecución de la ingeniería en los proyectos se generan los entregables o productos de ingeniería que forman parte de la entrega final de cada 
etapa. Estos entregables incluyen, a modo de ejemplo, criterios de diseño, planos estructurales, especificaciones técnicas, ubicaciones y listados de materiales, diagramas de líneas e instrumentación entre otros.

A continuación se desarrollarán breves descripciones de las etapas de diseño, para contextualizar el flujo de información de ingeniería a través del desarrollo completo de un proyecto minero.

\section{Estudio Conceptual}

Esta primera etapa de desarrollo de ingeniería, también llamada Ingeniería de Procesos o de Perfil, se inicia con la entrega de requerimientos y características básicas del proyecto, especificados por el Cliente, a la empresa de ingeniería. El producto final de esta etapa corresponde a la entrega al Cliente de documentos de estudio de una o más alternativas posibles de procesos, equipos, sistemas o emplazamientos a utilizar para el proyecto en análisis, además de las necesidades de servicios, con una estimación de magnitud de la inversión. Esto hace posible que el Cliente tome decisiones más informadas a partir de la idea base y continuar a la siguiente etapa de diseño y evaluación, sin necesidad de hacer grandes inversiones para estudios más detallados desde un comienzo.

El grado de precisión y desarrollo que se maneja para esta etapa es equivalente a la clase 5 o 4, definidas por The Association for the Advancement of Cost Engineering (AACE), que corresponde a lo siguiente:

Costo de inversión estimado desde $-30 \%$ a $+50 \%$ del valor real.

Desarrollo de la ingeniería de proceso hasta un $10 \%$.

\section{Estudio de Pre-Factibilidad}

Segunda etapa del desarrollo de la ingeniería de pre-factibilidad de un proyecto minero, también denominada ingeniería preliminar, que hace uso de la información desde la etapa anterior y agrega nuevos estudios que permiten obtener otro nivel más en la precisión de las estimaciones. Esto consiste en la presentación de las alternativas más viables con un desarrollo superior, para los procesos principales, la infraestructura general, los equipos mayores, los sistemas más importantes y sus requerimientos de recursos, de entre los evaluados en la fase anterior. El resultado de la estimación 
permitirá seleccionar la mejor opción técnico-económica, que será la base para el desarrollo de las siguientes fases.

Para esta segunda etapa de estimación y desarrollo de ingeniería se habla de un grado de precisión equivalente a clase 3 definida por AACE, cuyas características son:

Costos de inversión estimado desde $-20 \%$ a $+30 \%$ del valor real.

Desarrollo de ingeniería de pre-factibilidad entre $10 \%$ y el $25 \%$

\section{Estudio de Factibilidad}

Tercera etapa que corresponde al desarrollo de la ingeniería básica del proyecto, tomando como base la alternativa de mayor factibilidad técnico-económica. En esta etapa el enfoque es completo al efectuar la ingeniería básica para la alternativa, tomando en cuenta la ingeniería definitiva y las adquisiciones de los equipos principales, determinación de los equipos e infraestructura y generando el programa maestro de actividades y del presupuesto de inversión del proyecto, con otro nivel adicional de exactitud. Se destacan además gestiones iniciales de permisos, especificaciones técnicas, solicitudes de cotización y fijación de la disposición y ubicación final. Realizado todo esto, al finalizar esta etapa, se toma la decisión sobre la viabilidad del proyecto.

Para esta tercera fase de estimación y desarrollo de ingeniería se debería alcanzar un grado de precisión equivalente a la clase 2 definida por AACE:

Costo de inversión estimado desde un $-10 \%$ a un $+10 \%$ del valor real.

Desarrollo de la ingeniería básica entre el $25 \%$ y el $70 \%$.

\section{Implementación del Proyecto}

Durante la fase de implementación del proyecto se desarrolla la etapa final de diseño o ingeniería de detalle. Los objetivos principales durante esta fase son la culminación del desarrollo de la ingeniería, a través de la mayoría de los diseños y la emisión de todos los documentos y planos definitivos solicitados para la construcción. Esto permite determinar el presupuesto estimado final, que le da al Cliente el control sobre la inversión. Además, dependiendo del programa y las necesidades, existe la posibilidad que la construcción en terreno comience de forma paralela a las últimas actividades de la ingeniería, mientras el desarrollo de ésta esté completo para las labores 
a ejecutar, lo que requiere de una buena coordinación entre las áreas y los planes de ejecución.

Esta etapa corresponde al grueso de la ingeniería total, por lo que se tiene que hacer uso de la mayoría de los recursos destinados a ella. Esto se debe a que en la etapa anterior se confirma la viabilidad del proyecto, se toma la decisión de proseguir y se deben confeccionar todos los registros específicos pendientes del proyecto, para ahorrar costos en las fases anteriores. Se pueden destacar, entre otros, los documentos técnicos aprobados y certificados, las órdenes de compra restantes y los procedimientos de operación.

Es también durante esta etapa que se incluyen a los diseños los elementos de seguridad para la construcción y la operación, además de la definición de los métodos constructivos a emplear y la inclusión de las revisiones hechas en conjunto con la gerencia de construcción. Al incorporar estos aspectos en este punto de desarrollo, se hace posible aumentar su efectividad y disminuir los costos.

En esta última etapa de estimación y desarrollo de ingeniería debería alcanzar un grado de precisión equivalente a la Clase 1 AACE llegando a:

Costo de inversión estimado desde un $-5 \%$ a un $5 \%$ del valor real.

Desarrollo de la ingeniería de entre un $95 \%$ y un $100 \%$.

Una vez iniciadas las obras, grupos de profesionales de las diferentes disciplinas son asignados o movilizados a la obra, para cumplir con las necesidades de diseño que se pueden presentar durante la construcción, las pruebas y la puesta en marcha del proyecto. Estas labores incorporarán revisiones de diseño por interferencias, errores, actualizaciones u otras problemáticas presentadas durante el desarrollo del trabajo y la emisión de planos As-Built que muestran el estado de las obras terminadas. Esto se realiza a través de la inspección, la absolución de preguntas técnicas y la supervisión y confirmación de las compras en obra.

\subsubsection{Adquisiciones y Contratos}

Se conoce como adquisiciones al proceso completo de adquisición u obtención de equipos, materiales, personal o servicios externos a la organización del proyecto, requeridos por el Contratista, en representación del Cliente. Puntualmente consiste de la acción o proceso de obtener bienes y servicios mediante órdenes de compra y contratos determinados por acuerdos mutuos entre el proveedor de éstos y la organización del proyecto. 
Para la gestión del proceso de adquisiciones de manera eficiente, se guía el proceso utilizando el Plan de Adquisiciones, organizando los tiempos de entrega y contratación, así como también, las metas presupuestarias. Este plan se enfoca en definir los contratos, evaluaciones económicas y técnicas, programas de compras, órdenes de compra, cotizaciones, entre otros. Además se establecen los procedimientos de inspección, logística y manejo de bodega, los de fabricación y entrega a terreno, por parte del proveedor.

\section{Selección y Evaluación de Proveedores y Contratistas}

Es el proceso que se realiza durante y más allá del desarrollo de un proyecto específico, para calificar a los proveedores de servicios, equipos, insumos, materiales y mano de obra y llevar un registro histórico con información sobre su desempeño, garantías, capacidades y la calidad del servicio prestado.

El proceso se inicia con una prospección de potenciales proveedores, de acuerdo al producto que se requiera adquirir o contratar en el proyecto, para después realizar una precalificación de éstos, a partir de antecedentes solicitados, evaluaciones o encuestas, para posteriormente seleccionar a aquellos que pasarán al registro de proveedores aprobado. Entre los requerimientos claves a investigar, se destaca el rendimiento en seguridad presentado y la evaluación de los procedimientos presentados en esta materia.

Luego se procede a convocar a licitación, proceso mediante el cual se invita a los proveedores o contratistas precalificados a participar enviando una propuesta técnica y económica terminada, a partir de la última información disponible. Estas propuestas son formales y se evalúan tanto económica, como técnicamente, éstas se realizan por adquisiciones e ingeniería, pero de forma independiente. Ambas evaluaciones se evalúan y son entregadas al Cliente para que tome la decisión definitiva, se adjudique el contrato y se emita la orden de compra, la cual incluirá los requisitos definitivos del producto y las fechas de entrega acordadas.

Durante todo el desarrollo del servicio, se sigue evaluando periódicamente el desempeño los proveedores y contratistas seleccionados, para considerarlo en la base de datos. Las evaluaciones, que nuevamente consideran como aspecto importante el rendimiento en seguridad, se realizan a través de inspecciones y cumplimiento de acuerdos, aplicación de procedimientos o auditorías de calidad a estas empresas. 


\section{Seguimiento de Equipos y Materiales Importantes}

Tratándose de materiales, equipos o bienes importantes o críticos es importante hacer seguimiento de los procesos que el proveedor y la ingeniería realizan, debido a que cualquier retraso o dificultad en la entrega o la aprobación de la documentación final o en los productos y su fabricación, pueda resultar en costos elevados, atrasos en los programas y conflictos con los contratistas de la construcción.

Una vez que la documentación técnica certificada por el proveedor se encuentra disponible y aprobada por ingeniería, se libera y se procede a emitir la orden de fabricación. Es en este momento que se inicia la inspección y la supervisión en la fábrica o instalaciones del proveedor de forma periódica, para comprobar el cumplimiento de los hitos y fechas. También se debe considerar, la aprobación del plan de transporte y logística necesarios para entregar el producto en obra, elaborado por el proveedor.

\section{Control y Gestión de Bodegas en Obra}

Una vez iniciados los trabajos de construcción, se hace necesario administrar y gestionar de manera eficiente los equipos y recursos materiales que se han hecho llegar a los almacenes en terreno. Esto incluye los registros y control de ingresos y de egresos realizados por la gerencia de construcción, los proveedores y los contratistas, mantenimiento de inventarios y generación de reportes que den cuenta de posibles problemas, proyecciones y acciones correctivas. Esto es crítico en la mayoría de los casos, ya que tratándose de la falta de disponibilidad de materiales, la obra se puede detener.

\subsubsection{Gestión de la Construcción}

La fase de construcción de un proyecto EPCM es la etapa durante la cual se planifican y luego se materializan las obras e instalaciones diseñadas, para luego hacer entrega al Cliente. A través de este desarrollo los contratistas de construcción se encargan de la ejecución de las faenas, en tanto el equipo de profesionales de la construcción de la empresa contratista EPCM realiza labores de planificación, gestión y administración de estos trabajos y contratos. 
Durante esta etapa de ejecución, el contratista general realiza trabajos de supervisión, dirección y coordinación de las actividades de construcción, en concordancia al diseño realizado, especificaciones técnicas, programa de presupuesto, estándares específicos de trabajo y procedimientos y planes de seguridad aplicados al proyecto, para asegurar la correcta y eficiente materialización de las obras por parte de los contratistas elegidos. Un punto relevante para la organización es la comprobación que el personal ha sido correctamente entrenado para las labores asignadas y los planes establecidos debidamente aplicados, principalmente en lo relacionado a la importancia de la calidad y seguridad en el trabajo.

Desde la óptica de la empresa EPCM, la construcción tiene varias etapas principales, cuyo desarrollo permitirá realizar una gestión eficiente y segura de los recursos y plazos dispuestos para el proyecto, priorizando el cuidado de los intereses del Cliente. Se pueden mencionar las etapas de: elaboración del plan de ejecución de la construcción, los estudios de constructibilidad del proyecto, la administración y movilización de los contratistas a terreno, la administración de los trabajos durante el periodo de obras y la supervisión de dichas obras, para culminar con la entrega de las instalaciones finalizadas al Cliente.

\section{Plan de Ejecución de la Construcción}

El plan de ejecución de la construcción es el proceso de estudio y diseño de opciones que permiten establecer una guía, para poder ejecutar de forma efectiva el proceso de construcción y actividades complementarias. Inicialmente, se incluye la determinación de la secuencia lógica de las obras, de acuerdo a las necesidades del proyecto y del Cliente y las interacciones entre actividades poniendo énfasis en la seguridad y calidad de los trabajos, la disponibilidad de mano de obra, los materiales y de la ingeniería requerida. También, el establecimiento de estrategias de contratación y de compras en terreno es importante, a manera de definir las especificaciones básicas que deben cumplir tanto contratistas como proveedores. Complementando esto, se puede indagar sobre posibilidades que permitan optimizar los tiempos de ejecución, prefabricando algunas estructuras, por ejemplo, la organización que se presentará en obra y en la oficina principal, junto a las instalaciones y servicios de labores necesarios para operar, la logística de entrega y transporte de bienes y servicios, los métodos constructivos y el control del grado de avance de los contratistas. Finalmente, se incluye 
en el plan las políticas y estrategias a ser implementadas por los contratistas, en cuanto a relaciones laborales, sustentabilidad, seguridad, calidad y ambiental.

\section{Estudios de Constructiblidad}

Como complemento a la etapa anterior, se deben efectuar estudios de constructibilidad, en los cuales se busca realizar análisis anticipados de variables que puedan impactar la construcción del proyecto a ejecutar. El objetivo principal es incorporar la planificación de la construcción en las decisiones de diseño, de forma tal de prevenir dificultades, conseguir ahorros tempranos en los costos del proyecto y disminuir los riesgos durante el periodo de construcción.

El estudio toma en cuenta los objetivos de la construcción del proyecto, sus características y generalidades, tales como ubicación geográfica y política, clima, conectividad y características de las vías de acceso, permisos necesarios, infraestructura cercana, disponibilidad de recursos, materiales, personal, equipos, alojamiento, servicios médicos, medios de transporte, proveedores y contratistas disponibles en la zona, otros proyectos a ser realizados paralelamente y posibles interferencias con ellos, entre otros puntos para fundamentar las decisiones. Además, se realizan coordinaciones con ingeniería para la definición de los métodos constructivos a emplear y medidas de seguridad a implementar, para su incorporación a los diseños finales.

\section{Administración y Movilización de Contratistas}

Una vez definido el plan de ejecución y terminados los diseños y las estimaciones para la construcción, es momento de movilizar al personal a terreno a ejecutar los trabajos.

La movilización de profesionales, trabajadores y recursos a la obra para iniciar el proceso de construcción se programa con la finalidad de satisfacer las necesidades logísticas y de disponibilidad de mano de obra, materiales y equipos durante las primeras etapas del trabajo. Entre los puntos importantes a considerar están las instalaciones temporales y el suministro de servicios básicos para trabajar, tales como los sanitarios y de comunicación.

Por su parte, la administración de los contratos de construcción y de las labores, tiene por objetivo controlar y asegurar el cumplimiento de los alcances de trabajo 
encargado a cada contratista, siguiendo los acuerdos con el Cliente. Esto se traduce en supervisar su desempeño en temas tales como el cumplimiento de plazos, de costos, especificaciones técnicas, los equipos y recursos comprometidos y los planes de seguridad implementados. Entre las principales actividades a realizar por el grupo de gestión de la construcción para llevar a cabo la administración y supervisión de contratos se pueden mencionar:

- Definir los alcances de obra a contratar, para que se adjudiquen de manera clara, permitan optimizar los tiempos de trabajo, eviten interferencias en las labores entre dos o más contratistas y se ajusten en cierta medida a las capacidades o los métodos de los contratistas locales.

- Coordinar con el contratista los requerimientos de información, respecto a costos, plazos, diseños u otras contingencias que deban ser aclaradas, para ser reflejadas donde corresponda, de modo de conseguir propuestas más exactas.

- Revisión y aprobación de procedimientos de construcción y planificación elaborados por el contratista, entre los que resaltan el programa de actividades y el plan de seguridad. Esto se debe a que el contratista es el responsable de desarrollar estas actividades a un nivel de detalle mayor, para su alcance específico y los recursos que manejará.

- Elaboración de órdenes de cambio para modificar los de alcances de trabajo en caso de presentarse dificultades o imprevistos, a ser aprobadas por el cliente.

- Control, aprobación y reporte de los avances de trabajos de construcción, en base al programa establecido, especificaciones técnicas y controles de calidad ejercidos para cumplir con los procedimientos.

- Preparación de estados de pago al Contratista, como agentes del Cliente, a partir de las metas cumplidas, inspecciones y reportes de avance, además del cumplimiento de estándares de seguridad y demás aspectos legales.

- Confección de planes de contingencia, para lograr recuperación de atrasos o adelantarse a ellos, señalando siempre las causas, responsabilidades y acciones correctivas a implementar.

- Efectuar el seguimiento y control del cumplimiento del programa de suministros por parte de los proveedores de materiales en terreno. 
- El objetivo final de esta actividad es lograr el cumplimiento total de los tiempos y del programa general, manteniendo un alineamiento total, con el presupuesto programado y los estándares de calidad y seguridad.

\section{Administración del Sitio de Construcción}

Adicionalmente, la administración del sitio de construcción o terreno es de responsabilidad de dicha gerencia e incluyen algunas actividades que se desarrollan durante la etapa de ejecución del proyecto, cuya finalidad es contar con todos los servicios necesarios para el trabajo y una adecuada administración de ellos, para el correcto funcionamiento de las labores de terreno. Se puede solicitar para ello: transporte dentro y fuera de la obra, campamentos, alimentación, comunicaciones entre otros. De esta forma es posible mantener una fuerza laboral adecuada a los requerimientos del proyecto en cada fase, permitiendo trabajos idóneos. Se destacan los siguientes servicios:

- Recursos Humanos: tienen a su cargo la responsabilidad de buscar personal o aprobar los propuestos por los contratistas, capacitar en materia de seguridad, reglamentos de trabajo y conducta de obra y organizar la movilización de los colaboradores al inicio y término de cada turno.

- Administración de campamento: encargado de la administración y organización de los servicios de alimentación, alojamiento, elaboración de actividades recreacionales dentro de la obra y la confección e implementación de los planes de emergencia del campamento, en proyectos donde se requiera uno.

- Compras en obra: gestiona los requerimientos de materiales y equipos desde terreno, junto con su recepción y distribución a los almacenes o labor en obra.

- Servicios administrativos generales: encargados del control de inventarios, administración de correspondencia, suministros, servicios de oficina y limpieza, además del soporte de tecnología de información y sistemas de comunicaciones.

\section{Ejecución de Obras y Entrega}

El proceso de construcción se completa con la ejecución misma de obras por parte de los contratistas y proveedores de servicios, de acuerdo a las condiciones mencionadas anteriormente, hasta que se alcanza gradualmente el término de las obras. 
En este punto, el contratista termina su alcance de trabajo y la gerencia de construcción puede entregar parte de las obras al Cliente, ya sean componentes o sistemas completos, a medida que se van terminando. Con ello se puede dar inicio a las labores de inspección, pruebas y comisionamiento necesarios, conducidos por el equipo del Cliente o quienes sean designados por éste. Se complementa esto con la entrega final de los diseños realizados de acuerdo a lo construido finalmente en las instalaciones e infraestructura, los manuales de uso, los certificados y garantías de los equipos y sistemas.

\subsection{La Empresa y la Problemática Actual del Sector 1.2.1 Problemática Actual del Sector}

El Perú es un país de antigua tradición minera, la cual mantiene y cultiva gracias a la presencia de empresas líderes a nivel internacional. Contamos con un enorme potencial geológico, la presencia de la Cordillera de los Andes a lo largo del territorio, constituye nuestra principal fuente de recursos minerales.

A nivel mundial y latinoamericano el Perú se ubica entre los primeros productores de diversos metales (oro, plata, cobre, plomo, zinc, hierro, estaño, molibdeno, entre otros), lo cual no solo es reflejo de la abundancia de recursos y la capacidad de producción de la actividad minera peruana, sino, de la estabilidad de las políticas económicas en nuestro país. Los minerales producidos en nuestro país, son de gran demanda en el mercado mundial actual, cuyo desarrollo se basa en la producción y la industria. Estados Unidos, China, Suiza, Japón, Canadá y la Unión Europea son nuestros principales demandantes. Es así que el Perú es una de las economías con mayor crecimiento en América Latina (8.5\% en el 2010, 6.5\% en el 2011, 6.0\% en el $2012,5.8 \%$ en el 2013 y $2.4 \%$ en el 2014), lo cual es complementado con solidez macroeconómica: bajas tasas de inflación, superávit fiscal y comercial y fuerte reservas internacionales netas.

A nivel internacional en julio del año 2008, la agencia de riesgo crediticio Standard and Poor`s otorgó al Perú el "Grado de Inversión”, previamente, ésta recategorización fue otorgada por Fitch rating en abril del mismo año y por la Canadian Agency Dominion Bond Rating Service (DBRS) a fines del 2007. Siguiendo en esta línea internacional el Perú ha suscrito diversos convenios bilaterales, incluyendo Tratados de Libre Comercio (TLC) con Estados Unidos, Canadá, China, Singapur, 
Corea del Sur y México y se encuentra en negociaciones con Japón, Tailandia y la Unión Europea. Asimismo, el país es miembro de la Asia Pacific Economic Cooperation (APEC) y de la Comunidad Andina de Naciones (CAN).

Las oportunidades que ofrece el Perú han hecho que sea uno de los países de la región donde se observa mayor inversión en minería, con resultados destacados y presencia de empresas líderes de la minería mundial. Recientes estudios del Ministerio de Economía y Finanzas, informan que, en los últimos cuatro años, la inversión minera en el Perú superó los US\$ 34,020 millones, obteniendo un crecimiento del 142\% en comparación con lo invertido entre los años 2006 al 2011. En las últimas décadas, América Latina ha sido testigo del crecimiento acelerado de las industrias extractivas, en particular la minería. En el Perú, entre 1992 y 2013, las concesiones mineras pasaron de abarcar el $7 \%$ del territorio nacional al $22 \%$.

En los próximos años se producirá un incremento sustancial en la producción de metales. Por ejemplo, la producción de cobre se duplicará con los proyectos Las Bambas, Constancia y Toromocho, y las ampliaciones de las minas de Cerro Verde, Toquepala y Antamina. Se estima que el PBI de la minería metálica crecerá en un promedio del $7 \%$ anual.

La importancia de la minería, también se ve reflejada en el ranking de producción, ya que el Perú es el primer productor de zinc, estaño, plomo y oro en América Latina, y en el mundo, el tercero de zinc y estaño, y el sexto de oro.

La constitución política del Perú establece que el Estado Peruano es soberano de los recursos renovables y no renovables y que los mismos se otorgan para su aprovechamiento fijando las condiciones a particulares (inversionistas). Así también, establece la participación adecuada de ingresos y rentas que el Estado recibe por la explotación de los recursos de los gobiernos regionales.

El gobierno central es el encargado de administrar los recursos públicos y transferirlos a los gobiernos regionales y gobiernos locales. Además de los ingresos por el aprovechamiento de los recursos naturales, el Estado también percibe tributos como el Impuesto General a las Ventas (IGV), Impuesto Selectivo al Consumo (ISC), Impuesto Temporal a los Activos Netos (ITAN), Aranceles de Importación, entre otros.

En la última década, la economía nacional ha tenido cifras muy positivas, ocasionando que el país alcance una importante estabilidad y atraiga capitales extranjeros. La economía mostró una gradual recuperación a lo largo del 2015. Así, mientras que a fines del 2014 la tasa de crecimiento del PBI se situaba alrededor del 1\% 
interanual, los registros tendieron luego a mejorar trimestre a trimestre y en el último trimestre del 2015 alcanzó el 4.6\%. De esta manera, el PBI avanzó 3.3\% en el 2015, por encima del $2.4 \%$ del 2014.

Dos fueron los principales elementos que le dieron soporte al desempeño de la actividad primaria. El primero de ellos fue el sustancial incremento de la extracción de cobre, que luego de avanzar 10\% interanual en el primer semestre, aumentó más de $40 \%$ en el segundo (47\% en el cuarto trimestre del 2015). Toromocho y Constancia, dos minas que iniciaron su etapa producción en 2014, elevaron paulatinamente su extracción a lo largo del 2015; la primera de estas minas alcanzará su capacidad máxima operativa en el 2016, mientras que Constancia, el año pasado superó largamente y de manera sostenida el anuncio inicial que hizo sobre lo máximo que podía producir. A ello se sumó, de un lado, la recuperación durante el segundo semestre de los volúmenes extraídos por Antamina, actualmente el proyecto cuprífero más grande del Perú, luego de los problemas operativos que enfrentó el año anterior; y de otro lado, el sorpresivo inicio en el cuarto trimestre de la etapa de producción de dos minas que eventualmente tendrán un tamaño comparable al de Antamina: la ampliación de Cerro Verde y las Bambas. Como resultado la producción de cobre en el Perú superó los 1,6 millones de toneladas métricas en el 2015, aumentando así $26 \%$ en comparación con la producción del año anterior y aportando directamente algo más de 1 punto porcentual al crecimiento del PBI del año (según estimaciones, cerca de 2 puntos porcentuales en el cuarto trimestre del 2015).

La minería, al igual que los demás sectores, realiza el pago de sus tributos consistentes en impuestos (como los nombrados anteriormente: IGV, ITAN, Aranceles, entre otros) y contribuciones, para lo cual el sector contribuye al Estado a través del pago de Derecho de Vigencia y Penalidad (aplicable al otorgamiento y vigencia de una concesión minera) y la Regalía Minera (contraprestación por la extracción del recurso mineral).

La participación de la carga total de tributos y aportes del sector minero está conformada aproximadamente por: Impuesto a la Renta con el 27\%, la Participación de los Trabajadores con el 8\%, la Regalía Minera con el 6\%, el Impuesto Retenido por Pago de Dividendos con el 3\%, el Programa Minero de Solidaridad con el Pueblo (Aporte Voluntario) con el $2 \%$ y otros impuestos que suman $2 \%$, dejando a las empresas mineras con una utilidad del $52 \%$. Cabe indicar que los porcentajes señalados no están referidos a los que las empresas de acuerdo a ley deben pagar por dichos 
conceptos, sino a la carga que ofrecen dentro de la totalidad de sus obligaciones y aportes. Asimismo, debemos recordar que este cálculo recaería para las empresas mineras que estuvieran obligadas a estos tributos, ya que la Regalía Minera solo se aplica a las empresas del Régimen General (grande y mediana empresa).

\section{Figura 1.2: Carga Total De Tributos y Aportes Del Sector Minero.}

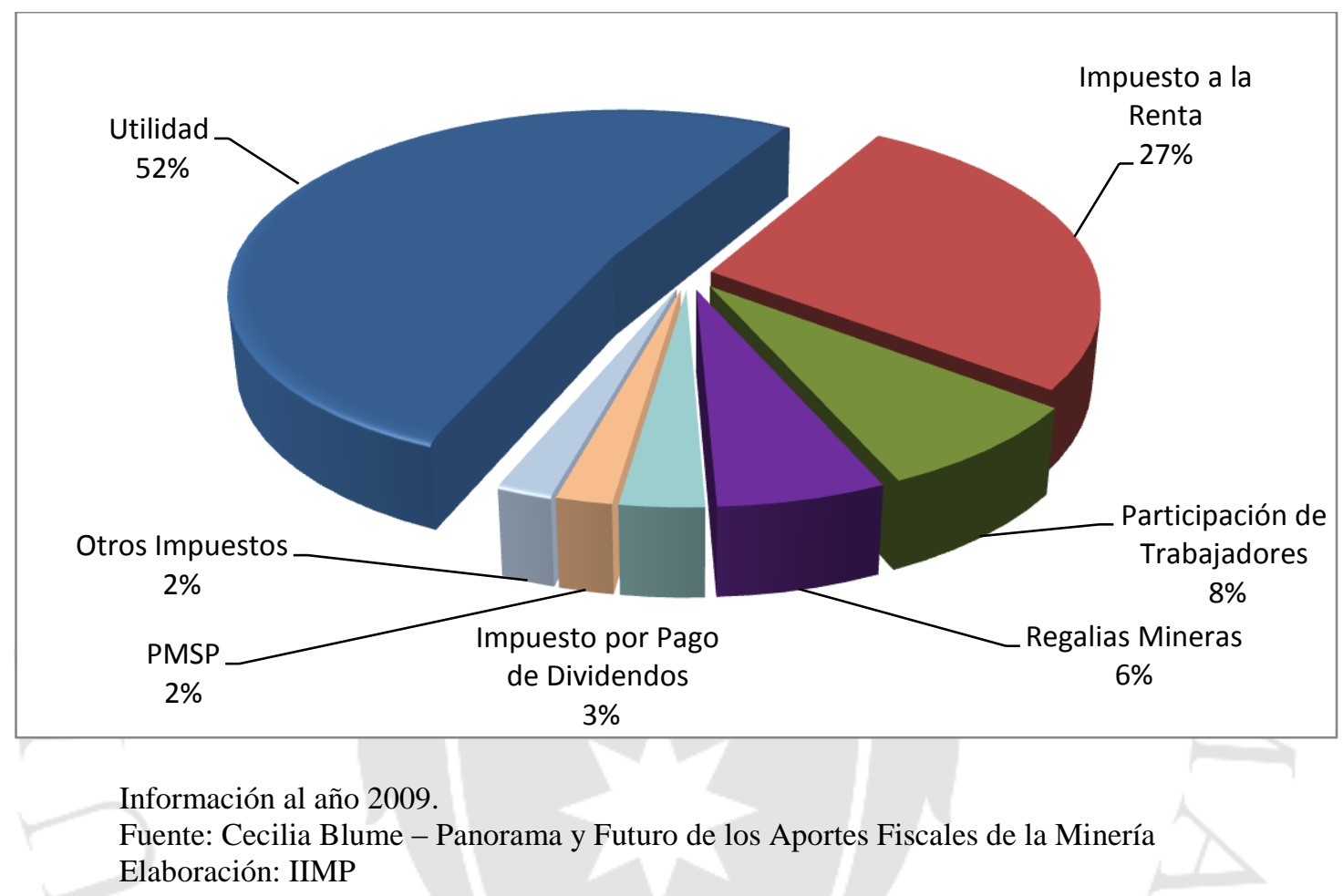

Las empresas mineras realizan el pago del impuesto a la renta de tercera categoría, según la Ley $\mathrm{N}^{\circ}$ 27506, Ley de Canon Minero, el 50\% del IR del sector, el Estado lo transfiere a los Gobiernos Locales y a los Gobiernos Regionales (incluyendo universidades nacionales) como concepto de Canon Minero. En el 2009, el IR llegó a S/. 3,018 millones.

La transferencia del Canon Minero en el 2013 registró una contracción de $25.51 \%$ con relación al 2012, alcanzando la suma de S/. 3,817 millones y en el 2014 una caída del $21.96 \%$ en relación al 2013, registrando la suma de S/. 2,979 millones. Por segundo año consecutivo se registra un descenso en el monto del Canon Minero después que el 2012 se obtuviera la cifra de S/. 5,124 millones lo cual significó un crecimiento del $23.26 \%$ respecto del 2011 donde alcanzó el importe de S/. 4,157 millones. 
Por otro lado, la transferencia de la Regalía Minera en el año 2013 se redujo levemente en $3.57 \%$ con respecto al año anterior y una reducción del $8.58 \%$ en el 2014 , respecto del 2013. Esta contraprestación fue afectada en gran medida por los efectos de la crisis financiera internacional, ya que grava el valor de la producción de las empresas mineras. Así se obtuvo S/. 438 millones durante el 2014.

En el caso del Derecho de Vigencia, en el 2012 sumó S/. 164 millones y 172 millones en el 2013, lo cual significó un incremento del 4.69\% y en relación al 2013 y el importe obtenido en el 2014, se produjo un incremento del $5.03 \%$, lo cual confirma una tendencia al alza desde el año 2010 con un importe de S/. 142 millones, después que en el 2009 se obtuvo S/. 116 millones lo que significó un crecimiento del 22.62\%. El pago es recaudado en dólares americanos y es administrado por el Instituto Geológico, Minero y Metalúrgico (INGEMMET)

\section{Tabla 1.4: Recaudación del Estado por Actividades del Sector Minero Según Conceptos, Años 2012 al 2014 (Nuevos Soles)}

\begin{tabular}{|c|c|c|c|c|c|c|c|}
\hline \multirow{2}{*}{ CONCEPTO } & \multicolumn{3}{|c|}{ ANOOS } & \multicolumn{2}{|c|}{ VARTACIONA BSOLUTA } & \multirow{2}{*}{\multicolumn{2}{|c|}{$\frac{\text { VARTACION \% }}{2012 / 2013 \text { 2013/2014 }}$}} \\
\hline & 2012 & 2013 & 2014 & $2012 / 2013$ & $2013 / 2014$ & & \\
\hline Canon Minero & $5,124,235,060$ & $3,817,165,283$ & $2,978,748,572$ & $(1,307,069,777)$ & $(838,416,711)$ & (26) & (22) \\
\hline Regalías Mineras & $496,572,185$ & $478,831,011$ & $437,758,520$ & $(17,741,174)$ & $(41,072,491)$ & (4) & \\
\hline Derechos de Vigencia & $164,714,004$ & $172,438,817$ & $181,115,546$ & $7,724,813$ & $8,676,729$ & 5 & \\
\hline TOTALES & $785,521,249$ & $4,468,435,11$ & $3,597,022,638$ & $(1,317,086,138)$ & $(870,812,473)$ & & \\
\hline
\end{tabular}

Fuente: MEF / Portal de Transparencia Económica INGEMET. Elaboración: Ministerio de Energía y Minas.

Tratándose de un impuesto relevante de recaudación para el Estado, haremos una breve referencia al Impuesto a la Renta, referido a nuestro tema.

El IR es aquel que grava las ganancias o ingresos de personas naturales o jurídicas. En nuestro país existen cinco categorías de IR, cada cual está en función de la naturaleza o la procedencia de las rentas. En el caso específico del IR de Tercera Categoría, esta grava las rentas de procedencia del capital, del trabajo y de la aplicación de ambas cuyas actividades deriven de las rentas comerciales, industriales, servicios o negocios. 
En el 2011 la recaudación del IR de tercera categoría de los sectores productivos registró la suma de S/. 23,307 millones, 33.12\% más de lo recaudado durante el 2010 cuando llegó a S/. 17,508 millones. Este aumento corresponde a un mayor ingreso de parte de los sectores productivos debido, principalmente, a los buenos precios de los minerales, una mayor producción de metales (oro, plata, cobre, entre otros) como consecuencia de la necesidad de materia prima de parte de países como China. El crecimiento se puede apreciar hasta el año 2012 con una recaudación de S/. 25,141, para que en adelante en los años 2013 y 2014, con una recaudación de S/. 22,662 y S/. 22,238 de millones, respectivamente, se produzca una contracción debido a la crisis financiera internacional que se ha venido acentuando debido a la baja en los precios de los metales y la paralización o cierre de proyectos mineros, como consecuencia de la disminución de las necesidades de productos primarios por parte de los países industrializados. Debido a que el IR tiene relación directa con el Canon Minero, la recaudación por éste concepto sufrirá una disminución, lo cual afectará directamente en las transferencias a los Gobiernos Regionales y Locales. A pesar de las dificultades presentadas en el 2014, el IR Minero representó el tercer mayor valor de lo recaudado con el $10.12 \%$, por debajo del Comercio en primer lugar con $17.04 \%$ y Manufactura en segundo lugar con $12.86 \%$. A continuación, se muestran los datos estadísticos de la recaudación del IR de 3ra categoría por sectores de la economía. 
Tabla 1.5: Recaudación del Impuesto a la Renta de 3ra. Categoría

Por Sectores, Años 2010 al 2014 (Millones de Nuevos Soles).

\begin{tabular}{|c|c|c|c|c|c|}
\hline Sectores & 2010 & 2011 & 2012 & 2013 & 2014 \\
\hline Minería & 5,618 & 7,764 & 6,456 & 3,321 & 2,251 \\
\hline Comercio & 2,267 & 2,909 & 3,430 & 3,878 & 3,790 \\
\hline Manufactura & 2,307 & 2,938 & 3,267 & 3,167 & 2,860 \\
\hline Hidrocarburos & 1,056 & 1,835 & 2,253 & 2,057 & 2,228 \\
\hline Construcción & 715 & 1,050 & 1,385 & 1,522 & 1,972 \\
\hline Pesca & $\quad 124$ & 134 & 143 & 94 & 116 \\
\hline Agropecuaria & 44 & 92 & 76 & 96 & 85 \\
\hline Otros Servicios (I) & 5,377 & 6,585 & 8,131 & 8,527 & 8,936 \\
\hline Total & 17,508 & 23,307 & 25,141 & 22,662 & 22,238 \\
\hline
\end{tabular}

(I) Incluye actividades inmobiliarias, empresariales y de alquiler, telecomunicaciones, intermediación financiera, salud, servicios sociales, turismo y hotelería, generación de energía eléctrica, agua y otros.

Fuente: SUNAT.

Elaboración: CooperAcción

A continuación, la presentación de algunas reflexiones del Sr. Roque Benavides, CEO (Chief and Executive Officer) de la empresa Minas Buenaventura, con ocasión de un debate sobre Minería, Impuesto e Inversión, promovida por el Instituto de Gobierno y Gestión Pública de la Universidad San Martín de Porres:

“...escuchando por supuesto al padre Arana, siempre me trae a muchas cosas a reflexión, creo que hay aspectos que mucha gente se olvida y que no recuerda de la historia. Se dice siempre que hay que recordar la historia para no cometer los errores en el futuro.

El padre Arana menciona que el Perú es un país minero, por lo tanto, no es de las otras cosas como la agricultura. Realmente nuestro país no se puede dar el lujo de desarrollar un sector y no todos los demás porque el Perú tiene muchas potencialidades. La agricultura evidentemente es una de ellas, los servicios también, la minería también, porque hay zonas donde en el fondo no se puede hacer gran cosa en minería, en agricultura, pero que puede contribuir enormemente con un sector minero 
moderno, un sector minero por supuesto cuidando los más altos estándares medioambientales puede contribuir en el desarrollo del país. Cuando hablo de historia estoy pensando en algo que mucha gente se olvida. El último yacimiento que se desarrolló en el Perú antes de Yanacocha fue Cuajone en 1969.

De 1969 a 1993 no se desarrolló un solo proyecto minero en el Perú. ¿Cómo podemos decir que el Perú es un país minero? Obviamente que no lo es todavía, hay que desarrollar mucho más. $Y$ ¿por qué hay que desarrollar mucho más?, porque la minería contribuye, especialmente en un aspecto que es perverso: el centralismo.

Si nosotros queremos descentralizar nuestro país, si queremos darle más oportunidades a gente que vive en el área rural, pues necesitamos carreteras, necesitamos comunicaciones, necesitamos competitividad de algunas zonas de nuestro país que hoy día no la tienen. ¿Cómo se logra eso?, con actividad económica. Cada zona del Perú tendrá sus propias potencialidades, nadie puede negar que el Perú ha sido bendecido con recursos minerales, seguramente también tenemos recursos petroleros y creo que merecemos desarrollar esos productos con sostenibilidad en beneficios de todos los peruanos para generar riqueza en zonas donde no se podría generar otras actividades.

La Empresa es percibida como si fuera un sector que no requiere de mucha tecnología, que no requiere muchos profesionales. Nada más falso. ¿Ustedes han pensado en algún momento cómo se descubre un yacimiento? Un yacimiento se descubre con mucha tecnología, desde imágenes satelitales, la geofísica, la geoquímica. Por supuesto, el talento de tanto y tantos geólogos que hemos tenido en el Perú y que vienen de nuestras universidades y por lo tanto, la integración entre una actividad como la minera y las universidades de nuestro país es intensa. Nosotros tenemos que darles oportunidades a esos profesionales. Como digo, contribuye a justificar carreteras y comunicaciones en un país que está dividido por una costa semiárida, por una cordillera que realmente es agreste y, por supuesto, cómo hacemos para llegar a la selva si es que no tenemos carreteras que pasen por esa sierra.

El desarrollo de nuestro país tiene que ser armónico, tiene que contemplar la posibilidad de que todas estas actividades contribuyan. Se dice que la minería representa el 6 o 7 por ciento del PBI y por supuesto que ese es el caso. Sin embargo, también se dice que la construcción crece enormemente.

Yo me pregunto, ¿cuánto de ese cálculo del PBI tiene que ver con la minería?, ¿cuánto tiene que ver con los servicios? Me hacían un cálculo el otro día que por cada 
puesto de trabajo que genera la minería, se generan siete puestos de trabajo integrándonos con otros sectores. Y eso es lo que está sucediendo en el Perú.

En Cajamarca, ciertamente, hay muchísima gente que depende del sector minero, pero yo no me voy a quedar solamente en Cajamarca, yo voy a Huancavelica donde se fundó la compañía minera Buenaventura y pienso en la mina Recuperada, que queda en la zona de Huachocolpa en la provincia de Huancavelica, probablemente la única fuente de trabajo que hay ahí a 4300 metros de altura. Es una mina que se llama Recuperada, que no es sino una mina marginal que da puestos de trabajo a cerca de 600 personas. Mucha gente dirá que esa cantidad de personas representan pocos puestos de trabajo, yo les puedo asegurar que en esas zonas inhóspitas es la única alternativa. Yo creo que tenemos que buscar darles oportunidades a todos y en todas las partes que podamos desarrollar actividades en nuestro país. Es evidentemente un sector integrador, un sector que puede contribuir enormemente a los que se ha dado por llamar la hermandad del agua y cuando digo la hermandad digo, los agricultores y los mineros juntos.

Donde se debe represar el agua que cae todos los años en la Sierra del Perú debería represarse a los 4,000 metros de altura en Cajamarca. Nuevamente el 80 a 85 por ciento del agua de lluvia se va al mar. ¿Qué significa esto?, que evidentemente hay una época de lluvias y mucho del año seco. Lo que hay que hacer es represar el agua y en ese sentido la minería puede contribuir enormemente a favorecer el desarrollo de todas esas zonas donde hay tanta lluvia".

Finalmente, con referencia a la problemática del sector minero, el impacto de éste es uno de los problemas que afecta al medio ambiente mundial, donde el Perú no se encuentra exento de dicho problema, ya que es un país con grandes yacimientos mineros. De la misma manera, se sabe que la minería tiene grandes beneficios económicos, pero a la vez grandes problemas socio-ambientales. A continuación, se detalla el origen de este problema y sus causas políticas.

Los problemas de la minería se originan, por lo general, a nivel de la minería artesanal y a la pequeña minería. En la minería artesanal la informalidad de la misma constituye su principal problema, ya que limita las posibilidades reales para su desarrollo integral: contaminación ambiental, depredación de yacimientos existentes, graves deficiencias de seguridad, discriminación social y económica, conflictos con las

\footnotetext{
${ }^{1}$ (Roque Benavides; Minería, Impuesto e Inversión, 2012)
} 
compañías mineras formales, falta de transparencia en los manejos financieros, etc. Estos son solo algunos de los efectos más resaltantes. Otro problema es que políticamente no es bueno permitir que esta actividad se mantenga en la informalidad, porque afecta la credibilidad del país en tanto se afirme oficialmente que es política nacional, apoyar la inversión minera en condiciones de estabilidad y seguridad jurídica. En cambio, en la pequeña minería, principalmente el problema se origina en la precariedad del trabajo, caracterizada, aparte de una faena muy dura, por graves deficiencias de seguridad y las consecuencias extremadamente negativas para la salud, causadas directamente por intoxicación, accidentes, polvos, etc. Pero también, indirectamente, por la gran cantidad de agua estancada que en zonas cálidas es lugar de incubación de organismos que afectan la salud.

En relación a las causas políticas, existe una débil fiscalización por parte del estado peruano sobre los aspectos ambientales. A través del Ministerio de Energía y Minas (MEM), que a su vez es propietario o accionista de empresas mineras, es regulador de las políticas del sector minero, es fiscalizador para el cumplimiento de las normas ambientales y a la vez promotor de las inversiones mineras. Por ello, el MEM, tiene jurisdicción sobre tierras, agua y la inversión minera. No existe ninguna institución que vigile las actividades del MEM que proteja los derechos e intereses de las comunidades afectadas. Por otro lado, vemos que la Constitución, dirigida a la minería, ha hecho recaer en el Estado la función de evaluar y preservar los recursos naturales, fomentar su racional aprovechamiento y promover su industrialización para impulsar el desarrollo económico. Sin embargo, el Estado no está cumpliendo con dichas funciones; por ello surgen los problemas de la minería ya expuestos anteriormente.

En resumen, el problema de la minería no es en sí misma, sino la falta de responsabilidad de los empresarios mineros que no respetan los estándares ambientales, desequilibrando el ecosistema, además de generar problemas sociales. Para esto, el Estado debe crear instituciones que vigilen las actividades mineras para que protejan los derechos de las comunidades que han sufrido este profundo impacto.

\subsubsection{La Empresa en el Contexto Minero}

La Empresa al formar parte del sector minero, está inmersa a los beneficios e impases que como consecuencia de las decisiones gubernamentales, al marco legal y 
además las fluctuaciones en los cambios en los precios de los minerales y como consecuencia, decisiones de las empresas que invierten en el rubro por los proyectos en los cuales decidieron participar, está supeditada, para su continuidad, a la puesta en marcha de las obras de inversión.

Haciendo un poco de historia sobre la minería en nuestro país, se puede decir que ésta se empieza a registrar en la época colonial. Antes de la llegada de los españoles a nuestro país, el antecedente que se tiene (época pre-inca) es escaso y por lo general exacerbado por los conquistadores. Así lo hace saber Luis Felipe Villacorta Ostolaza en su obra: “Antonio Raimondi, contexto histórico de su labor geológica y minera:” ...La conquista del imperio del Tahuantinsuyo a manos de las huestes hispanas comandadas por Francisco Pizarro y la riqueza de fábula representada por el rescate y posterior repartija del oro y plata de Atahualpa, constituyen la suma de hechos históricos en los que se fundamenta el origen de la fama áurea del Perú. Incluso se puede postular la idea de que la "abundancia” del oro prehispánico y su aprobación como parte del "botín” por el rescate del Inca fueron ingredientes sustanciales en la formación de una idiosincrasia social que concibe al Perú como un país de fácil riqueza”.

También, don Mario Samamé Boggio, en su obra: "El oro en el Perú” (1994), menciona que el periodo de mayor auge de éste metal precioso está comprendido entre 1735 y 1779, durante el cual se extrajo en promedio 1,000 a 3,000 kgs. por año. La producción de plata entre los años 1836 a 1900 fue de 5,903 TM (Toneladas Métricas). Respecto al oro desde 1836 a 1885, la producción registrada fue de 19,400 kgs. La minería aurífera llega a su máximo descenso en el decenio 1886 - 1895, con una producción de $162 \mathrm{kgs}$. promedio al año, pero en los años siguientes se descubre y entra en producción la mina Santo Domingo, en Carabaya, con el cual se constituye la empresa Inca Mining Co., y así la producción alcanza un promedio de 1,160 kgs. anuales, en el quinquenio $1896-1900$.

Según las cifras del Ministerio de Energía y Minas, durante el periodo comprendido entre 1901 al 2009 la producción de oro llegó a la cifra de 2’656,534kgs., entre 1903 al 2009, la plata arrojó 114'654,371 kgs., la de cobre fue de 23.9 millones de TMF (Toneladas Métricas Finas); la de plomo alcanzó 12.5 millones de TMF y la de zinc, entre los años 1924 al 2009, fue de 33.6 millones de TMF.

Desde los primeros años de la década de los noventa, el gobierno peruano reimpulsó la promoción de la inversión privada, la cual tuvo como instrumento principal el asegurar la estabilidad jurídica para las inversiones. Estas condiciones se 
establecieron a través de derechos, garantías y obligaciones. Asimismo, se inició la privatización de empresas estatales. Dicho ímpetu promocional vino acompañado del desarrollo e implementación de la regulación de aspectos ambientales asociados, de tal manera que en 1993 se dictó la primera reglamentación sectorial en medio ambiente, exigiéndose para las operaciones antiguas la presentación del Programa de Adecuación y Manejo Ambiental (PAMA) y para todo nuevo proyecto minero, el correspondiente Estudio de Impacto Ambiental (EIA).

En los últimos 20 años, la producción minera ha evolucionado debido, en principio, a las ventajas competitivas que ofreció el país a la inversión extranjera. Seguido de esto los yacimientos mineros de clase mundial que posee el país, los cuales en los últimos años se han puesto en marcha (Antamina, Lagunas Norte, entre otras) y a los elevados precios internacionales de los metales. En el caso del oro, en 1990 registró una producción de 70.9 mil onzas finas aproximadamente, siendo su crecimiento constante año tras año. Este metal tuvo su pico máximo en el 2005 con 6,687 miles de onzas finas y en adelante se mantuvo en una producción no menor a las 5,000 miles de onzas, hasta el año 2014 donde apreciamos una disminución y cuya producción nacional fue de 4,500 miles de onzas finas lo cual significó una caída del 10\% respecto a la producción del 2013 que fue de 5,024 miles de onzas finas, disminución que se debió a los menores niveles de producción de las principales mineras como Yanacocha y Barrick Misquichilca, además de un menor reporte de la producción artesanal en proceso de formalización de Madre de Dios, debido a los esfuerzos concertados de adecuar las actividades extractivas auríferas a las disposiciones promotoras de la formalidad y preservación del medio ambiente. De igual forma, la plata en 1990 presentó una producción de 67,000 miles de onzas finas, teniendo desde 1992 un incremento sostenido alcanzando en el 2009 de, 126,118 miles de onzas finas y para el año 2014 una producción nacional de 121,459 miles de onzas finas, logrando un crecimiento de $2.74 \%$ respecto a lo obtenido en el año 2013, que fue de 115,935 miles de onzas finas, manteniendo así, la tendencia positiva registrada en periodos anteriores, lo cual se explica por un desempeño positivo de las principales mineras productoras de plata y una mejora en las expectativas de inversión. En el caso del cobre, al inicio de la década del 90, reportó una producción de 300 miles de TMF (toneladas métricas finas) y en el lapso de 20 años llegó, en el 2009 a se tuvo una producción de 1,280 miles de TMF, para llegar al 2014 con una producción de 1,380 miles de TMF, casi manteniendo los niveles de producción, lo cual significó un ligero crecimiento del $0.26 \%$ respecto del 
2013 que fue de 1,376 miles de TMF, esto como resultado del proyecto Toromocho, el crecimiento sustancial de la Minera Antapaccay y el aporte destacado de Southern Perú Copper Corporation, que permitieron atenuar la caída de la producción de cobre de la Compañía Minera Antamina, que tuvo dificultades que afectaron su desempeño. Por su parte, el plomo arrojó una producción de 210 mil TMF en 1990 y llegó a su máxima producción en el 2008 con 345 mil TMF, para en el año 2011 sufrir una considerable caída en su producción a 230 mil TMF y recuperarse hacia el 2014 con una producción de 278 mil TMF lo cual representó un incremento de 4.51\% respecto del 2013 con una producción de 266 mil TMF, debido a crecimientos significativos de la Sociedad Minera Corona, Compañía Minera Caudalosa y Trevalli Perú SAC. Con referencia al zinc, entre el periodo 1990 - 2003 este metal presentó un paulatino crecimiento que se inició con 600 mil de TMF, llegando a un máximo nivel de producción en el 2008 con 1,600 miles de TMF, para que en los siguientes años se observe una caída constante en su producción, hasta el año 2012 donde se recuperó y en el año 2014 llegar a una producción de 1,319 miles de TMF, lo cual representó una contracción del $2.40 \%$ en relación al año 2013 con una producción de 1,352 miles de TMF, esto debido al comportamiento de las principales empresas que aportan a su producción, como por ejemplo la Compañía Minera Antamina, a consecuencia de variables endógenas generadas por ciertas expectativas laborales y condiciones de reducida concentración del mineral en las zonas de explotación.

En las gráficas que se muestran a continuación se podrá apreciar la evolución de la producción nacional anual de los metales mencionados anteriormente, que va de los años 2005 al 2014: 
Figura 1.3: Producción Nacional de Oro Periodo 2005 - 2014

(Miles de Onzas Finas)

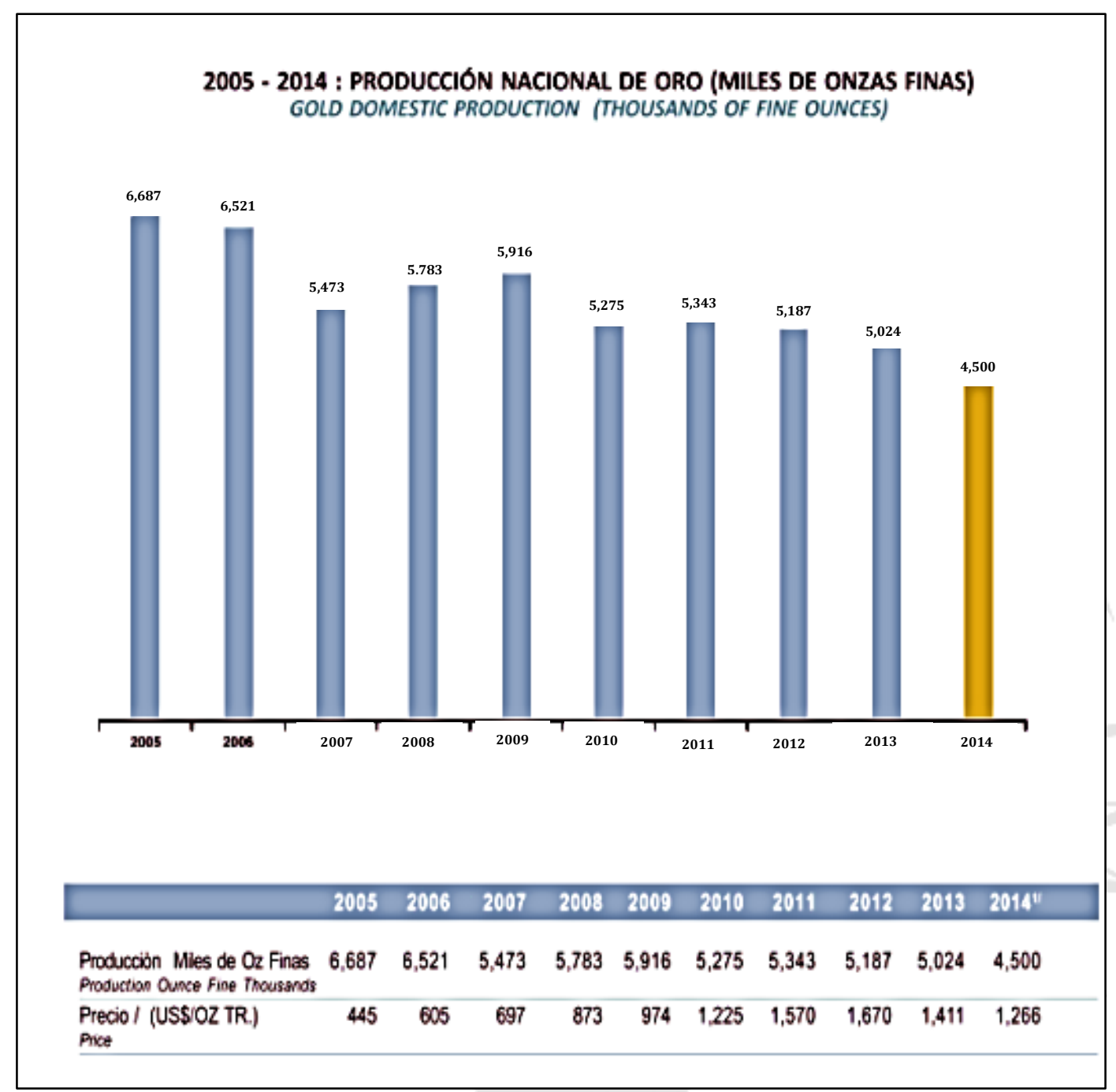

Cifras Preliminares.

Fuente: Perú 2014 - Anuario Minero Reporte Estadístico.

Elaboración: Ministerio Energía y Minas. 
Figura 1.4: Producción Nacional de Plata Periodo 2005 - 2014

(Miles de Onzas Finas)

2005 - 2014 : PRODUCCIÓN NACIONAL DE PLATA (MILES DE ONZAS FINAS) SILVER DOMESTIC PRODUCTION (THOUSANDS OF FINE OUNCES)

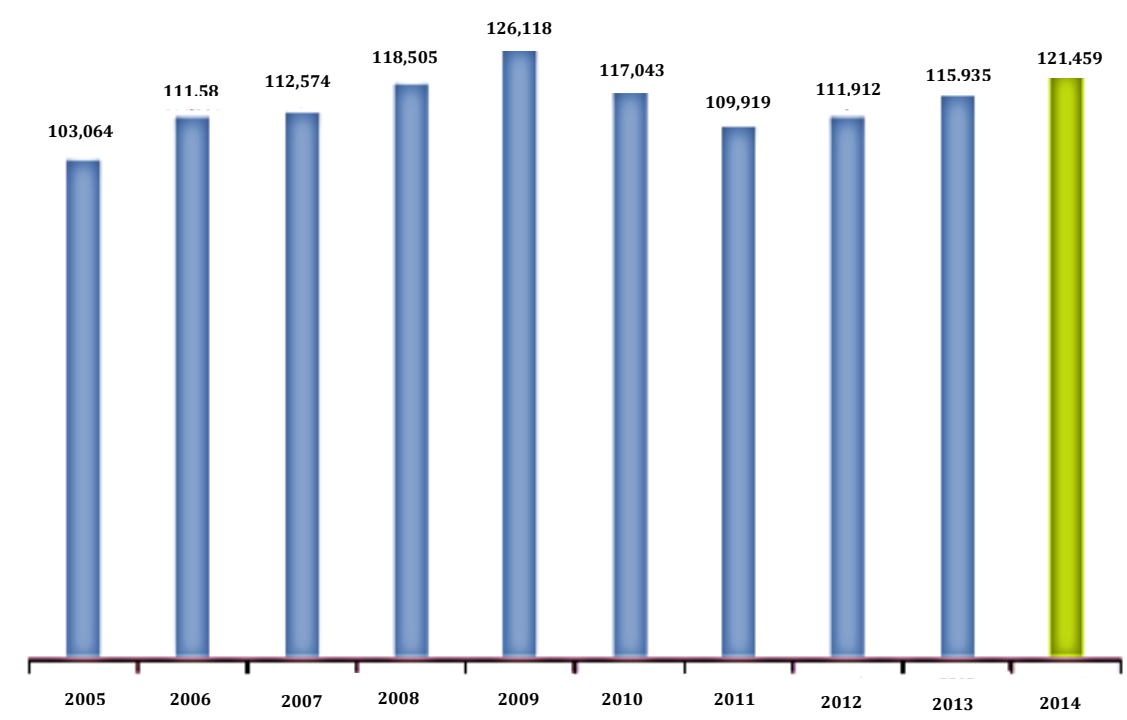

Produccion Mies de $\mathrm{Oz}$ Finas Production Ounce fine Thousands

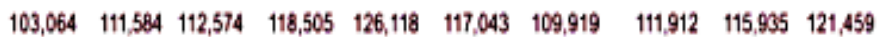
Precio/ (US\$Oz. Tr.) $\begin{array}{llllllllll}7.3 & 11.6 & 13.4 & 15.0 & 14.7 & 202 & 35.2 & 31.2 & 23.9 & 19.1\end{array}$

Price

Cifras Preliminares.

Fuente: Perú 2014 - Anuario Minero Reporte Estadístico.

Elaboración: Ministerio Energía y Minas. 
Figura 1.5: Producción Nacional de Cobre Periodo 2005 - 2014

(Miles de Toneladas Métricas Finas)

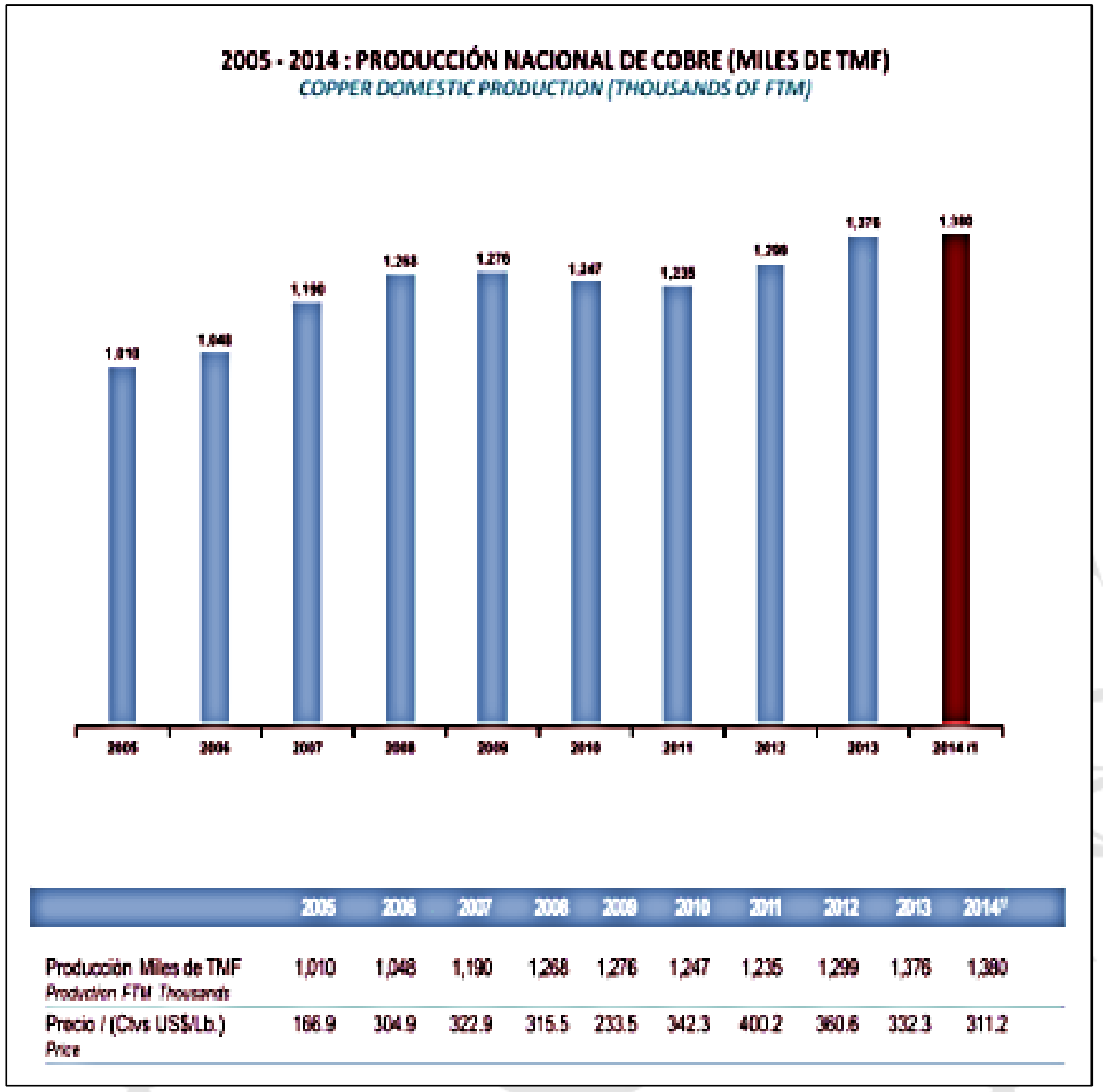

Cifras Preliminares.

Fuente: Perú 2014 - Anuario Minero Reporte Estadístico.

Elaboración: Ministerio Energía y Minas. 
Figura 1.6: Producción Nacional de Plomo Periodo 2005 - 2014

(Miles de Toneladas Métricas Finas)

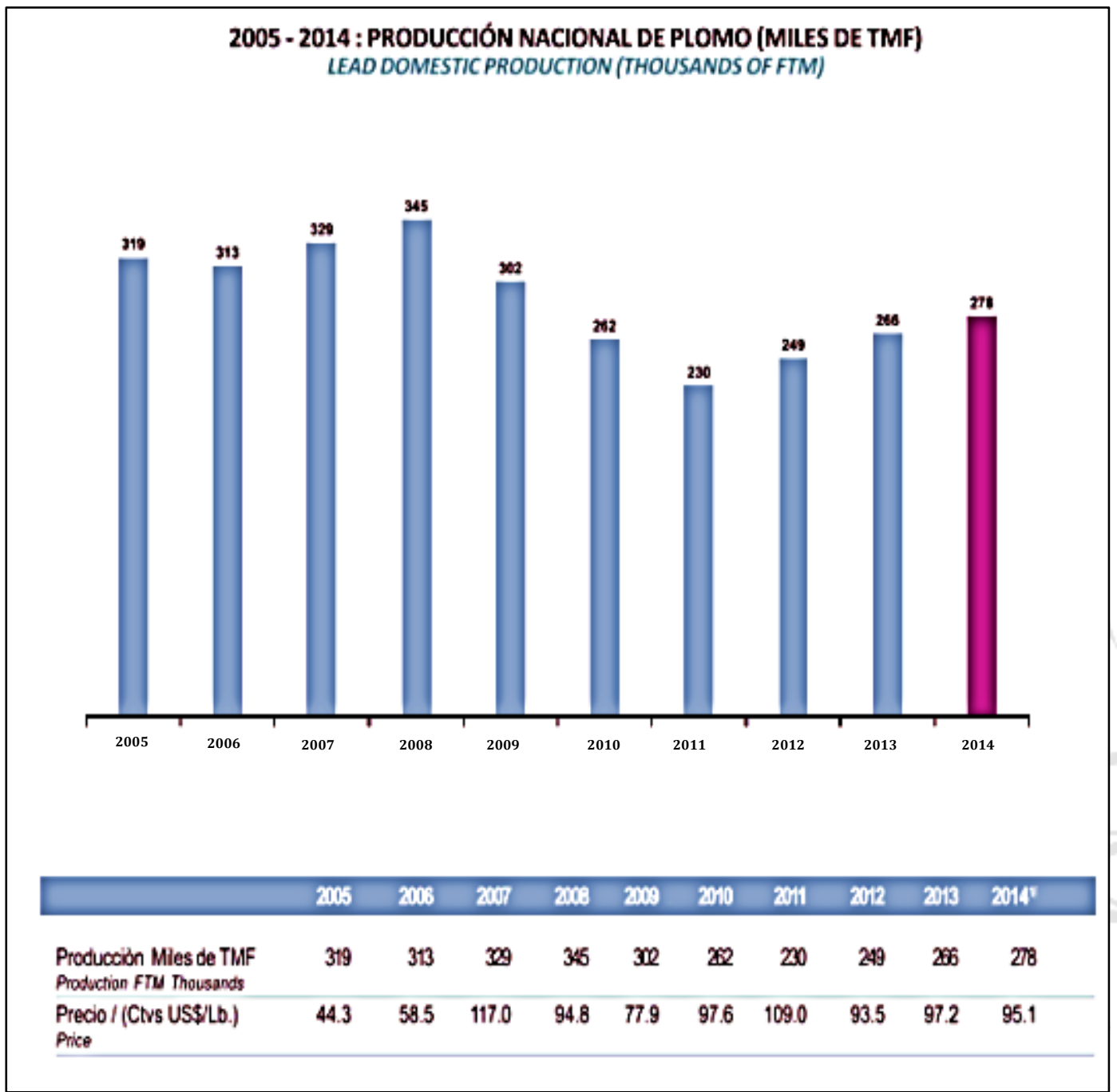

Cifras Preliminares.

Fuente: Perú 2014 - Anuario Minero Reporte Estadístico.

Elaboración: Ministerio Energía y Minas. 
Figura 1.7: Producción Nacional de Zinc Periodo 2005 - 2014

(Miles de Toneladas Métricas Finas)

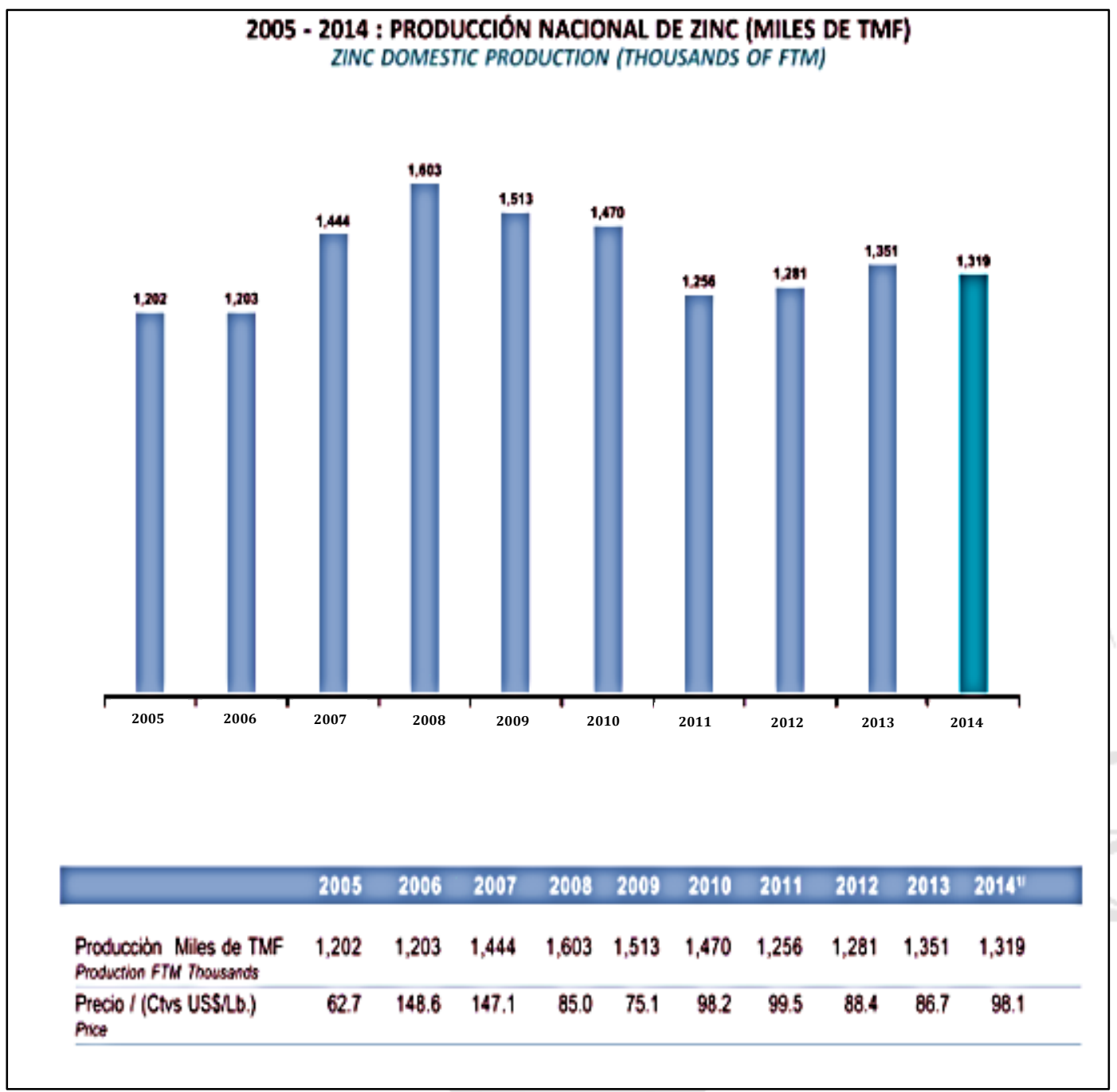

Cifras Preliminares.

Fuente: Perú 2014 - Anuario Minero Reporte Estadístico.

Elaboración: Ministerio Energía y Minas.

\subsection{Objetivo y Alcance del Proceso de Costeo}

El objetivo del costeo en La Empresa es recopilar y determinar los elementos de costos que intervienen en el proceso de desarrollo del proyecto y que de acuerdo a las especificaciones del contrato acordado entre ambas partes, sean considerados como costos o gastos reembolsables por los servicios prestados y cuya finalidad es la preparación y presentación de la facturación legal al Cliente, la cual va a contener toda 
la información de los cálculos y soportes que sirvan como sustento del servicio a prestar y que están enmarcados dentro del contrato de construcción acordado.

En los contratos EPCM, el compromiso de la empresa que brinda el servicio, comienza antes de la construcción y sigue hasta el cierre del proyecto y en algunos casos se prolonga durante el periodo de garantía de la construcción. El trabajo propio de construcción es efectuado vía el Contratista de la obra, bajo la estricta supervisión y dirección del Cliente EPCM. Cabe recordar que los contratos de obra son usualmente celebrados entre el Contratista EPCM (como Agente del propietario) y los Contratistas de Obra.

El Contratista EPCM actúa como agente del propietario (Cliente) para las actividades de procura y gestión de la construcción. Sin embargo, el contrato EPCM reconoce que el propietario o dueño de la obra, puede efectuar directamente la procura de los materiales y equipos a fin de ser incorporados en los trabajos de los subcontratistas del proyecto.

Una efectiva comunicación entre Cliente y Contratista EPCM es esencial para el éxito del proyecto. Deben estar alineados en todos los aspectos de la obra: alcances del trabajo, especificaciones técnicas, cambio de gestión, subcontratos, estrategias de compras, acceso y uso de lugar, requerimientos del proyecto, interfaces u operaciones de progreso, autoridades financieras, procedimientos de contabilidad, reportes de avance, asuntos públicos, entre otros. Aunque deben respetarse ciertos protocolos, la comunicación directa entre el Contratista EPCM y varios departamentos funcionales y contrapartes del Cliente resultarán muy útiles. Todas las comunicaciones que tienen que ver con aspectos que afectan al proyecto (costos, programación, calidad, seguridad, imagen), deben buscar la participación tanto del Cliente, como del Contratista EPCM.

El costeo, finalmente, da como resultado el resumen de todas las operaciones realizadas en el proceso de ejecución del proyecto, en el cual se puede encontrar elementos de costos directos, como la mano de obra, la utilización de materiales asociados a la construcción y costos indirectos como los gastos para la gestión y administración del proyecto. 


\section{CAPITULO 2: ENFOQUE Y DESARROLLO DEL}

\section{INFORME}

\subsection{Otorgamiento y tipos de Contrato en una empresa EPCM}

\subsubsection{Otorgamiento del Contrato de Construcción}

El Contrato de Construcción es el documento que firman el Contratista y Constructor, mediante el cual el segundo, se obliga a ejecutar la obra o el proyecto y al Contratista a pagarla. El Contrato debe describir qué trabajos hay que realizar y cómo ha de efectuarse el pago de los mismos.

Los trabajos a realizar son con frecuencia complejos y suponen muchas operaciones diferentes, exigiendo al Constructor la compra de multitud de materiales y diferentes elementos manufacturados, así como el empleo de una amplia gama de maquinaria y la participación de fuerza laboral de diferentes disciplinas y profesiones.

El otorgamiento de las licencias y permisos necesarios para operar las minas dependen directamente de la etapa en la cual se encuentre el proyecto minero y del tamaño del mismo ya que normalmente las licencias están claramente diferenciadas entre las necesarias para la pequeña minería y las que se requieren para la mediana y gran minería debido a su magnitud y escala de equivalencia. Es claro que en un primer momento se requerirá obtener licencias exploratorias, luego se requerirá autorizaciones para la construcción y posteriormente autorizaciones para la operación que funcionarán en tanto se mantenga la producción minera y finalmente las autorizaciones de cierre que deben ser gestionadas por la organización para cumplir con todos los requisitos legales y regulatorios aplicables al proyecto en el marco sectorial en el cual se desenvuelven.

Una vez obtenida la adjudicación del contrato de construcción, La Empresa generalmente garantiza al Cliente la ejecución, desarrollo y finalización de sus proyectos por medio de garantías limitadas, proporcionándoles la certeza que una vez se termine el trabajo, éste se cumplirá en la fecha programada, también asumir ciertos requisitos técnicos lo que significa que reunirá estándares industriales de calidad, de desempeño a pesar que en el momento de la adjudicación no se tenga conocimiento exacto de los riesgos inherentes al desarrollo del proyecto. En caso La Empresa no llegue a completar el proyecto en la fecha prevista o si ésta no cumple con los 
estándares de rendimiento o de garantía de calidad, puede asumir la responsabilidad en virtud de las obligaciones adquiridas en el Contrato para efectos de costos del Cliente, referidos a cualquier retraso o costo para la realización de la obra y la consecución de los estándares de desempeño y calidad acordados. En la medida que puedan ocurrir estos eventos, el costo total del proyecto (incluyendo daños y perjuicios por pagar) puede superar las estimaciones y proyecciones iniciales, lo cual puede significar una considerable reducción de las ganancias o en ocasiones, una pérdida considerable para ese proyecto.

Respecto a aceptar responsabilidad por daños a terceros o daños indirectos y adoptado seguros al respecto, los programas de gestión y prevención de riesgos diseñados para reducir estas posibles responsabilidades, un evento de la naturaleza que ocasione daños significativos en el sitio donde se ejecute alguno de sus proyectos, podría resultar en perjuicio de La Empresa, ya que se tendría que asumir el pasivo del evento, para evitar cualquier tipo de reclamo en su contra que pueda dañar su reputación, más aún si el evento o daño, también perjudica la propiedad pública. Estos pasivos, dependiendo de la magnitud, podría en ocasiones superar los límites y afectar la capacidad de obtener los seguros u honorarios generados. Además, los Clientes, Subcontratistas y Proveedores comprometidos con indemnizar a La Empresa en caso sucedan estos eventos con las consecuentes pérdidas, podrían negarse o no estar en la capacidad de responsabilizarse o cumplir con el pago de estos pasivos. Por ejemplo, podría darse el caso de un reclamo de seguro médico ya sea en parte o en su totalidad, el cual de tener éxito y ser de una magnitud considerable, podría tener un impacto sustancial en las operaciones.

Las licencias y permisos constituyen la actividad y secuencia de tareas más largas a programarse en cualquier proyecto minero no solo por la demora y el nivel de detalle necesario para construir los estudios que puedan sustentar la licencia respectiva, sino también por el tiempo de aprobación de los respectivos permisos por parte del regulador. En ese contexto las principales licencias y permisos a tener en cuenta en toda actividad minera son básicamente las denominadas licencias sociales, ambientales, técnicas u operacionales y corporativas. En la actualidad contextual de la relación con las partes interesadas es claro que las primeras marcan la factibilidad de las segundas, es decir, las licencias sociales y ambientales son las que definen si el proyecto puede o no continuarse hacia el futuro. 
Las licencias sociales son aquellas que se derivan de la relación existente entre la compañía minera y el entorno social en el que opera, en ese contexto es necesario tener en cuenta a las partes interesadas del área de influencia directa e indirecta del proyecto minero lo cual incluye principalmente los siguientes:

- Convenio de usufructo.

- Contrato-autorización de uso de propiedad superficial.

- Acuerdo comunal de exploraciones.

- Estudio de impacto social.

- Acuerdo de construcción con las comunidades.

- Acuerdo de operación con las comunidades.

- Convenio de desarrollo comunal.

Las licencias ambientales son las que se derivan de los impactos del proyecto sobre la línea de base del medio ambiente donde van a ser desarrollados previa aprobación de la autoridad regulatoria que engloba el proyecto minero, lo cual incluye principalmente lo siguiente:

- Licencia Ambiental de Exploraciones.

- Estudio de Línea de Base Ambiental del Proyecto (ELB).

- Estudio de Impacto Ambiental de Operación Minera (EIA).

- Programa de Adecuación y Manejo Ambiental (PAMA).

- Licencia de Uso de Aguas domésticas e industriales.

- Estudio de Impacto Ambiental de actividades eléctricas.

- Autorización de Cierre Ambiental con aprobación de Plan de Cierre.

Las denominadas licencias técnicas u operacionales son las que se derivan de las necesidades operativas de los procesos que deben ser desarrollados en la operación minera proyectada desde los estudios de ingeniería más tempranos que logren definirse sobre el proyecto a nivel de pre-factibilidad, factibilidad e ingeniería de detalle. Estas licencias son principalmente las siguientes:

- Autorización de perforaciones para exploración minera.

- Autorización de construcción de mina y planta.

- Autorización de construcción de polvorín de explosivos.

- Autorización de consumidor directo para combustibles. 
- Autorización de generación eléctrica.

- Autorización de Concesión de beneficio.

- Certificado de Operación Minera (COM).

Finalmente tenemos las denominadas licencias corporativas que son las que se derivan principalmente de la necesidad de cumplir regulatoriamente con los principales códigos estandarizados de la industria a las cuales la organización voluntariamente se suscribe. Estas licencias son principalmente certificaciones de cumplimiento del Código del Cianuro, Certificaciones de calidad (ISO 9001), Certificaciones Ambientales (ISO 14001), Certificaciones de Laboratorio (ISO 17025), Certificaciones de Seguridad de la Información (ISO 27001) y Certificaciones de Seguridad y Salud Ocupacional (OHSAS 18001, NOSA 5 estrellas, DUPONT, etc.) y homologaciones de proveedores que se necesitan en tanto la empresa corporativa lo requiera como parte de la política corporativa a implementar en la organización.

\subsubsection{Tipos de Contratos}

Los Contratos son un acuerdo de voluntades que pueden ser verbales o escritos, manifestados en común entre dos o más personas con capacidad (partes de contrato), que se obligan en virtud del mismo, regulando sus relaciones relativas a una determinada finalidad o cosa y a cuyo cumplimiento pueden complementarse de manera recíproca, si el contrato es bilateral o complementarse una parte a la otra, si el contrato es unilateral, pero además del acuerdo de voluntades, algunos contratos exigen, para su perfección otros hechos o actos de alcance jurídico, tales como efectuar una determinada entrega o exigen ser formalizados en un documento especial de modo que, en esos casos especiales, no basta con la sola voluntad.

Dependiendo del país pueden existir requisitos contractuales diferentes, pero básicamente el contrato es el mismo, las diferencias radican en la variedad sociocultural y jurídica donde se realice.

Contrato es un término con origen el vocablo latino "contractus" que nombra al convenio o pacto, ya sea oral o escrito, entre partes que aceptan ciertas obligaciones y derechos sobre una materia determinada. El documento que refleja las condiciones de este acuerdo también recibe el nombre de contrato. 
En la actualidad con los avances que ha tenido la industria y los cambios que se han producido en el mercado, los clientes se ven obligados en la necesidad de tomar numerosas decisiones respecto a la estructuración de contratos, las cuales tendrán gran influencia en el éxito del proyecto, en especial en dos aspectos muy importantes para el Cliente: el tiempo y el costo.

La complejidad de cada proyecto de construcción determinará el camino al Cliente para tomar decisiones sobre el tipo de contrato que más acomoda al proyecto, debiendo considerar que cada tipo opera de manera única, creando diferentes relaciones entre el Cliente y el Contratista y que, por lo tanto, su empleo tiene un resultado particular para cada situación.

Los contratos de construcción de una determinada obra obligan al Constructor a realizar la obra y al Cliente o Propietario a pagarla. El contrato debe por lo tanto describir detalladamente qué es lo que hay que construir y cómo se va a pagar lo construido. Para esto el contrato deberá incluir algunos documentos donde se especifiquen y dejen en claro temas contractuales de importancia:

\section{Proyecto}

Es conveniente que forme parte del contrato el Proyecto completo, pues si es un buen Proyecto, incluye en él no solo la descripción gráfica y pormenorizada de todos y cada uno de los trabajos a realizar, sino también condiciones, calidades de ejecución y formas de abono de cada una de las unidades. Además permite al Constructor obtener una idea clara de cuáles son los objetivos finales de lo que va a hacer y por tanto le permitirá conocer a fondo no solo lo exigible técnicamente, sino también lo conveniente en el proceso constructivo. Desde un punto de vista puramente legal, se suelen especificar los documentos del proyecto que son contractuales, es decir, que forman parte legal del contrato e incluso el orden de prioridades en caso de divergencias entre unos documentos y otros.

\section{Pliego de condiciones generales}

En las condiciones generales del Contrato se especifican responsabilidades, obligaciones y poderes de cada una de las partes contratantes y sus competencias en los campos de actuación respectivos. 


\section{Oferta}

Es el documento de compromiso, firmado por el Contratista y aceptado por escrito por el Cliente, donde se fija el precio ofertado y el plazo ofrecido para la terminación de los trabajos, respetando las condiciones fijadas en el Contrato.

\section{Documentos aclaratorios}

De algún posible punto difícil o importante del Contrato, como puede ser el de la fianza, premios o sanciones por retrasos, forma de actuar en caso de aparición de emergencias imprevisibles, reparto de riesgos, etc.

\section{Contrato propiamente dicho}

Es el documento firmado por ambas partes obligándose en los términos fijados en los documentos antes descritos, que se resumen en el compromiso del Contratista a construir y al Cliente a pagar lo construido.

La clasificación o denominación de cada tipo de Contrato depende en gran medida de la forma de realizar el pago al Contratista.

Los Contratos de construcción han ido evolucionando con el paso del tiempo, hasta hace aproximadamente 25 años la tendencia a nivel global era manejar contratos en tres partes: el Cliente, el Arquitecto y el Contratista General. En aquellas épocas, el Cliente contrataba directamente con el Arquitecto el diseño del proyecto, para que una vez terminado el mismo, se lleve a cabo el contrato de construcción a través de un acuerdo a suma alzada (Bass 2001 p.1).

Respecto a los tipos de Contratos, Nigel J. Smith dice lo siguiente:

"Los diversos contratos existentes operan de manera diferente entre sí. La forma como opera cada uno, depende en gran medida de la forma cómo se realiza el pago del Cliente al Contratista." 2

La complejidad de cada proyecto de construcción marcará el camino al Cliente para tomar decisiones acerca del tipo de contrato que más acomodará al proyecto, debiendo reconocer que cada tipo opera de manera única, creando diferentes relaciones entre el Cliente y el Contratista y que, por lo tanto su empleo tiene un resultado particular para cada situación.

\footnotetext{
${ }^{2}$ (Smith, Nijel J.; Engineering Project Management, 2002, p. 175)
} 
En el presente capítulo trataremos acerca de los tipos de contratos, clasificados de acuerdo a la literatura encontrada al respecto y también, de acuerdo a la Ley de Contrataciones y Adquisiciones del Estado.

La clasificación o denominación de cada tipo de contrato depende en gran medida de la forma de realizar el pago al contratista.

En este sentido, Nigel Smith, señala tres formas básicas de pago o tipos de contratos:

- Aquel basado en el precio, en nuestro medio llamado Suma Alzada o también Llave en Mano.

- El basado en ratios o cantidades, conocido en nuestro medio como Precios Unitarios.

- El basado en el costo, que funciona en base a incentivos y constituye un intermedio entre los dos anteriores.

En el Reglamento de la Ley de Contrataciones y Adquisiciones del Estado Peruano, se establece que:

“...las bases de los procesos de selección para la adquisición y contratación de bienes, servicios y ejecución de obras indicarán los sistemas y procedimientos que se utilizarán para determinar el precio y sus posibles ajustes, sobre la base de las condiciones pre-establecidas en función a la naturaleza y el objeto principal del contrato. Dichos sistemas deben ser el de suma alzada y el de precios unitarios, tarifas o porcentajes...,

Además, es importante resaltar el hecho de que la Ley, al igual que los autores consultados coinciden en establecer que el mecanismo de pago por los servicios, determina el tipo de contrato entre el Cliente y el Contratista.

Habiendo hecho una breve reseña sobre el concepto y algunos documentos que deben acompañar a los Contratos, se pasará a desarrollar cada uno de ellos.

\subsubsection{Contratos a Suma Alzada o Llave en Mano}

Nigel Smith, define este tipo de contrato como aquel bajo el cual el Cliente paga al Contratista un precio acordado por completar una cantidad de trabajo previamente pactado.

${ }^{3}$ (TUO Ley de Contrataciones y Adquisiciones del Estado / D.S.N ${ }^{\circ}$ 083-2004-EPCM, 2004; 
Por su parte Humberto Podetti, lo define como un tipo de contrato con precio inmodificable, y que en consecuencia, “...ambas partes han establecido sus obligaciones de modo definitivo, con la aspiración de que ni el objeto, ni el precio, ni las condiciones externas en que aquellos pactaron, cambien hasta el momento de la finalización de los trabajos, entrega de la obra y liquidación final de las cuentas. "4

Respecto a este tipo de contrato, el Reglamente de la Ley de Contrataciones y Adquisiciones del Estado, en su Artículo 56, dice lo siguiente:

“...En el sistema de suma alzada, el postor formula su propuesta por un monto fijo integral y por un determinado plazo de ejecución. Tratándose de obras, el postor formulará dicha propuesta considerando los trabajos que resulten necesarios para el cumplimiento del objeto de la prestación requerida según los planos, especificaciones técnicas, memoria descriptiva y presupuesto de obra que forman parte del Expediente Técnico, en ese orden de prelación; considerándose que el desagregado por partidas que da origen a su propuesta y que deben presentar como parte de la misma, es referencial. Este sistema sólo será aplicable cuando las magnitudes y las calidades de la presentación están totalmente definidas en las especificaciones técnicas y en los términos de la referencia y, en el caso de obras, en los planos y especificaciones técnicas respectivas; calificación que corresponde al área usuaria ... „,

Estos contratos se basan en un monto total (por lo que también se les llama: ("basados en el precio") que será abonado al Contratista por la ejecución de los trabajos que estén contemplados dentro del juego de documentos de la licitación, es decir: los planos, memoria descriptiva, estudios de suelos, topografía y especificaciones técnicas, por lo que “...la mínima desviación en la extensión del proyecto incluida en dichos documentos, salvo que sea corregida después en otras cláusulas del contrato, cambiará la extensión; mientras que los costos conexos quedarán contemplados en la orden de cambio una vez otorgada la obra. Aunque todo esto parece fácil, no lo es tanto como parece..."

Smith, dice que debido a su relativa inflexibilidad, este tipo de contratos por lo general incluyen "cláusulas de variación" que permiten al cliente realizar modificaciones al proyecto, pero siempre de la mano de un proceso de negociación entre ambas partes en cuanto al precio y al tiempo que tomarán los cambios. 
En ellos, además, se debe incluir cláusulas tales que permitan al Cliente eliminar una partida, para lo cual se debe establecer un monto máximo hasta el cual se puedan deducir trabajos, el cual debe ser menor que el subtotal de la obra, de esta manera se protege el Contratista, evitando que se deduzca una cantidad que supere el monto del contrato.

De otra parte, esta modalidad, implica la especialización del Contratista así como la obligación de éste de entregar un producto terminado, normalmente, de una obra o proyecto de altísima complejidad que implica la integración de un sin número de actividades y de disciplinas. La utilización de esta modalidad para obra que comúnmente se ejecuta bajo modalidades de contratos de obra o de locación de obra, culmina simplemente en la celebración de un contrato a precio global o alzado pues es la esencia de este tipo de contratos la complejidad y la amalgama de trabajos y servicios especializados.

Ventajas y Desventajas que presenta este tipo de contrato:

Entre las principales ventajas y desventajas reconocidas por Smith tenemos que: Ventajas:

- Es un tipo de contrato fácil de comprender y bastante usado en la industria de la construcción.

- Permite tener una muy buena aproximación del monto final de la obra de parte del Cliente, reduciéndose la incertidumbre y el consecuente riesgo financiero.

- La administración del contrato es sencilla cuando hay pocas variaciones o cambios en el proyecto.

- Fomenta y facilita un proceso de licitación más competitivo entre los contratistas.

- Requiere pocos recursos para la administración del proyecto por parte del cliente, permitiéndole destinarlos hacia otros proyectos.

\section{Desventajas:}

- No es conveniente adoptarlo en proyectos en los que se esperan grandes cambios en el diseño, pues presenta mínima flexibilidad ante los cambios.

- Existe la posibilidad de que un contratista que haya ofertado un monto muy bajo deba ser el encargado de asumir gran parte de los riesgos, por 
lo que se enfrentará a una situación de pérdida, que originará reclamos y relaciones antagónicas, llegando a peligrar el desarrollo del proyecto.

- El Cliente tendrá poca participación e influencia sobre la fase de construcción.

- Respecto a este tipo de contrato, la Ley General de Contrataciones y Adquisiciones del Estado, sostiene que para adoptarlo, se debe tener completo el diseño del proyecto, para que de esta manera, se pueda establecer durante la licitación, el alcance de los trabajos a realizar.

- Los contratos a suma alzada constituyen la forma de contratación más empleada a nivel mundial en proyectos de edificaciones, en la que los pagos son hechos por el Cliente por un monto acordado con el Contratista a lo largo de varias etapas, pues se pagan cifras preestablecidas cada vez que se van alcanzando ciertos hitos durante el avance de la construcción. Bajo este tipo de contrato, el Cliente traslada la responsabilidad al Contratista de construcción.

- Uno de los aspectos a reconocer respecto a este tipo de contrato es que no se incentiva la calidad de los trabajos, más allá de lo que se requiere en las especificaciones.

\subsubsection{Contratos Precios Unitarios}

Jacobsen (2006) lo define como un tipo de contrato bajo el cual la cantidad total de trabajo a realizar, solo se puede conocer luego de completar los trabajos, y que generalmente no se puede conocer al momento de la presentación de propuestas durante una licitación.

Respecto al pago, nos dice que este se hace de acuerdo a los precios acordados para una unidad de trabajo (por ejemplo, metros cúbicos de movimientos de tierra o metros lineales de muro construido)

Para N. Smith este es un tipo de contrato que se basa en precios prefijados que corresponden a la ejecución de un trabajo o partida específica. Señala además, que bajo este tipo de contratos, es posible identificar el tipo de trabajo o partida a realizar, pero no se puede determinar la cantidad de trabajo hasta que se complete el proyecto. 
Finalmente, menciona que el pago bajo este régimen contractual es mensual y es determinado por el Cliente a partir del metrado del trabajo realizado y los precios unitarios acordados en el contrato.

Respecto a este tipo de contrato, el Reglamento de la ley de Contrataciones y Adquisiciones del Estado, en su Artículo 56, señala lo siguiente:

“...En el sistema de precios unitarios, tarifas o porcentajes, el postor formula su propuesta ofertando precios, tarifas o porcentajes en función de las partidas o cantidades referenciales contenidas en Las Bases, y que se valorizan en relación a su ejecución real, así como por un determinado plazo de ejecución; y, en el caso de obras ofertará considerando los precios unitarios de las partidas contenidas en Las Bases, las condiciones previstas en los planos y especificaciones técnicas, así como las cantidades referenciales... "6

Este tipo de contratos constituye una buena alternativa para proyectos en los que se requiera empezar la ejecución sin haber completado necesariamente el diseño, debido a que permite el traslape de actividades y además representa un tanto sencilla de controlar la cantidad de trabajo realizada. Además, constituye una alternativa importante para aquellos proyectos que requieren ser manejados con precios previamente fijados (por ejemplo, proyectos manejados con suma alzada), pero en los que la extensión del trabajo no se ha definido al momento de la contratación.

Es importante reconocer la necesidad que el Cliente o el equipo que lo asesore (gerencia de proyectos o la supervisión) tenga experiencia en el área de construcción, pues para autorizar las órdenes de pago al Contratista es necesario un minucioso control de las cantidades de trabajo ejecutadas por éste.

También es importante reconocer que, si bien este tipo de contrato presenta cierto nivel de flexibilidad ante los cambios en el diseño, tanto el cliente como el contratista deben tener especial cuidado en el tipo de cambios que se implementen durante la ejecución, puesto que en el documento de contrato únicamente se establecieron las partidas contempladas en el diseño inicial del proyecto, por lo que de darse la inclusión de nuevas partidas se podrían desarrollar relaciones antagónicas entre las partes contratantes.

Ventajas y Desventajas que presenta este tipo de contrato:

Entre las principales ventajas y desventajas reconocidas por Smith tenemos que:

${ }^{6}$ (TUO Ley de Contrataciones y Adquisiciones del Estado / D.S.Nº 083-2004-EPCM, 2004; Articulo 56) 
Ventajas:

- Constituye un tipo de contrato bastante usado en la industria de la construcción.

- Permite cierto grado de flexibilidad para los cambios en el diseño.

- Permite cierto grado de traslape en las actividades de diseño y construcción.

- Fomenta un proceso de licitación muy competitivo.

Desventajas:

- La resolución de disputas y reclamos es bastante difícil y se desarrollan relaciones adversas entre las partes.

- Existe cierto grado de limitación en cuanto a la flexibilidad para la inclusión de nuevos trabajos, pues es difícil establecer un precio para las nuevas partidas que no están incluidas dentro del contrato.

- La participación del Cliente en el desarrollo del proyecto es bastante limitada.

- El precio final del trabajo no puede ser determinado hasta que no se concluyan las labores, especialmente cuando se han realizado cambios sustanciales en el proyecto.

\subsubsection{Contratos de Incentivos}

N. Smith define este tipo de contrato como aquel que el pago es realizado en base al costo de los trabajos realizados más un monto por gastos generales y utilidad del Contratista, pero además se tiene un acuerdo del "costo probable" o "costo objetivo" del alcance de los trabajos, lo que permite desarrollar un mecanismo de incentivos para manejar cualquier diferencia entre el costo total real de los trabajos y el "costo objetivo" acordado.

Este tipo de contrato presenta dos características positivas para el desarrollo del proyecto: la primera, es el efecto de la motivación que originan los incentivos para el Contratista, la segunda es el hecho que ambas partes deben trabajar conjuntamente para mantener el costo real del proyecto por debajo del "costo objetivo" y de esta manera, poder compartir los ahorros.

Menciona además el empleo de este tipo de contrato cuando exista una definición poco clara del trabajo a realizar al momento de la licitación o cuando se 
esperen variaciones considerables en el diseño del proyecto conforme se desarrolla la ejecución de la obra.

Debe evaluarse su uso cuando se tengan proyectos técnicamente complejos o cuando los trabajos involucren considerables riesgos que sean difíciles de cuantificar y finalmente, cuando el Cliente desee participar activamente del desarrollo y manejo del proyecto.

Humberto Podetti define este tipo de contrato como: “...unos de los más justos y equitativos para la ejecución de obras, ya que remite estrictamente a la realidad la determinación del precio y de la obra, pero requiere de verdadera cooperación y colaboración entre las partes, por cuanto puede prestarse a abusos y descontrol por parte del constructor...,"7

\section{Ventajas y Desventajas que presenta este tipo de contrato:}

Entre las principales ventajas y desventajas reconocidas por Smith tenemos que:

Ventajas:

- Se realiza un pago justo y existe un buen control de riesgo.

- Se permite un gran nivel de flexibilidad ante los cambios en el diseño.

- Hay una identificación entre ambas partes, pues las dos buscan minimizar el costo final del proyecto para mantenerlo debajo del costo objetivo, con lo que resultan menos discrepancias y reclamos al cierre del proyecto.

- El Cliente participa activamente del proyecto en la fase de construcción.

- Permite conocer los costos reales, lo cual es muy útil para el control del proyecto y para poder evaluar los posibles cambios.

\section{Desventajas:}

- No se requiere una definición extensiva de los alcances del proyecto para comenzar a ejecutarlo, reduciendo la duración del mismo.

- Facilita la reducción en la duración del proyecto.

- Se reduce el antagonismo en la relación entre el Cliente y el Contratista.

- Desde el punto de vista del Cliente su participación es esencial, además debe tener una actitud de colaboración y buena disposición para las relaciones con el Contratista.

\footnotetext{
${ }^{7}$ (Humberto Podetti; Contrato de Construcción, 2004; p.255)
} 
- Requiere procedimientos administrativos complejos, por lo que es probable que se dé un aumento en los gastos administrativos, por ejemplo, el seguimiento y control de los costos es muy importante (compra de materiales, alquiler de equipos, pago de planillas, etc.)

\subsubsection{Contratos Costos Reembolsables}

Para la Universidad de Cooperación Internacional, un contrato de costos reembolsables se utiliza cuando el alcance exacto del trabajo es incierto y, por lo tanto, los costos no se pueden determinar con la suficiente precisión. Este tipo de contratos establece que el Cliente pague los costos incurridos realizados por el Contratista al nivel señalado en el contrato. Un contrato de costos reembolsables, requiere que el Contratista cuente con un sistema de contabilidad que pueda considerar los costos del proyecto, por su parte el Cliente tiene el mayor riesgo en lo referente a éstos debido a que los costos totales le son desconocidos.

Por su parte Juan Carlos Gómez Guzmán, consultor de costos y precios de contratos públicos, sostiene que un contrato de costos reembolsables, es aquél en el que se paga al Contratista por los costos reales incurridos en la realización del contrato, más una cuota de utilidad, hasta el límite del presupuesto establecido. Es decir, contratos celebrados con precios provisionales y susceptibles de ser adjudicados principalmente en procedimientos acordados o en un diálogo competitivo.

En virtud de un contrato de costos reembolsables, el Contratista se compromete a colaborar con su mejor esfuerzo para completar el contrato suscrito. Estos contratos incorporan el pago de los costos incurridos admisibles, en la medida establecida en el contrato. También incluyen una proyección del costo total para comprometer fondos y fijar un límite máximo que el Contratista no puede exceder (excepto bajo su propio riesgo). Aunque se podría aceptar una eventual aprobación por el órgano de contratación de costos que excedieran el límite máximo del presupuesto, esto sucedería solo cuando se produjeran en la realidad eventos excepcionales.

La utilización de este tipo de contratos es adecuada cuando la naturaleza o el alcance del trabajo que se ha de llevar a cabo no se puede definir correctamente desde un inicio, cuando las incertidumbres propias de la ejecución del contrato no permiten estimar con la exactitud adecuada sus costos para utilizar cualquier tipo de contrato o cuando los riesgos asociados en la ejecución del contrato son altos. Los contratos que 
encajan entre las anteriores circunstancias son por ejemplo, contratos cuyo objetivo sea la investigación y desarrollo de un nuevo proyecto tecnológico, cuando se debe gestionar una tramitación de emergencia por motivos de acontecimientos catastróficos o también cuando el objeto se trate de la realización de infraestructuras con un periodo largo de ejecución. En estos casos, el poder adjudicador apenas puede hacer otra cosa más que determinar un esquema de especificaciones sobre los que se desarrollará el objeto del contrato y una estimación de costos.

No cabe duda que ésta es una manera de contratación de alto riesgo para la administración del Cliente, ya que no sabe cuál será el costo final del contrato en el momento de suscribirlo. Sin embargo, este tipo de contratos compensa ese riesgo cuando la preocupación por la calidad es mayor que el costo. En muchas ocasiones, el precio de un contrato de costos reembolsables resulta menor que si se hubiera otorgado en un procedimiento abierto con precios fijos, ya que en estos el Contratista está poco motivado a reducir costos si ha conseguido introducir un margen elevado de beneficio para cubrir su riesgo financiero y operativo.

No obstante, en los contratos de costos reembolsables, además de la desventaja del riesgo del precio para el Cliente, en cuanto a la incertidumbre del costo final al momento de la suscripción del contrato, se puede añadir otra por el hecho de tener el contratista menos incentivo para ser eficiente, en comparación con un contrato a precio fijo, si se toma en consideración que su margen no es el adecuado ante la certeza de saber cubierto el costo incurrido. Y esto puede suceder, por ejemplo, cuando el órgano de contratación ha apreciado una cuota menor de beneficio para el Contratista por ser los requisitos y especificaciones del contrato relativamente simples, no especificar una tecnología compleja o no requerir de personal altamente calificado, entre otros motivos o en el caso contrario, cuando no se ha proyectado adecuadamente las incertidumbres, riesgos tecnológicos y económicos del Contratista en la ejecución del contrato.

Por tales motivos, para disminuir el efecto de dichos riesgos y pagar un precio final equilibrado, los costos para los que el Contratista tiene derecho a ser reembolsado deben establecerse de manera muy clara en el contrato. Este es un procedimiento complejo que debe ser analizado cuidadosamente, ya que mientras la determinación de algunos costos directos puede ser relativamente sencilla, otros, tal vez no lo sean.

Y, en cualquier situación, los costos reembolsables (y sus beneficios) presentados por el Contratista para ser compensados, deben quedar sometidos a la comprobación del cumplimiento de ciertas reglas contables y de su soporte documental 
(una auditoría de costos incurridos). Es decir, se requiere de una auditoría del contrato para garantizar que solo sean pagados los costos reembolsables y así asegurarse que el Contratista esté haciendo, de manera adecuada y eficaz, el control de los costos.

Únicamente son reembolsables los costos admisibles. El costo total del contrato debe ser la suma de los costos directos e indirectos permitidos, razonables y debidamente efectuados y/o asignados, de acuerdo a lo estipulado en las condiciones del contrato. Estos costos deben ser establecidos de acuerdo con las prácticas de contabilidad de costos generalmente aceptadas o las aprobadas en el contrato y ser aplicadas consistentemente en el transcurso del tiempo.

Un costo es razonable si la naturaleza, la cantidad y valor no exceden de lo que se incurriría por una persona prudente ordinaria en la gestión de un negocio competitivo.

En la determinación de la razonabilidad de un costo en particular, se harán las siguientes consideraciones:

- Si el costo es de un tipo generalmente aceptado como normal y necesario para el desarrollo de la actividad o la ejecución del contrato de un contratista.

- Las restricciones y requisitos por factores tales como las prácticas generalmente aceptadas del funcionamiento del negocio, normas administrativas y las condiciones del contrato.

- La acción que personas prudentes tomarían en las mismas circunstancias, teniendo en cuenta sus responsabilidades como propietarios de la empresa y deberes respecto de sus empleados, clientes, la administración y el público en general.

- Desviaciones relevantes de las constantes del Contratista en sus operaciones que puede incrementar de forma injustificada los costos del contrato.

- Las especificaciones, cronograma de entrega y los requerimientos de calidad del contrato en particular, ya que tienen influencia en los costos.

Los costos directos del contrato, que son claramente atribuibles a un solo proyecto, pueden incluir, entre otros:

- La mano de obra directa.

- Los materiales.

- Las subcontrataciones. 
Otros costos que pueden estar disgregados en más de un proyecto y no pueden ser asignados directamente al objeto del contrato, es decir, los costos indirectos, pueden incluir, entre otros:

- Los gastos de la oficina central.

- Los gastos de personal de administración.

- Las amortizaciones del inmovilizado.

La atribución de estos costos se calculará acorde a la regla contable que especifique los métodos que han de seguirse para su agrupación homogénea y la fijación de bases de reparto equitativas que tengan en cuenta vínculos de causalidad o de utilidad con el objeto del costo.

Asimismo, se debe establecer un procedimiento para el cálculo del beneficio del Contratista que tome en cuenta el valor aportado y el riesgo económico y financiero asumido. Por esta razón, con el fin que el Contratista pueda mantener su flujo de efectivo, en el cálculo de su beneficio debe tomarse en cuenta el costo de sus operaciones de financiamiento relacionadas con el contrato, por los gastos financieros en los que incurra entre los pagos parciales del contrato.

Los costos son calculados con base en los registros contables del Contratista y otros registros que deben ponerse a disposición del órgano de contratación, llámese Cliente, como un libro abierto. El poder adjudicador también puede supervisar las actividades administrativas y productivas del contratista para comprobar que no realiza prácticas ineficientes, inadecuadas o excesivas y están libres de fraude.

\section{Tipos de Costos Reembolsables}

\section{Sistema de costos y costes}

En los que el contratista no recibe ninguna cuota de beneficio o en su caso, una utilidad fijada de antemano. Sólo se pagan los costos incurridos en la ejecución del contrato. Este tipo de contrato puede utilizarse en los de ejecución de obras y fabricación de bienes muebles por el Cliente y ejecución de servicios con la colaboración de empresarios particulares o en los de investigación y desarrollo, en particular futuras asociaciones para la innovación, en las que participen organizaciones sin fines de lucro, como por ejemplo centro de investigaciones y universidades. 


\section{Precio determinado por el costo incurrido}

Contratos en los que el precio puede formularse en términos de precios unitarios referidos a los distintos componentes de la prestación o a las unidades de la misma que se entreguen o ejecuten, siendo éste uno de los sistemas tradicionales de fijación de precios. En estos casos, se paga el costo incurrido admisible y aprobado por el órgano de contratación, más un beneficio calculado conforme se determine en el contrato. El pago del contrato se puede hacer al término del mismo o mediante certificaciones parciales y liquidación final.

\section{Contratos de margen fijo (beneficio) con incentivos}

El Contratista puede incentivarse para operar de manera más eficiente por la introducción de un objetivo de costos que se persigue. Aquí, el límite de costo que se busca ha sido acordado en la negociación del contrato. Al finalizar la ejecución del contrato, se compara el costo real incurrido con el costo objetivo, teniendo en cuenta los cambios en el contrato que se hayan acordado. Si el costo total incurrido es menor que el costo objetivo, los ahorros son compartidos entre las partes, sobre la base del incentivo acordado (a menudo un porcentaje de los ahorros).

$\mathrm{Si}$ el costo total incurrido es mayor que el costo objetivo, los costos adicionales también se pueden compartir. Este tipo de contratos es apropiado cuando se requiere motivar al Contratista en el desempeño eficaz de su prestación, como en los de investigación y desarrollo, contratos de obras para infraestructuras, suministros de fabricación o en cualquiera de las prestaciones de un contrato de colaboración entre el sector público y el sector privado.

Sin embargo, en ocasiones, puede no ser eficaz vincular el beneficio (incentivo) del Contratista a un ahorro de costos, sino que más importante la calidad y el rendimiento del objeto del contrato. En este caso, el incentivo está vinculado a los resultados provisionales identificables y su método de cálculo también es negociado en el contrato.

\section{Costos compartidos}

El contrato de costos compartidos es un contrato de costos reembolsables en el que se compensa al Contratista sólo la parte convenida de los gastos admisibles, no 
percibiendo el Contratista beneficio alguno. Este tipo de contrato, a diferencia del “costo y costas" es muy apropiado en cuanto a su utilización con entidades lucrativas cuando el objeto es una investigación y desarrollo y éstas se van a beneficiar de la venta o alquiler de la patente.

\subsection{Roles y Responsabilidades de las áreas dentro de la empresa}

Para el desarrollo del tema de los roles y responsabilidades de las áreas dentro de la empresa, en este caso de construcción, tomaremos como base el modelo MAC4DV que es la agrupación de herramientas y conocimientos obtenidos de los sistemas de administración por valores y de empresas de alto rendimiento, además, de las experiencias de empresas constructoras para la formación de nuevas estructuras, procesos, políticas, normas y procedimientos organizativos, cuyo soporte se encuentran en procesos de reingeniería y mejora constante para la creación de la empresa de élite sectorial.

Este es un modelo de valores que rige la conducta y procedimientos de los recursos humanos en los procesos y métodos de la organización, que deberá operar estructuralmente bajo un régimen de cuatro direcciones, además podrá formar parte de procesos de sistemas y trabajos entre sus áreas y puestos, propone el trabajo en equipo horizontal y verticalmente de áreas especializadas, que permitan el aprendizaje de nuevos conocimientos por sus relaciones interdisciplinarias. Es un modelo que define el proceso administrativo (dirección, planeación, organización, integración, control y ejecución) en su aplicación en concordancia con sus tramos de control, por lo anterior este modelo se caracteriza por estar en constante mejora por el origen, definición y características de sus equipos de trabajo, que buscan la excelencia en calidad, atención y servicio enfocado al cliente, busca ante todo ser un modelo de organización.

Este tipo de empresa deberá ser conformada por ejecutivos que se encuentran en constante crecimiento profesional, líderes que están en constante generación de oportunidades de negocios, cuya característica principal es su mentalidad ganadora, no limitan sus capacidades, hacen de sus logros particulares un triunfo para la organización, trabajan en equipo, lo manejan y lo desarrollan, además generan, en consecuencia, una organización innovadora, visionaria, desarrolladora, líder y ganadora, con altos estándares de productividad y competitividad, su lema es "ser el mejor". 
Se busca que sean organizaciones que se preguntan de manera constante en dónde encontrar las oportunidades, no donde están en ese momento. Deberían ser empresas en constante competencia y acostumbrada a ganar, empresas cuya particularidad máxima es que trabajan en equipo, con objetivos y metas bien definidas, equipos con alto grado de interacción entre sus miembros y entre otros equipos de la organización, de manera tal que se convierten inter funcionales y auto dirigibles.

Tratándose este tipo de empresas de una estructura organizacional muy amplia, se intentará enfocar y desarrollar los roles y responsabilidades de algunas de las áreas más importantes:

\section{Recursos Humanos}

La gestión de esta área en términos concretos es la que tiene a su cargo la contratación de personas para incorporarlas a la organización, coordinarlas y desarrollarlas, que trabajan conjuntamente de acuerdo a estrategias determinadas para el cumplimiento de los objetivos de la organización.

Es relevante crear un área de Recursos Humanos que esté totalmente integrada a la organización, que se adecue a los métodos de trabajo de la empresa constructora y que comprendan que este sector es muy diferente en cuanto a otros sectores productivos, que propongan nuevos procesos, sistemas, programas y políticas, que reflejen una gestión de los recursos humanos adaptados al sector. Para el entendimiento de la empresa en que se va a operar un proyecto de recursos humanos, es necesario primeramente hacer un análisis de la problemática que afronta este tipo de organización, sus formas tradicionales de gestión y resultados, lo mencionado anteriormente es muy importante porque el área de Recursos Humanos en la empresa constructora, es una de las áreas a la que no se le da la debida importancia, es un área considerada no relevante para el logro de los objetivos de la organización e incluso hay empresas que si le dan importancia, pero como área meramente estructural y lo limitan o se auto limita a desarrollar solo funciones de rutina con poca relevancia (por sus formas), como la contratación y supervisión, dejando de tomar en cuenta el aspecto más importante para llegar a ser una empresa altamente competitiva, como lo es el desarrollo de los recursos humanos, al igual que los aspectos relacionados a la salud, higiene y seguridad. 
El director de la organización debe estar consciente que esta área es relevante para ejecutar el proyecto de cambio que se pretende, un modelo nuevo, que lo que busca es ser un mejor competidor, con aspiraciones a llegar a ser una empresa de élite del sector, por lo tanto, la organización no puede prescindir de relegar a ninguna área y mucho menos a ésta, que será quien proporcione personal altamente capaz para contribuir a la consecución de los objetivos de la organización. Hay que comprender que el recurso humano, es el más importante de una organización, ya que este será el responsable de manejar el resto de los recursos, como son los financieros, los tecnológicos y materiales

Algunas de las funciones del área de Recursos Humanos son:

- Análisis de los puestos de trabajo.

- Proveer a la organización de personal.

- Desarrollo de personal (crecimiento potencial del recurso).

- Evaluación del personal.

- Gestionar la salud, higiene y seguridad en el trabajo.

- Sistema de compensaciones.

- Investigación y constante búsqueda de nuevos procesos para el desarrollo del recurso humano de la organización.

- Soporte a unidades de negocios corporativos.

Las funciones anteriores reflejan un sistema convencional de gestión de Recursos Humanos, pero que al momento de aplicación de los mismos, lleva una alta dosis de cambio, de acuerdo al desarrollo por sus innovaciones políticas, procesos, programas, que estratégicamente se crean de acuerdo a la circunstancia actual que vive este tipo de organizaciones, con sus problemáticas y los cambios que experimenta de todo tipo en su entorno el sector de la construcción, sobre todo la globalización.

Los objetivos de la gestión del área de Recursos Humanos:

- Contar con los mejores talentos del mercado laboral

- Retener los mejores talentos dentro de la organización

- Desarrollar y motivar a los empleados de la organización

- Promover la mejora constante elevando los índices de productividad y rentabilidad de la organización

- Mejoras constantes en las condiciones de trabajo

- Cumplimiento de la normatividad y legislación de la organización. 
Actualmente es difícil encontrar perfiles tan completos según lo exige el proyecto de cambio, pero es de necesidad estar lo más apegado a lo que requiere la organización o en su defecto, tratar de suplir los aspectos faltantes del ejecutivo con capacitación para lograr un titular de recursos humanos de alto rendimiento, especialista en el sector, capaz de ser generadora constante de talentos, de individuos exitosos, con mentalidad ganadora, sin olvidar que sus bases de desarrollo serán los valores personales y organizacionales.

\section{Administración y Finanzas}

Esta área tiene a su cargo cubrir las necesidades y usos de fondos de la empresa, obteniendo recursos financieros y usándolos para fines rentables, además, en su función de control será responsable de la gestión contable y de sistemas por sus aportes de herramientas para controles de auditorías administrativas y financieras y con la facultad del área de Recursos Humanos integrándola a un proceso de cambio organizacional.

Algunas de las funciones del área de Administración y Finanzas son:

- Determinación de las necesidades de recursos financieros (óptimos).

- Obtención de financiamientos (rentables).

- Aplicación de recursos financieros (productivos).

- Análisis (evaluación).

- Gestión contable (administración del área).

- Gestión de sistemas (administración del área).

- Supervisión del área de Recursos Humanos.

- Contribución con estudios económicos y financieros en proyectos de inversión a la gerencia de proyectos.

- Investigación y desarrollo de sistemas y procesos de sus áreas.

- Establecer los objetivos de la gestión del área de Administración y Finanzas.

- Dotar a la organización de recursos financieros para la operación de proyectos y de la organización misma.

- Administrar idóneamente los recursos financieros y hacerlos altamente rentables. 
- Abastecer a la organización de información clara, confiable, exacta y responsable del área de contabilidad en tiempo y forma para los fines convenientes.

- Aportar en los procesos de trabajo mediante el buen funcionamiento de los sistemas informáticos y su desarrollo.

- Cumplir con la gestión del área de Recursos Humanos de acuerdo a los procesos, sistemas y programas establecidos por la organización para su correcto funcionamiento.

- Contribuir al desarrollo organizacional

\section{Dirección de Construcción}

Es la encargada de la confección y presupuesto de obra de proyectos de construcción, además, de su aplicación técnica, determinando procesos y sistemas de trabajo con los estándares de calidad en concordancia a las especificaciones técnicas y procedimientos establecidos en el contrato por el Cliente y por el Contratista.

Algunas de las funciones del área del área de Construcción son:

- Gestor de presupuestos (técnicos).

- Gestor del área de diseño.

- Coordinar la ejecución de la obra.

- Contribuir de materia técnica operativa para la preparación de proyectos de inversión al área de gerencia de proyectos.

- Ejecutar el proyecto.

- Investigación y desarrollo de nuevos procesos y sistemas de construcción y diseño.

- Dentro de los objetivos podemos mencionar:

- Entregar en el tiempo acordado y forma acordada la obra con los estándares de calidad establecidos en el proyecto.

- Confección de diseños innovadores minimizando costos con programas, procesos y sistemas de construcción que acorten los tiempos de la construcción.

- Contribuir al desarrollo de la organización con nuevas propuestas técnicas. 


\section{Dirección de Ventas}

Esta es el área encargada de dirigir el área de ventas, cuyo objetivo principal es efectuar la venta de obras ejecutadas por la empresa en todas sus formas, teniendo en cuenta cubrir sus objetivos y metas de facturación. Su gestión cubre todo el proceso de la venta, para ello organiza y coordina la actividad de la fuerza comercial con la de los servicios involucrados antes y después de las coordinaciones para la venta.

Se pueden mencionar las siguientes funciones para el área de Ventas:

- Gestión de ventas (planeamiento, organización, dirección, control e integración)

- Acopiar información de las necesidades y expectativas de los clientes (marketing)

- Recopilación e información de los clientes después del proceso de venta (post venta)

- Información sobre mercados (situación actual y a futuro) o posibles modificaciones del mercado.

- Informes sobre la competencia.

- Contribuir con la empresa constructora (corporativa) para el desarrollo organizacional con la aportación y participación en estudios de mercado para la gerencia de proyectos.

- Encargado de las relaciones públicas (clientes y equipos)

- Preparación del presupuesto de ventas anuales y cumplimiento de la facturación proyectada.

- Presupuestos de gastos del departamento comercial.

- Dentro de sus objetivos encontramos:

- Incremento de las ventas de la organización.

- Atraer clientes y mantener los actuales.

- Contribuir en el incremento de la imagen de la organización.

Contribuir con el desarrollo organizacional con la aportación de sus vastos conocimientos en materia de ventas y de mercados (en todos sus procesos) y en la confección de estudios en materia para la integración de proyectos de inversión para el corporativo mediante el soporte a equipos y a la gerencia de proyectos. 


\section{Gerencia de Proyectos}

Esta gerencia es la responsable de la organización, el planeamiento, la motivación y el control de los recursos con la finalidad de alcanzar las metas establecidas para lograr el éxito de un proyecto dentro de las limitaciones establecidas. Estas limitaciones suelen ser el alcance, el tiempo, la calidad y el presupuesto.

De este modo el objetivo de la gerencia de proyectos es hacer uso de los recursos disponibles para conseguir determinadas metas; lo cual implica la interacción entre conocimiento, tecnología, entorno, estructuras, procesos, servicios y productos. En tal sentido, las soluciones de la gestión y la dirección de proyectos (metodologías, técnicas, tecnologías, modelos, herramientas) deberán ser la base para proceso de gestión del proyecto. Este proceso a su vez debe ser el correcto y basado en principios razonables.

Las claves de la gerencia de proyecto para la consecución de los objetivos establecidos de manera exitosa son los siguientes:

- Debe tener un alcance controlado.

- Debe existir comunicación constante y efectiva entre las partes interesadas del proyecto.

- El plan de proyecto es un medio para lograr los objetivos, responsabilidades y es utilizado para medir el progreso durante la ejecución del proyecto.

- Los objetivos deben ser coordinados entre el director del proyecto, el cliente y la dirección de la empresa.

- Debe existir siempre el apoyo de la dirección del proyecto.

Además de los puntos mencionados, la gerencia de proyectos debe gestionar los planes, proyectos y obras para que sean realizados con calidad y de manera oportuna, optimizando costos y tomando como base las metas y planes institucionales para el diseño y posterior desarrollo en mediación ambiental, gestión social y otros.

Algunas de las funciones:

- Planificar y desarrollar los proyectos de mediación ambiental, encargándose de la preparación de todos los estudios y aprobaciones (estudios de pre inversión, planes de cierre, factibilidad, ingeniería de detalle, expedientes técnicos) previos a su ejecución.

- Administrar, controlar y hacer seguimiento a los servicios de consultoría contratados para el diseño y planificación de los proyectos. 
- Conducir, administrar y supervisar los contratos de estudios, suministros y obras que desarrolla la empresa.

- Desarrollar las acciones de la consolidación y suministro de información, relacionados a la programación y control de los proyectos.

- Brindar información ejecutiva y estadística de los recursos que administra y los avances de los proyectos, para evaluar el comportamiento de cada uno de ellos.

- Desarrollar los estudios económicos financieros de oportunidades de inversión de la empresa, estableciendo la metodología de evaluación, parámetros y variables a emplearse e indicadores de rentabilidad.

- Desarrollar la evaluación económica financiera de los proyectos de inversión solicitados por las demás áreas de la empresa.

\section{Gerencia de Compras o Adquisiciones}

Para tener un mayor entendimiento de ésta área, se citarán algunas definiciones de interés acerca de los que es y se hace dentro de esta gerencia.

Compras: es la actividad que se propone suministrar bienes o servicios en los términos, acuerdos o especificaciones que se requieran o que determine el proyecto en las mejores condiciones de calidad, precio y servicio a cambio de dinero.

Comprador: es aquella persona con la facultad de satisfacer las necesidades por medio de una compra de un bien o servicio, requerido o solicitado por un área o persona que forma parte de la empresa.

Por lo tanto, el área de compras tiene a su cargo todas las adquisiciones de la organización, como son: materiales para construcción, servicios (subcontratos y similares de obra) y demás adquisiciones de operación (no aplicada a la obra de manera directa), en las mejores condiciones de calidad, precio y servicio.

El proceso de compras está conformado por una serie de actividades y procedimientos bien definidos, que se inicia a través de una requisición u orden compra sujeta a verificaciones de las áreas relacionadas, como aquella que la requiera, control de proyectos que corrobora forme parte de la necesidad de la obra, administración y finanzas en cuanto a contar con los fondos disponibles para la compra del bien o servicio, entre otras áreas y que termina con la entrega de materiales para su utilización en obra o para lo que fue adquirido, esto en lo relacionado al aspecto técnico y en 
cuanto al aspecto administrativo termina cuando se concreta el desembolso al proveedor, lo cual puede ser relativo de acuerdo al compromiso del área, ya que muchas veces se compromete o incluye en sus funciones la supervisión de la aplicación real de lo comprado, cuestión de políticas y procesos de cada organización.

El proceso de compras, una vez la organización haya hecho el requerimiento de un bien o servicio por medio de una requisición $\mathrm{u}$ orden de compra, elabora una dinámica de procesos y actividades para cubrir o abastecer el pedido, este proceso es complejo, porque no sólo se trata de la acción de compra, sino hacer un despliegue de estrategias planeadas y organizadas para conseguir un valor competitivo que se refleje en beneficios, calidad e imagen de la empresa, pero principalmente, contribuir en gran medida en la satisfacción de los clientes.

El arte de comprar, es saber negociar, valiéndose de todos los conocimientos adquiridos en base a experiencias y habilidades para lograr objetivos, como son: obtener para la organización los mejores precios al momento de adquirir los materiales y servicios en el mercado (calidad), con facilidades crediticias (créditos, tiempos y montos), con la mejor atención (servicio) y finalmente con un adicional de competencia (desarrollo, capacitación, infraestructura, negocios y alianzas)

En el proceso de compras de una empresa constructora se pueden distinguir las siguientes actividades:

- La requisición u orden de compra de materiales.

- Registro y clasificación de materiales.

- Ubicación de proveedores.

- Solicitud de cotizaciones.

- Evaluación de cotizaciones y presupuestos.

- Selección de proveedores y negociaciones.

- Elaborar, poner en circulación y hacer seguimiento de las órdenes de compras.

- Ingreso, almacenaje, resguardo y entrega de suministros.

- Seguimiento de procesos de proveedores, revisión y pago de las facturas.

- Otras actividades indirectas que realiza son:

- Control de inventarios.

- Control de cuentas por pagar a proveedores.

- Generación y transferencia de información al área de contabilidad. 
- Generación y transferencia de información a la gerencia de proyectos.

Dentro de los objetivos del área de compras y adquisiciones podemos mencionar:

- Generar utilidades basados en la reducción de costos en el proceso de compras (incluyendo la compra misma) tomando en cuenta los estándares de calidad que requiere el proyecto, con el fin de mantener la empresa competitivamente en operación.

- Contribuir en la ejecución y operación de los trabajos de construcción en cuanto a plazos y forma generada por la planeación estratégica de adquisiciones en su proceso total.

- Relación de proveedores que generen un desarrollo compartido por medio de negocios, alianzas y capacitación, entre otros.

- Contribuir con la buena imagen de la organización relacionada con las buenas prácticas comerciales basado en valores éticos y morales.

- Dentro de las funciones podemos mencionar:

- Investigación, análisis y selección de proveedores y precios

- Relaciones comerciales.

- Desarrollo del área y del personal (compras-control de inventarios)

- Recepción, evaluación y registro de requisiciones u órdenes de compra.

- Coordinación de los sistemas de recepción, almacenaje, resguardo y entrega de materiales.

- Salvaguarda de la calidad de los materiales y servicios (actividad compartida).

- Finiquitar convenios y contratos con proveedores.

- Seguimiento de operaciones post compra con los proveedores (revisión y pagos).

- Levantamiento de inventarios.

- Realización de auditorías internas administrativas (procesos, actividades y documentos)

- Supervisión de almacenes y bodegas.

- Investigación de mercados.

- Pronosticar situaciones de los mercados. 
- Disminuir o eliminar la interrupción de los procesos de construcción por falta de suministros.

- Minimizar o eliminar pérdidas por mermas, robos, controles entre otras situaciones.

A continuación, se presenta gráfica de las actividades de un proceso de compras:

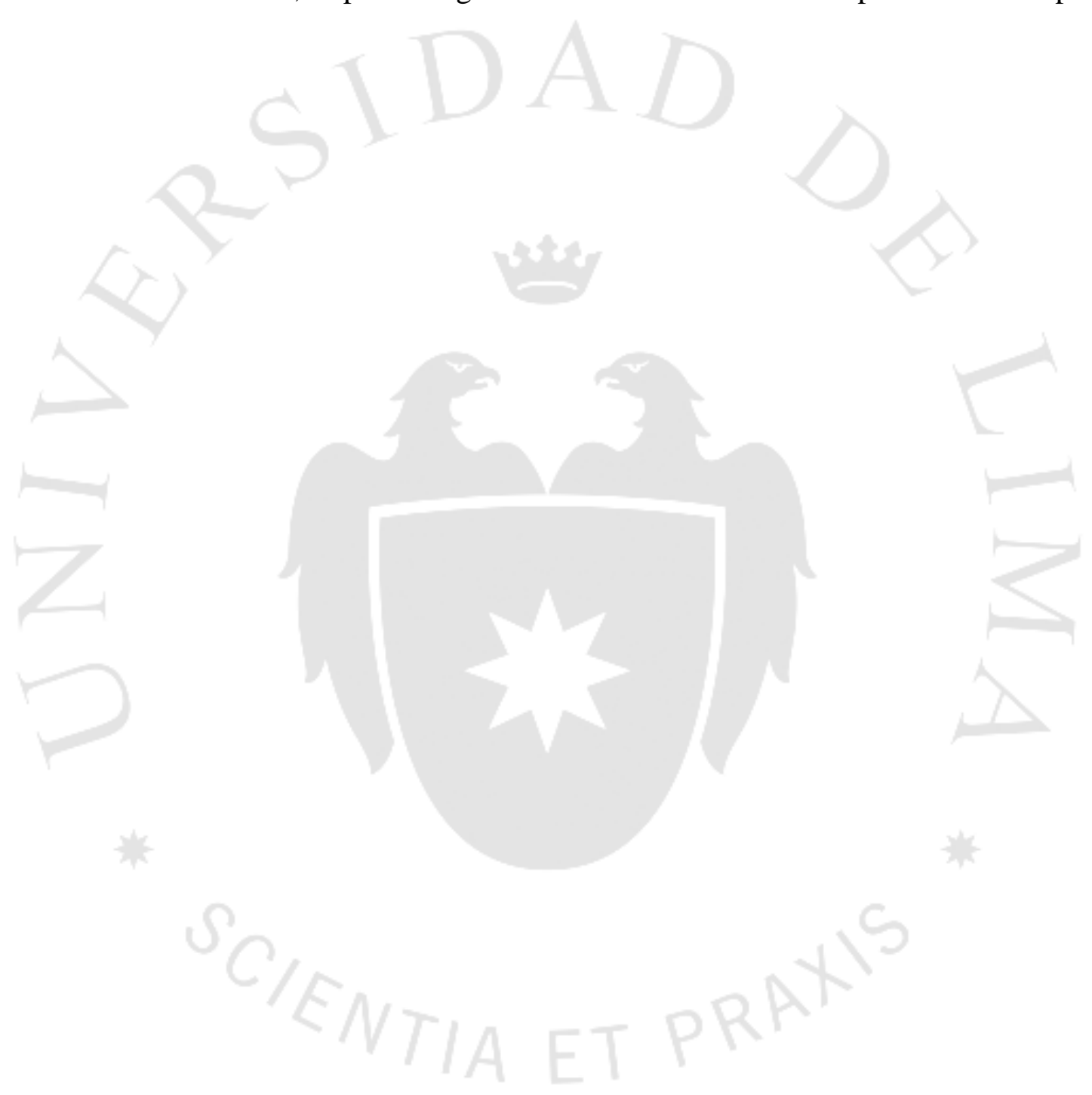




\section{Figura 2.1: Cuadro de Flujo de Compras}

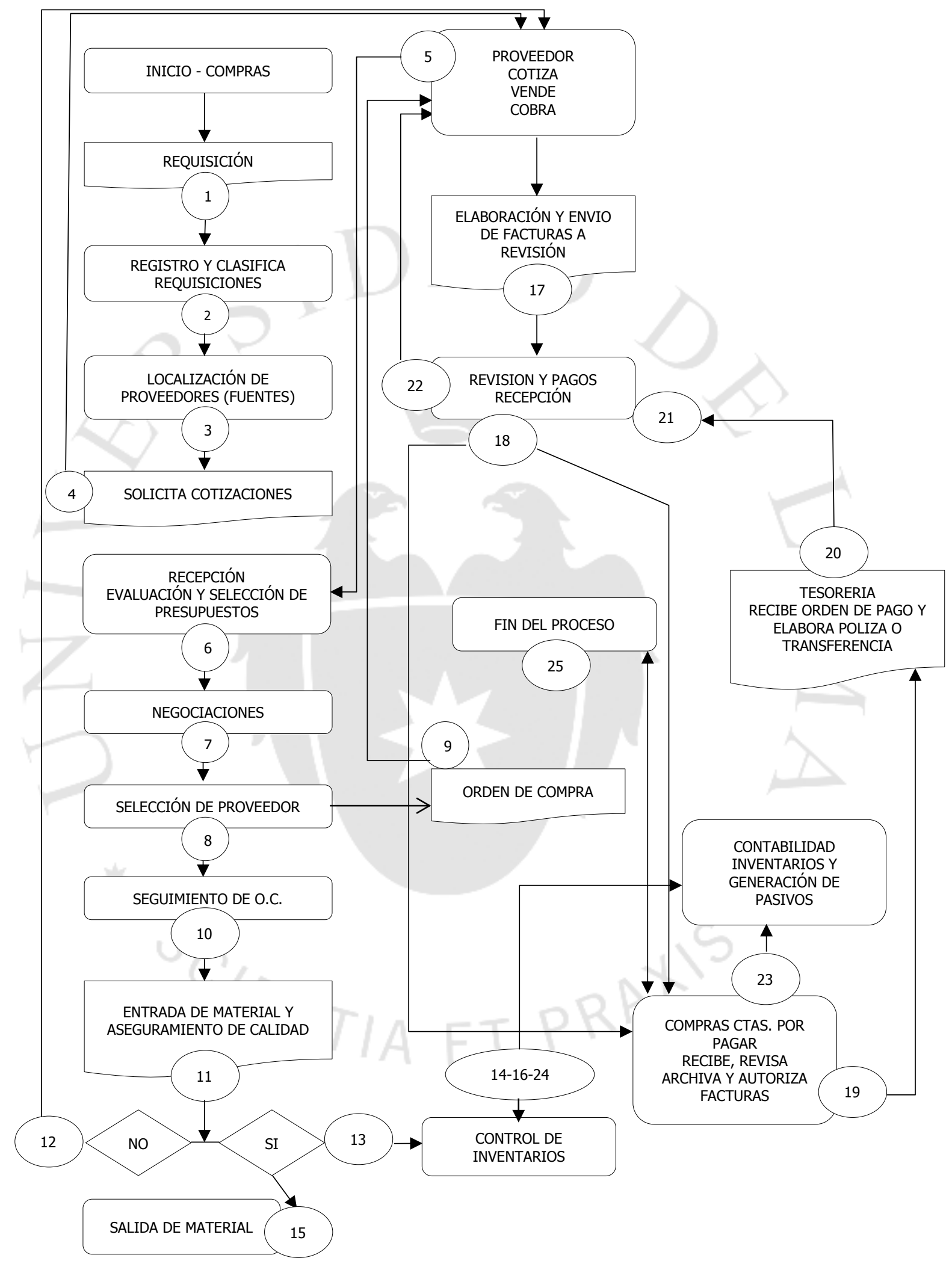

Fuente: http://www.monografias.com/trabajos90/area-compras-y-su-proceso-empresa-constructora/areacompras-y-su-proceso-empresa-constructora.shtml 


\subsection{Aspectos Contables y Tributarios del proceso de facturación}

En este punto se tratará de enfocar los aspectos Contables y Tributarios más relevantes relacionados con el proceso de facturación de la empresa, los cuales son usados como base una correcta preparación y presentación del documento final al Cliente.

Se tomará como sustento un breve resumen de los conceptos y lineamientos que se puedan recoger en las NIC's, NIIF's, Ley General de IR, IGV, Comprobantes de Pago y todo aquél documento que nos pueda ayudar con el desarrollo del proyecto.

La Empresa, tratándose de una compañía que brinda servicios de gerenciamiento de ingeniería y construcción, podemos empezar por referirnos a los contratos que realiza para desarrollar proyectos de construcción y hacer mención a los aspectos contables y tributarios relacionados.

\section{NIC11: Contratos de Construcción:}

\section{$\checkmark$ Objetivo}

El objetivo de la norma es prescribir el tratamiento contable de los ingresos ordinarios y de los costos asociados con los contratos de construcción. Debido a la naturaleza propia de la actividad, la fecha en que comienza y que termina caen normalmente en diferentes periodos contables, por tanto es fundamental al contabilizar los contratos de construcción la distribución de los ingresos de actividades ordinarias y los costos que cada uno de ellos genere, entre los periodos contables a lo largo de los cuales se ejecuta.

\section{$\checkmark$ ¿Qué es un contrato de construcción?}

Un contrato de construcción es un contrato que de manera específica se negocia para la construcción de un activo o de un grupo de activos interrelacionados (NIC 11.3). Bajo la NIC 11, si el contrato cubre dos o más activos, la construcción de cada activo debe ser contabilizada por separado si (a) para cada activo presentaron propuestas por separado, (b) se negociaron por separado partes del contrato relacionadas con cada activo, y (c) se pueden medir los costos y los ingresos ordinarios de cada activo. De otra manera, el contrato debe ser contabilizado de manera completa. (NIC 11.8) 


\section{$\checkmark \quad$ ¿Qué se incluye en los ingresos ordinarios y en los costos del contrato?}

Los ingresos del contrato deben incluir la cantidad que se acordó en el contrato inicial, más los ingresos ordinarios provenientes de las alteraciones al trabajo original del contrato, más los reclamos y pagos de incentivos que (a) se espera recoger y (b) se pueden medir confiablemente. (NIC 11.11). Los costos del contrato deben incluir los costos que se relacionan de manera directa con el contrato específico, más los costos que sean atribuibles a la actividad general del contratista en la extensión en que se puedan asignar razonablemente al contrato, más todos los otros costos que se puedan cargar de manera específica al cliente bajo los términos del contrato (NIC 11.16).

\section{$\checkmark$ Contabilidad}

Si el resultado del contrato de construcción se puede estimar confiablemente, los ingresos ordinarios y los costos deben ser reconocidos en proporción a la etapa de terminación de la actividad del contrato. Esto se conoce como método de contabilidad del porcentaje de terminación (NIC 11.22). Para ser capaz de estimar de manera confiable el resultado del contrato, la empresa tiene que ser capaz de hacer un estimado confiable del total de los ingresos ordinarios del contrato, la etapa de terminación y los costos para terminar el contrato (NIC 11.23-24).

Si el resultado no se puede estimar confiablemente, no se debe reconocer utilidad. En lugar de ello, los ingresos ordinarios del contrato deben ser reconocidos solamente en la extensión en que se espera recuperar los costos del contrato; además, los costos del contrato se deben llevar a gastos cuando se incurren en ellos (NIC 11.32).

La etapa de terminación del contrato puede ser determinada en una variedad de formas, incluyendo la proporción en que los costos incurridos del contrato correspondientes al trabajo desempeñado para la fecha se pueden considerar con relación a los costos estimados totales del contrato, estudios sobre el trabajo realizado o terminación de una parte física del trabajo del contrato (NIC 11.30)

La pérdida que se espera en el contrato de construcción debe ser reconocida como gasto tan pronto como tal pérdida sea probable (NIC 11.22 y 11.36) 


\section{$\checkmark$ Información a revelar}

Una entidad revelará:

- El importe de los ingresos de las actividades ordinarias del contrato reconocidos como tales en el periodo;

- Los métodos utilizados para determinar la porción del ingreso de actividades ordinarias del contrato reconocido como tal en el periodo; y

- Los métodos usados para determinar el grado de realización del contrato en proceso.

Una entidad revelará, para cada uno de los contratos en curso, al final del periodo sobre el que se informa, cada una de las siguientes informaciones:

- La cantidad acumulada de costos incurridos y de ganancias reconocidas (menos las correspondientes pérdidas reconocidas) hasta la fecha.

- La cuantía de los anticipos recibidos; y

- La cuantía de las retenciones en los pagos.

\section{Presentación}

- Los activos que representen cantidades, en términos brutos, debidas por los clientes por causa de contratos de construcción; y

- Los pasivos que representen cantidades, en términos brutos, debidas a los clientes por causa de estos mismos contratos.

La cantidad bruta debida por los clientes, por causa de contratos, es la diferencia entre:

- Los costos incurridos más las ganancias reconocidas; menos

- La suma de las pérdidas reconocidas y las certificaciones realizadas.

Siguiendo con la NIC 11 referente al tratamiento contable de los contratos de construcción, se pasará a desarrollar conceptos adicionales que son también relevantes: 


\section{$\checkmark$ Ingresos del Contrato}

Los ingresos son valuados al valor real de las contraprestaciones recibidas o por recibir, tomando en cuenta las incertidumbres existentes en esa fecha, pudiendo modificarse (aumentado o disminuyendo) en los periodos siguientes como consecuencia de la ocurrencia de hechos y la resolución de las incertidumbres iniciales.

- Ingresos distintos al convenido en el contrato o ingresos determinados con posterioridad al contrato:

La Variación es una instrucción dada por el cliente para un cambio en el alcance del trabajo que debe ser realizado según el contrato, lo que puede llevar a un aumento o disminución de los ingresos; que probablemente sea aprobado por el cliente y puede ser valuada contablemente, como, por ejemplo:

- Cambios en las especificaciones o diseños del activo; y

- Cambios en la duración del contrato

El Reclamo es el monto que el contratista busca cobrar al cliente u otra parte interesada como reembolso de costos no incluidos en el precio del contrato; que se considere solo si la negociación con el cliente ha alcanzado una etapa avanzada de modo que sea probable que el cliente acepte el reclamo y que dicho monto pueda valuarse contablemente. Ejemplo de situaciones que pueden dar lugar a reclamos:

- Demoras ocasionadas por el cliente

- Errores en las especificaciones o en los planos; y

- Variaciones en discusión en el trabajo contratado

Los Pagos de Incentivos son los montos adicionales a ser pagados al contratista si las normas de rendimiento especificadas se cumplen o se exceden, los cuales solo se reconocen cuando el contrato está suficientemente avanzado que sea probable que las normas de rendimiento especificadas se cumplan o superen y que puede valuarse confiablemente. Ejemplo:

- Premio por cumplimiento anticipado del contrato

De esta forma, en general se puede decir, que cualquiera de los conceptos antes mencionados dentro de la determinación de ingresos, para que sean considerados como tales deben cumplirse con las siguientes condiciones:

a. Sea probable que resulten en ingresos

b. Que puedan ser valuados confiablemente

Conceptos a considerar en las facturaciones de los avances realizados 
- Retenciones: de acuerdo con el párrafo 41 de la NIC son los importes de los avances facturados que no se pagan hasta que se satisfagan las condiciones especificadas en el contrato para la cancelación de tales importes o hasta que se hayan rectificado los defectos.

- Avances Facturados: son los importes cargados en las facturas por trabajos realizados sobre un contrato, hayan o no sido pagados por el cliente.

- Adelantos: son importes recibidos por el contratista antes que se realice el contrato.

\section{$\underline{\text { Reconocimiento de ingresos y gastos del contrato según NIC11 }}$}

El reconocimiento del resultado de un contrato de construcción dependerá del hecho que sean estimables confiablemente los ingresos y costos asociados con el contrato, pudiendo presentarse las siguientes situaciones:

\section{- Método del Estado de Cumplimiento}

También conocido como Porcentaje del Método de Terminación, coteja los ingresos con costos incurridos para alcanzar la etapa de terminación en función a la proporción del trabajo terminado, de tal manera que ingresos y costos se reconocen en el Estado de Resultados en los periodos contables en los que se realizan.

El porcentaje del método de terminación se aplica sobre una base acumulativa en cada periodo contable a las estimaciones corrientes de los ingresos y costos del contrato y cualquier modificación en la estimación de los ingresos o costos del contrato, se registra como un cambio en la estimación contable de acuerdo a lo reglado por la NIC 8 Ganancias y Pérdidas Netas del Periodo, Errores Fundamentales y Cambios en las Políticas de Contabilidad.

\section{- Reconocimiento Parcial}

El hecho que el resultado de un contrato no puede ser estimable confiablemente, es decir, que exista incertidumbre en la valuación de un contrato de construcción, para aplicar Reconocimiento Parcial, puede ocurrir entre otras por las siguientes circunstancias:

- La validez del contrato esté seriamente discutida 
- Su cumplimiento esté sujeto al resultado de un litigio, cuando el cliente no pueda cumplir con sus obligaciones o cuando el contratista no pueda terminar el contrato.

La incertidumbre y la aplicación del Reconocimiento Parcial, implican las siguientes acciones:

a) Se reconozca el ingreso únicamente hasta el punto en que sea probable que los costos incurridos sean recuperables.

b) Los costos del contrato sean reconocidos como gastos en el periodo en el que se incurren.

c) Cualquier pérdida prevista (si se prevee que los costos excederán los ingresos totales) se reconozca inmediatamente como gasto.

Cuando las incertidumbres que impedían la estimación confiable del resultado del contrato ya no existan, los ingresos y los gastos asociados con el contrato deberán reconocerse de acuerdo al Estado de Cumplimiento.

\section{- Costos No Recuperables}

Aquellos costos cuya recuperación no sea probable inmediatamente se conocerán como gasto. Ejemplo de tales costos son los siguientes:

- Costos de contratos que no están totalmente vigentes (validez seriamente discutida).

- Costos respecto de contratos cuyo cumplimiento está sujeto al resultado de un litigio.

- Costos de contratos relacionados con inmuebles que probablemente sean prohibidos o explotados.

- Costos de contratos en los cuales al contratista no pueda terminar el contrato o cumplir con sus obligaciones contractuales.

\section{- Cambios en las Estimaciones}

Como resultado de las incertidumbres inherentes de los negocios es posible que existan cambios en las estimaciones efectuadas, que hagan necesario la modificación de la primera estimación (porcentaje del método de avance del trabajo aplicado). Estas circunstancias pueden ser:

- Un cambio en la estimación de los ingresos o costos

- Un cambio en el resultado de un contrato 
En estas situaciones, debe aplicarse el tratamiento dispuesto por la NIC 8. Utilidad o Pérdida Neta del Periodo, Errores Fundamentales y Cambios en las Políticas Contables, debiendo efectuarse un ajuste en el Estado de Ganancias y Pérdidas en el periodo en que ocurra el cambio y de los siguientes. Lo anterior significa que no se modifican los estados financieros de periodos anteriores, sino, por el contrario, solo el periodo en que ocurrió este hecho y los siguientes. Por lo tanto, las estimaciones modificadas se usan en la determinación del monto de los ingresos y gastos a reconocerse en el periodo siguiente.

\section{$\underline{\text { Reconocimiento de ingresos y gastos del contrato (Tributariamente) }}$}

Si bien el artículo $57^{\circ}$ de la Ley del Impuesto a la Renta establece que las rentas de tercera categoría, ingresos y gastos, se considerarán producidas en el ejercicio comercial en que se devenguen, existen varias excepciones como la que se señala en el artículo $63^{\circ}$ de la mencionada norma. En este sentido en el caso concreto de las actividades de la construcción, el tratamiento tributario aplicable dependerá al ejercicio en que se impute los resultados del contrato. De lo anterior queda claro que en el caso que el contrato origine resultados imputables a un ejercicio debe aplicarse el sistema de devengado, con lo cual no habrá ninguna diferencia con la parte contable. Lo contrario sucede si el contrato genera resultados imputables a más de un ejercicio, puesto que como hemos visto queda a potestad del contribuyente el escoger entre las siguientes opciones:

\section{a) Método del Porcentaje de Ganancia Bruta}

Consiste en asignar a cada ejercicio gravable la renta bruta de aplicar sobre los importes cobrados por cada obra durante el ejercicio, el porcentaje de la ganancia bruta calculada para el total de la respectiva obra.

\section{b) Método de Diferencia entre el Importe Cobrado o por Cobrar y los \\ Costos Incurridos}

Consiste en asignar a casa ejercicio gravable la renta bruta que se establece deduciendo del importe cobrado o por cobrar por los trabajos ejecutados en cada obra durante el ejercicio comercial, los costos correspondientes a tales trabajos. 


\section{c) Método del Diferimiento}

Consiste en diferir el resultado hasta la total terminación de las obras, cuando estas, según contrato, deben ejecutarse dentro de un plazo no mayor de cinco (5) años, aplicándose, los impuestos sobre la ganancia así determinada en el ejercicio:

- En que se concluyen las obras, o

- Se recepcionan oficialmente las obras, cuando este requisito deba recabarse según las disposiciones vigentes sobre la materia.

- En el caso de contratos de obra en los cuales se deba terminar o se termine en plazo mayor de cinco años se podrá aplicar este método con las siguientes condiciones:

- Se liquidará el avance por el quinquenio.

- Se aplicará cualquiera de los dos métodos antes mencionados para los resultados siguientes.

d) Obligaciones de los Constructores con Contratos que generan resultados en más de un ejercicio

- Debe adoptarse un método a aplicarse uniformemente a todas las obras que ejecute la empresa y no podrá ser variado sin autorización de la SUNAT, la que determinará a partir de qué año podrá efectuarse el cambio.

- Se deberá llevar una cuenta especial por cada obra.

- Cualquier diferencia entre la renta bruta real y la establecida mediante los dos primeros métodos se imputarán al ejercicio en el que se concluyan las obras.

Pagos a Cuenta del Impuesto a la Renta a Realizar por los

\section{Constructores}

Todo contribuyente perceptor de rentas de tercera categoría se encuentra obligado a efectuar anticipos por el Impuesto a la Renta de un ejercicio determinado, para lo cual aplican dos sistemas dependiendo del hecho de haber obtenido renta neta imponible en el ejercicio precedente al anterior o anterior, sobre sus ingresos mensuales, sin embargo, en el caso particular de empresas 
constructoras tal determinación no es tan fácil ya que para determinar este anticipo se procede a sumar:

- Los ingresos por contratos ejecutados en un mismo ejercicio, más

- Los ingresos netos de los contratos con resultados imputables a más de un ejercicio de acuerdo a las siguientes consideraciones respecto al sistema de conocimiento del ingreso.

Tabla 2.1: Método de Asignación de Determinación del Ingreso Neto

\begin{tabular}{|l|l|}
\hline $\begin{array}{l}\text { METODO DE ASIGNACION DE } \\
\text { RESULTADO }\end{array}$ & $\begin{array}{l}\text { DETERMINACION DEL INGRESO NETO } \\
\text { PARA LOS PAGOS A CUENTA }\end{array}$ \\
\hline Porcentaje de Ganancia Bruta & $\begin{array}{l}\text { Ingresos Netos serán los importes cobrados por } \\
\text { avance de obra }\end{array}$ \\
\hline Diferencia entre importes cobrados & $\begin{array}{l}\text { Ingresos Netos serán los montos cobrados y por } \\
\text { cobrar por los trabajos ejecutados en ese mes o de } \\
\text { las valorizaciones efectuadas en obras en ese mes. }\end{array}$ \\
\hline Diferimiento hasta la Terminación & $\begin{array}{l}\text { Ingresos Netos serán los importes cobrados en } \\
\text { casa mes por avance de obra correspondientes al } \\
\text { último ejercicio de su ejecución. }\end{array}$ \\
\hline
\end{tabular}

Continuando con los aspectos tributarios relacionados al tema del costeo de nuestro proyecto, un componente a tener en cuenta es en el caso cuando en alguna de las obras a realizar se cuenta con personal extranjero o también conocidos como Expatriados, los cuales pertenecen a la misma empresa y también pueden ser personal o empresas independientes, pero por sus conocimientos y habilidades, se les puede contratar para el desarrollo de alguna de las labores dentro de la obra.

Este personal puede formar parte de la planilla cuando es un colaborador de la empresa y sus servicios y salario deben estar de acuerdo a su contrato laboral de asignación y no formar parte de ella, cuando brinda sus servicios profesionales, pero no forma parte de la empresa, en ambos casos sus servicios formarán parte de los costos 
reembolsables del proyecto, los cuales se incluirán en la valorización a presentar al Cliente.

\section{$\underline{\text { Servicios de Asistencia Técnica }}$}

Esta prestación de servicio por parte de personal o empresas independientes, es conocido como: Servicios de Asistencia Técnica y su tratamiento tributario lo encontramos en el Reglamento de la Ley del Impuesto a la Renta, Artículo 4, inciso c), el cual se pasará a revisar y desarrollar algunos conceptos y comentarios que puedan ayudar a tener un mayor conocimiento del tema.

"Se entiende por Asistencia Técnica a todo servicio independiente, sea suministrado desde el exterior o en el país, por el cual el prestador se compromete a utilizar sus habilidades, mediante la aplicación de ciertos procedimientos, artes o técnicas, con el objeto de proporcionar conocimientos especializados, no patentables, que sean necesarios en el proceso productivo, de comercialización, de prestación de servicios o cualquier otra actividad realizada por el usuario..."

En consecuencia, de lo señalado en el párrafo precedente, se desprende que para que se configure la Asistencia Técnica, deben concurrir de manera conjunta los siguientes requisitos:

a) Que se trate de un servicio independiente.

b) Que el servicio prestado tenga como objeto proporcionar o transmitir conocimientos especializados no patentables.

c) Que los conocimientos especializados no patentables que se proporcionan sean necesarios en el proceso productivo, de comercialización, de prestación de servicios o cualquier otra actividad realizada por el usuario.

Asimismo, el referido inciso c) establece que no califican como Asistencia Técnica, los siguientes supuestos:

- La contraprestación pagada a trabajadores del usuario por los servicios que presten al amparo de su contrato de trabajo.

- Los servicios de marketing y publicidad

- Las informaciones sobre mejoras, perfeccionamientos y otras novedades relacionadas con patentes de invención de procedimientos patentables y similares

- La supervisión de importaciones. 
En ese sentido, cabe distinguir la Asistencia Técnica de todas aquellas operaciones que no consisten en un hacer, sino, en la concesión o entrega (obligación de dar temporal o definitiva) de un bien o un derecho, aunque en virtud de tal concesión se advierta algún grado de transferencia tecnológica o de conocimientos especializados.

Ahora bien, al hacer referencia la norma a un servicio "independiente", debe entenderse que en dicho concepto no se consideren servicios que si bien podrían ser altamente especializados, se brinden al amparo de un contrato de trabajo en donde exista una relación de dependencia.

Adicionalmente, debido a que no hace distinción alguna, el servicio de Asistencia Técnica podría ser prestado tanto por una persona natural, como jurídica, exigiéndose únicamente que el servicio sea prestado por una persona independiente (ajena) de la empresa con la que no existe un vínculo laboral.

Sobre el particular, resulta incomprensible que al establecer la tasa de retención del Impuesto a la Renta aplicable a la "asistencia técnica", el artículo 56 de la Ley del Impuesto a la Renta disponga que la tasa del $15 \%$ se aplica única y exclusivamente si el usuario local presenta a la SUNAT una declaración jurada expedida por la empresa no domiciliada. Ello quiere decir que a las personas naturales no domiciliadas que presten servicios de "asistencia técnica" no se les puede aplicar la tasa de 15\%, debiéndosele retener $30 \%$. La desigualdad de trato en estos casos es evidente, aunque una acción distinta a una modificación legislativa parece bastante improbable de realizar en la práctica.

El sexto párrafo del inciso c) del artículo 4-A del Reglamento de la Ley del Impuesto a la Renta señala tres supuestos en los que necesariamente existe Asistencia Técnica. Dichos supuestos son los siguientes:

a) Servicios de Ingeniería: La ejecución y supervisión del montaje, instalación y puesta en marcha de las máquinas, equipos y plantas productoras; la calibración, inspección, reparación y mantenimiento de las máquinas, equipos; y la realización de las pruebas y ensayos, incluyendo el control de calidad, estudios de factibilidad y proyectos definitivos de ingeniería y de arquitectura.

b) Investigación y desarrollo de proyectos: La elaboración y ejecución de programas piloto, la investigación y experimentos de laboratorios; los servicios de explotación y la planificación o programación técnica de unidades productoras. 
c) Asesoría y consultoría financiera: Asesoría en valorización de entidades financieras y bancarias y en la elaboración de planes, programas y promoción a nivel internacional de venta de las mismas; asistencia para la distribución, colocación y venta de valores emitidos por entidades financieras.

Un tema importante al que se debe hacer referencia, es a los requisitos establecidos por la norma para gozar de la reducción de la tasa de retención (de $30 \%$ a 15\%), pero sobretodo, a las implicancias derivados del incumplimiento de tales requisitos.

Sobre el particular, cabe recordar que de acuerdo con el inciso f) del artículo 56 de la Ley del Impuesto a la Renta, el usuario deberá obtener y presentar a la SUNAT, una declaración jurada expedida por la empresa no domiciliada en que se indique, expresamente, que se prestará la asistencia técnica y registrarán los ingresos que se generen y además un informe de una firma auditoría de prestigio internacional que certifique la prestación efectiva de la asistencia técnica.

En cuanto a la condición de domiciliados o no y a la adquisición o pérdida de éste estatus, el TUO de la Ley del Impuesto a la Renta también ha definido las condiciones necesarias para estos casos, en el Capítulo II, artículos a tratar: 7 y 8 en cuanto a lo concerniente a nuestro trabajo y pasaremos a desarrollar:

“Art. 7.- Se considera domiciliadas en el país:

a) Las personas naturales de nacionalidad peruana que tengan domicilio en el país, de acuerdo con las normas del derecho común.

b) Las personas naturales extranjeras que hayan residido o permanecido en el país más de ciento ochenta y tres (183) calendario durante un periodo cualquiera de doce (12) meses.

c) Las personas que desempeñan en el extranjero funciones de representación o cargos oficiales y que hayan sido designadas por el Sector Público Nacional.

d) Las personas jurídicas constituidas en el país

e) Las sucursales, agencias u otros establecimientos permanentes en el Perú de personas naturales o jurídicas no domiciliadas en el país, en cuyo caso la condición de domiciliada alcanza a la sucursal, agencia u otro establecimiento permanente, en cuanto a su renta de fuente peruana.

f) Las sucesiones, cuando el causante, a la fecha de su fallecimiento, tuviera la condición de domiciliado con arreglo a las disposiciones de esta Ley. 
g) Los bancos multinacionales a que se refiere la Décimo Sétima Disposición Final y Complementaria de la Ley General del Sistema Financiero y del Sistema de Seguros y Orgánica de la Superintendencia de Banca y SegurosLey $\mathrm{N}^{\circ} 26702$, respecto a las rentas generales por sus operaciones en el mercado interno.

h) Las empresas unipersonales, sociedades de hecho y entidades a que se refiere el tercer y cuarto párrafos del Artículo $14^{\circ}$ de la Ley, constituidas o establecidas en el país.

Para efectos del Impuesto a la Renta, las personas naturales, con excepción de las comprendidas en el inciso c) de este artículo, perderán su condición de domiciliadas cuando adquieren la residencia de otro país y hayan salido del Perú, lo que deberá acreditarse de acuerdo con las reglas que para el efecto señale el reglamento. En el supuesto que no pueda acreditarse la condición de residente en otro país, las personas naturales, exceptuando las mencionadas en el incido c) de este artículo, mantendrán su condición de domiciliadas en tanto no permanezcan ausentes del país más de ciento ochenta y tres (183) días calendario dentro de un periodo cualquiera de doce (12) meses.

Los peruanos que hubieren perdido su condición de domiciliados la recobrarán en cuanto retornen al país, a menos que lo hagan de forma transitoria permaneciendo en el país ciento ochenta y tres (183) días calendario o menos dentro de un periodo cualquiera de doce (12) meses.

Las disposiciones sobre domicilio, contenidas en este capítulo, no modifican las normas sobre domicilio fiscal contenidas en el Código Tributario.

“Art. 8.- Las personas naturales se consideran domiciliadas o no en el país según fuere su condición al principio de cada ejercicio gravable, juzgada con arreglo a los dispuesto en el artículo precedente. Los cambios que se produzcan en el curso de un ejercicio gravable sólo producirán efectos a partir del ejercicio siguiente, salvo en el caso en que, cumpliendo con los requisitos del segundo párrafo del artículo anterior, la condición de domiciliado se perderé al salir del país”.

Otro punto importante a tratar es si los servicios prestados por "no domiciliados" afectos al Impuesto a la Renta, están gravados o deben pagar el respecto Impuesto General a las Ventas para lo cual se citarán los comentarios hechos por Sr. Daniel Montes Delgado del estudio Montes Delgado Abogados: 
“...habiendo cursado esquelas a algunas empresas que han presentado en el ejercicio 2012, diversas declaraciones de retención de Impuesto a la Renta (IR) por servicios recibidos de no domiciliados, estas esquelas no cuestionan el pago del IR, sino que afirman que, habiendo pagado ese impuesto, también debió pagarse el Impuesto General a las Ventas (IGV) por esos mismos servicios recibidos de no domiciliados. Sin embargo, eso no es necesariamente cierto en todos los casos, pese a lo cual estas esquelas acusan una "inconsistencia" y solicitan que la empresa pague el IGV supuestamente adecuado, o en todo caso, presente un escrito indicando las razones por las cuales no hará el pago, adjuntando los documentos relacionados con cada servicio, como el contrato (traducido al castellano, además) y el comprobante de la cancelación.

Si se tratara de servicios prestados en el Perú por sujetos domiciliados en el país, la regla no escrita de que los ingresos que pagan IR, deben pagar también IGV, podría ser aplicable, con un grado de alta probabilidad de acertar, porque en principio todos los servicios prestados por un domiciliado se encuentran gravados por el IGV, conforme a las normas de este impuesto, pero no ocurre lo mismo con los servicios prestados por sujetos no domiciliados, en cuyo caso solo están gravados aquellos servicios "prestados o utilizados en el país".

Si el sujeto no domiciliado ejecutó alguna clase de servicio empresarial en el territorio peruano (por ejemplo un estudio de mercado), entonces sí estará gravado con el IGV, y así debería ser declarado y pagado por la empresa usuaria del servicio. Pero si el servicio no se ejecutó en el país, todavía faltaría despejar la interrogante de si la empresa usuaria a "utilizado" el servicio en el Perú. Si ese es el caso, de nuevo nos encontramos con un servicio gravado con el IGV, el problema es que no es tan sencillo cuando un servicio es utilizado en el país. Se suele afirmar por algunos (SUNAT entre ellos) que la utilización se interpreta al primer "acto de disposición" sobre el servicio recibido, lo que no despeja muchas dudas y habrá que atender a las circunstancias de cada caso concreto para esclarecer esto.

Por otro lado, los ingresos por servicios realizados por sujetos no domiciliados estarán afectos al IR solo si se han llevado a cabo en el territorio nacional, exceptuando los intereses y retribuciones por colocación de capitales, que están gravados también si se "utilizan económicamente en el país" (con similares problemas de interpretación que en el caso del IGV). Por otro lado, la aplicación del IR a los servicios de no domiciliados incluye la retribución de trabajos de naturaleza personal, lo que denominamos en Perú las rentas de cuarta categoría (rentas de personas naturales 
independientes) y quinta categoría (rentas de personas naturales bajo relación de dependencia o subordinación). Estas rentas del trabajo pueden resultar afectas al IR, pero definitivamente no lo estarán al IGV, porque los prestadores de esos servicios no están afectos al IGV, por no ser empresas.

Entonces, queda claro que el pago del IR por servicios no domiciliados, no implica en todos los casos que haya que pagar el IGV por esos mismos servicios. Sin perjuicio de eso, en la medida que este es otro ejemplo de una acción inductiva de SUNAT que no constituye formalmente una fiscalización, las empresas notificadas no estarían obligadas a presentar documentos ni justificar el pago del IGV.

En referencia al pago, el artículo 70 de la Ley del Impuesto a la Renta, señala que las retenciones que deben practicarse, deben ser consideradas como pagos a cuenta del impuesto o como crédito contra los pagos a cuenta, de corresponder, salvo los casos en que esta Ley les acuerde el carácter de definitivo.

Estudiar el momento en que se efectúa la retención es importante, porque tiene implicancias y consecuencias jurídicas distintas que se analizarán a continuación:

a) Retención al momento del pago

El primer párrafo del artículo 76 de la Ley del Impuesto a la Renta, establece que las personas o entidades que paguen o acrediten a beneficiarios no domiciliados rentas de fuente peruana de cualquier naturaleza, deberán retener y abonar al fisco con carácter de definitivo dentro de los plazos previstos por el Código Tributario para las obligaciones de periodicidad mensual, los impuestos a los que se refieren los artículos $54^{\circ}$ y $56^{\circ}$ de esta ley, según sea el caso. En relación a la naturaleza de la retención del impuesto a la renta de no domiciliados regulado por el artículo 70 de la LIR, esta constituye retención de carácter definitivo, ya que la norma taxativamente así lo establece. Es decir, la retención que se efectúa al momento del pago al no domiciliado, es el impuesto que definitivamente corresponde abonar el fisco por IRND.

\section{b) Retención al momento de la contabilización}

El segundo párrafo del artículo 71 de la LIR, establece que los contribuyentes que contabilicen como costo o gasto las regalías, y retribuciones por servicios, asistencia técnica, cesión en uso u otros de naturaleza similar, a favor de no 
domiciliados, deberán abonar al fisco un monto equivalente a la retención en el mes en que se produzca su registro contable, independientemente de si se pagan o no las respectivas contraprestaciones a los no domiciliados. En relación a la naturaleza del IRND regulado por el artículo 70 de la LIR, esta constituye una retención del tipo de pago a cuenta, ya que en el mundo fáctico no se produjo, siendo una ficción de la norma, que obliga al contribuyente a efectuar el pago por un monto equivalente a la retención del IRND.

Otros de los conceptos impositivos a considerar por la empresa contratista, para el presente proyecto, relacionado a la presentación de la valorización y respectiva factura al cliente, son las retenciones por Detracción por los servicios de Ingeniería y Construcción y el Impuesto General a las Ventas por ser empresa perteneciente al Régimen General.

\section{$\underline{\text { Sistema de Detracciones (SPOT) }}$}

Iniciaremos por la definición general que hace SUNAT (Superintendencia Nacional de Administración Tributaria) al respecto:

"El Sistema de Detracciones (SPOT) es un mecanismo administrativo que coadyuva con la recaudación de determinados tributos y consiste básicamente en la detracción (descuento) que efectúa el comprador o usuario de un bien o servicio afecto al sistema, de un porcentaje del importe a pagar por estas operaciones, para luego depositarlo en el Banco de la Nación, en una cuenta corriente a nombre del vendedor o prestador del servicio, el cual, por su parte, utilizará los fondos depositados en el Banco de la Nación para efectuar el pago de:

a) Las deudas tributarias por conceptos de tributos, multas, los anticipos y pagos a cuenta por tributos, incluidos sus respectivos intereses y la actualización que se efectúe de dichas deudas tributarias, de conformidad con el artículo 33 del Código Tributario, que sean administradas y/o recaudadas por la SUNAT.

b) Las costas y los gastos en que la SUNAT hubiera incurrido a que se el inciso e) del artículo 115 del Código Tributario.

Los montos depositados en las cuentas que no se agoten cumplido el plazo señalado por la norma luego que hubieran sido destinados al pago de tributos, serán considerados de libre disponibilidad para el titular". 
El sistema de detracciones se aplicará, siempre que se tenga un Comprobante de Pago que permita sustentar Crédito Fiscal, así como Costo o Gasto para efectos tributarios, siempre que importe de la operación sea mayor a S/. 700.00 (Setecientos Nuevos Soles). Para nuestro caso, la empresa al brindar servicios de ingeniería y construcción, estará afecto a los porcentajes del 10\% y 4\%, respectivamente, de acuerdo con la última publicación de servicios y bienes afectos a este sistema y que rigen a partir del $1^{\circ}$ de Enero del 2015, de conformidad con el artículo $3^{\circ}$ del Decreto Legislativo $\mathrm{N}^{\circ} 940$ referido al SPOT.

Los sujetos obligados a efectuar el depósito son los siguientes:

a) El adquiriente del bien mueble o inmueble, usuarios del servicio o quien encarga la construcción sujeta al sistema.

b) Cuando el proveedor del bien, prestador del servicio o quien ejecuta el contrato de construcción reciba la totalidad del importe de la operación sin haberse acreditado el depósito, éste quedará obligado a efectuarlo hasta el quinto día hábil siguiente de recibido el importe, salvo en la venta de bienes en que el depósito deba efectuarse con anterioridad al traslado, en cuyo caso el proveedor realizará el depósito previo a dicho traslado, sin perjuicio de las sanciones que corresponda al adquiriente del bien, usuario del servicio o quien encarga la construcción.

c) El sujeto del IGV, en el caso de retiro de bienes.

d) El propietario de los bienes que realice o encargue el traslado de los mismos.

Finalmente, pero no menos importante, la empresa por ser persona jurídica, generar renta de tercera categoría y pertenecer al Régimen General del IGV, está afecta al Impuesto General a las Ventas al momento de emitir sus comprobantes de pago, es decir, facturas. 


\section{CAPITULO 3: COSTEO Y ELEMENTOS DEL COSTEO}

Continuando con el desarrollo del presente trabajo basado en la experiencia profesional se procederá a mostrar el cálculo de los ingresos y costos que considera la empresa por los servicios que brinda:

Tabla 3.1: Cálculo de Ingresos y Costos del Servicio

Cálculo de Ingresos y Costos del Servicio

\begin{tabular}{|c|c|c|c|c|c|}
\hline ELEMENTO/AREA & \# EMPLDS. & UBICACTÓN & HRS/MES & $\begin{array}{c}\text { PROMEDIO } \\
\text { CTO/HORA (s) }\end{array}$ & TOTALES $(\$)$ \\
\hline \multicolumn{6}{|l|}{ 1. MANO DE OBRA } \\
\hline \multicolumn{6}{|l|}{ CONSTRUCCIÓN } \\
\hline CONSTRUCCIÓN & & 4 TERRENO & 784 & 30.94 & $24,256.96$ \\
\hline TOTAL CONSTRUCCIÓN & 4 & 4 & 784 & 30.94 & $24,256.96$ \\
\hline \multicolumn{6}{|l|}{ GERENCIAMIENTO (MANAGEMENT) } \\
\hline CONTROL DE PROYECTOS & & 1 TERRENO & 230 & 28.95 & $6,658.50$ \\
\hline ADMINISTRACION CONTRATOS & & 3 TERRENO & 548 & 31.64 & $17,335.98$ \\
\hline ADMINISTRACION MATERIALES & & 1 TERRENO & 192 & 18.02 & $3,459.84$ \\
\hline CONTROL CALDAD & & 1 TERRENO & 116 & 37.39 & $4,336.75$ \\
\hline SEGURIDAD Y MEDIO AMEIENTE & & 8 TERRENO & 1,246 & 29.36 & $36,582.56$ \\
\hline SOPORTE TECNICO & & 1 TERRENO & 174 & 19.69 & $3,426.06$ \\
\hline ADMINISTRACION & & 4 TERRENO & 606 & 10.21 & $6,187.87$ \\
\hline CONTROL DOCUMERTARIO & & 1 TERRENO & 212 & 24.39 & $5,170.68$ \\
\hline RECURSOS HUMANOS & & 1 TERRENO & 51 & 19.01 & 969.51 \\
\hline SERVICIOS NEGOCIOS DE PROYECTOS & & 2 LMA & 338 & 18.74 & $6,334.12$ \\
\hline TOTAL GERENCIAMIENTO & 23 & $\sqrt{3}$ & 3,713 & & $90,461.87$ \\
\hline SUB TOTAL MANO DE OBRA & 27 & $\bar{z}$ & 4,497 & & $114,718.83$ \\
\hline MULTTPUCADOR (95\% DE M/O) & & & & & $108,982,89$ \\
\hline TOTAL MANO DE OBRA & & & & & $223,701.72$ \\
\hline \multicolumn{6}{|l|}{ 2. OTROS COSTOS DIRECTOS } \\
\hline PERSONAL LIMA $\quad(11.30 \$ / \mathrm{Hr})$. & & & & & $3,819.40$ \\
\hline PERSONAL TERRENO ( 7.50 \$/Hr.) & & & & & $31,192.50$ \\
\hline CARGOS RELACIONADOS MANO DE OBRA ( $15 \%$ DE M/O Y OCD ) & & & & & $38,807.04$ \\
\hline TOTAL OTROS COSTOS DIRECTOS & & & & & $73,818.94$ \\
\hline \multicolumn{6}{|l|}{ 3. COSTOS INDIRECTOS } \\
\hline PASAES Y TRASLADOS DE PERSONAL & & & & & $16,270.00$ \\
\hline COSTOS POUZZA EMPLEADOS & & & & & $19,595.52$ \\
\hline ALQUILERES, ALIMENTACION, EQUIPOS, OTROS GASTOS DE PERS. & & & & & $91,948.42$ \\
\hline TOTAL COSTOS INDIRECTOS & & & & & $127,813,94$ \\
\hline TOTAL FACTURADO POR EL SERVICIO & & & & & $425,334.53$ \\
\hline
\end{tabular}

Con los datos mostrados en el gráfico anterior se obtiene la siguiente estructura del negocio: 
Tabla 3.2: Grado De Avance Estimado Por Mes

\begin{tabular}{|l|r|r|}
\hline \multicolumn{1}{|c|}{ Conceptos } & \multicolumn{1}{|c|}{ Mes \$ } & Estructura \% \\
\hline Total Ingresos & $425,334.53$ & $100 \%$ \\
\hline Costos de Construcción y Gerenciamiento & $277,544.67$ & \\
\hline MOD & $114,718.83$ & \\
Construcción & $27 \%$ \\
Gerenciamiento & $24,256.96$ \\
Costos Indirectos & $90,461.87$ \\
\hline Margen estimado & $162,825.84$ & \\
\hline
\end{tabular}

Grado de Avance estimado por mes sobre un proyecto de 4 años

$2 \%$

A continuación se procederá a desarrollar el proceso de costeo de la empresa:

\subsection{Centros y Elementos del Costeo}

En este punto del presente trabajo se procederá a desarrollar cómo la Empresa estructura sus proyectos para definir, controlar y determinar sus ingresos y costos y la metodología para hacer los cálculos de los elementos del costeo, que finalmente formarán parte de la facturación a sus Clientes, que es donde traslada los costos por los servicios brindados.

Tratándose de un modelo del cálculo del costeo y posterior facturación que no es común en el mercado, ha sido motivo para el desarrollo de éste trabajo y que pueda servir como referencia para aquellas personas requieran información acerca de ésta forma particular de costeo.

\subsubsection{Centros de Costos}

La Empresa tratándose de una empresa que brinda servicios de ingeniería y construcción y en este caso particular un proyecto EPCM, tiene una muy particular forma de determinar su estructura para la asignación, control y registro de todos sus ingresos y costos del proyecto.

La estructura es de forma piramidal donde cada proyecto en particular tiene un nombre alfanumérico de 4 dígitos, llamado: "Definición del Proyecto" (Project Definition), único dentro de la empresa y con el cual se le reconocerá a través del tiempo. Para este caso particular, al proyecto se le asignó el nombre: A1BC, desde el cual se van a desprender los centros de costos, ingresos y las respectivas cuentas 
contables, que siendo la empresa una transnacional tiene que llevar dos contabilidades, la Corporativa (Norteamericana) y la Local, que es la de nuestro Plan Contable General Empresarial (PCGE), también usa como cuentas de gastos las de clase 6 y de ingresos la clase 7, así como también, las respectivas cuentas de clase 9, como destino de los costos.

Una vez creado el proyecto a través del Project Definition, lo cual implica haber ingresado todos los datos a los sistemas integrados que maneja la empresa, en lo referente a la futura administración del proyecto, se van creando distintos niveles de consolidación de información financiera y contable de acuerdo a las actividades que se realicen en las distintas áreas, del nivel más específico al nivel del registro de las transacciones del día a día con lo cual se alimentan las operaciones que se realizan para el proyecto desde todas las áreas involucradas, como por ejemplo: construcción, ingeniería, adquisiciones, recursos humanos, contabilidad y finanzas, entre otros. Los siguientes niveles en la estructura están referidos, siempre de acuerdo a las necesidades del proyecto, para nuestro caso, de la siguiente manera:
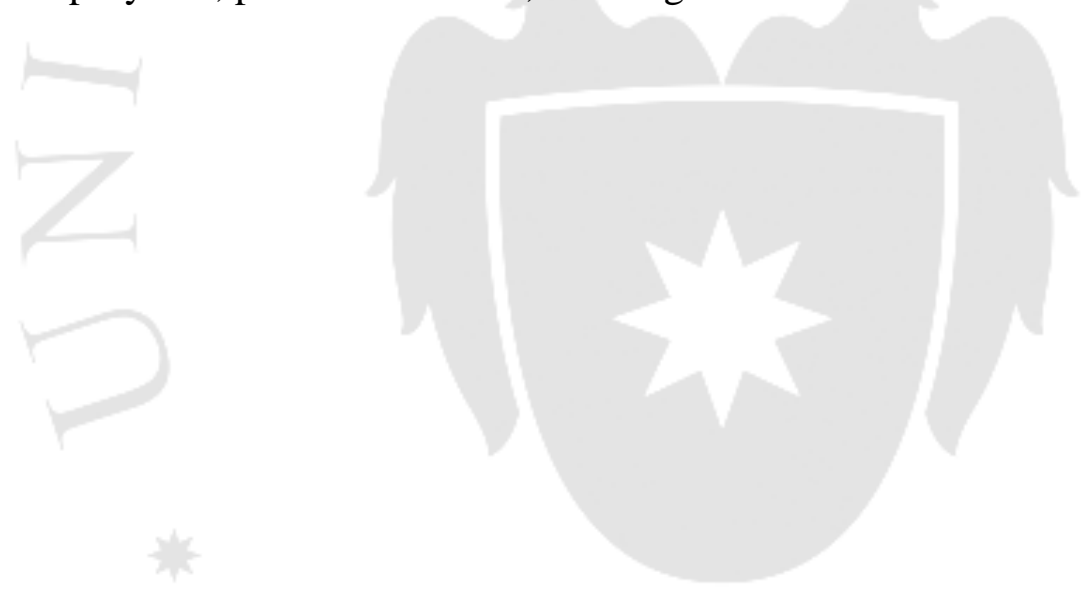
Tabla 3.3: Estructura de un Proyecto

\begin{tabular}{|r|l|l|}
\hline \multicolumn{4}{|c|}{ ESTRUCTURA DEL PROYECTO } \\
\hline \multicolumn{1}{|l|}{ CONCEPTO } & NOMENCLATURA & NIVEL \\
\hline PROYECTO EPCM & A1BC & 1 \\
\hline PROYECTO EPCM & A1BC & 2 \\
\hline PROYECTO EN & A1BC.EN & 3 \\
\hline PROYECTO CM & A1BC.CM & 3 \\
\hline PROY. CM PERU & A1BC.CM.PE & 4 \\
\hline PROY. CM PERU SERVICIOS PBWBS & A1BC.CM.PE.1 & 5 \\
\hline PROY. CM PE SERVICIOS IBWBS & A1BC.CM.PE.1.1 & 6 \\
\hline PROY. CM PE SERVICIOS & A1BC.CM.PE.1.1.1 & 7 \\
COSTOS AUXILIARES & 13050472 & $7 \mathrm{~A}$ \\
COSTOS AUXILIARES & 13050472 ANCL & $7 \mathrm{~A} 1$ \\
PROY. CM PE SERVICIOS & 00A1BC000031 & 7B \\
COSTOS REEMB. & 00A1BC000031 CM00 & 7B1 \\
PROY. CM PE SERVICIOS & 00A1BC000032 & 7C \\
COSTOS - NO REEMB. & 00A1BC000031 NB00 & 7C1 \\
PROY. CM PE SERVICIOS & 00A1BC000033 & 7D \\
INTER COMPANIIAS & 00A1BC000033 IC02 & 7D1 \\
\hline
\end{tabular}

En cada uno de estos niveles de gestión proporcionado por las áreas involucradas al momento de la creación de la estructura del proyecto y preparada por un área específica de la empresa, Control de Proyectos, se van registrando las actividades que realizan y que se especificaron en la estructura de costos e ingresos, para un mejor y detallado control de las operaciones, puede en algunos casos resultar trabajoso el registro tan detallado, dependiendo de la envergadura de la obra, pero la finalidad supera esfuerzos ya que sólo así se contará con información eficiente, oportuna de mucha ayuda para la empresa, así como también, para el Cliente y en caso se necesite para cualquier entidad fiscalizadora del Estado.

En el cuadro adjunto líneas arriba (Tabla $\mathrm{N}^{\circ} 7$ ), se pueden apreciar los niveles de estructura del proyecto, para lo cual se pasará a realizar una breve descripción de cada uno de los niveles:

Nivel 1: Creación del nombre del proyecto. Para fines de la empresa a esta nomenclatura se le llama: Definición del Proyecto (Project Definition), el cual es único y exclusivo para cada proyecto. 
Nivel 2: Consolidación de los resultados totales del proyecto. A este nivel ya empieza el reconocimiento de las operaciones que se realizan en el proyecto y se le llama: Código de Compañía (Company Code).

Nivel 3: A este nivel se consolidan resultados a nivel de las etapas de ejecución en la realización del proyecto. Para el caso dos etapas: EN (Engineering o Ingeniería) y CM (Construction Management o Gerenciamiento de Construcción). A este nivel las etapas pueden detallar las operaciones de acuerdo a sus necesidades, en este caso y para demostración, el detalle se presentará en la etapa del CM.

Nivel 4: Como por lo general la empresa realiza trabajos en países distintos a los de la Casa Matriz (USA) y las operaciones se tienen que diferenciar e indicar el país en el cual se desarrollará la obra, en este nivel, se especifica la ubicación geográfica, tratándose de Perú, se le nombra como: PE.

Nivel 5: En este nivel se podrá apreciar la Rentabilidad del proyecto, PBWBS (por sus iniciales en inglés referidas a Profitability Work Breakdown Structure).

Nivel 6: Se registran las operaciones provenientes de la facturación de los servicios que se brindan y pasan al Cliente. Entiéndase por facturación, a la recopilación de los ingresos y egresos de un período (mensual, anual), los cuales pasarán al nivel anterior, después de los respectivos análisis, a formar la rentabilidad del proyecto. En este caso se distinguirá en el concepto las iniciales, IBWBS (Invoicing Billed Work Breakdown Structure), referido a la facturación.

Nivel 7: Finalmente en este nivel, se consideran las operaciones por los ingresos y gastos del proyecto a través del registro de las facturas que emite la empresa por los servicios que presta o las facturas o comprobantes que ingresan por las compras generadas por las necesidades para el desarrollo del proyecto. Es a este nivel donde ya se consideran las cuentas contables que maneja la empresa también de las clases 6 y 7 para costos y gastos e ingresos, respectivamente y son las que acompañan a los niveles de la estructura para fines de la presentación de sus reportes e informes financieroscontables. Este nivel de estructura por su nomenclatura es llamado: Network Activity (NWA), en el cual los primeros 8 (Auxiliares) y el total de 12 dígitos (Soporte) representan la estructura de costos referidos al proyecto específicamente y los últimos 4 dígitos, se refieren a la actividad, la cual está referida al tipo de trabajo al que está referido el costo o gasto. En este caso, sólo encontramos tres tipos: los Auxiliares, los Costos o Gastos Reembolsables y los Costos o Gastos No Reembolsables, los cuales se 
desarrollarán más adelante. Dependiendo del proyecto o la obra, las Actividades pueden tener mucho detalle.

Se pueden distinguir tres niveles de registro de las operaciones:

1. Costos Auxiliares (Ancillary Cost): para fines de la empresa el concepto que se le da es: "en vez de". Esto quiere decir que son los costos o gastos que no se consideran directamente, sino, se registran y cobran como un porcentaje establecido dentro del Contrato, previo acuerdo, ya que estos no generan beneficio o valor al proyecto, se puede tomar como ejemplo los gastos por planillas de sueldos, fotocopias o mensajería, claramente estos son costos o gastos propios para el funcionamiento de la empresa, pero no generan beneficio exclusivo para el proyecto, es decir, no generan valor agregado directo para el Cliente. Se caracterizan porque no se pueden discriminar claramente si corresponde a operaciones de la misma empresa o del desarrollo en particular de un proyecto específico.

2. Costos Reembolsables: estos son los que están directamente relacionados con la actividad y ejecución del proyecto y que se cobrarán o pasarán dentro de la facturación al Cliente. Acá se pueden considerar los gastos por el trabajo de los empleados asignados al proyecto, dentro de los gastos se pueden considerar los comprobantes de pago que se reciben por las compras de bienes o adquisición de servicios para la ejecución de la obra, dentro de los cuales se pueden considerar materiales, gastos de pasajes de los empleados que se movilizan o desmovilizan dentro de la obra.

3. Costos No Reembolsables: son aquellos que siendo costos o gastos necesarios para la ejecución del proyecto, no deben trasladarse al Cliente, ya que dentro del Contrato ya están establecidos como costos propios de la Empresa. Se pueden mencionar como ejemplo: la contratación de servicios legales de la empresa, el costo por el uso de los sistemas contables de la empresa, que si bien es cierto contribuyen para los reportes financieros de la empresa relacionados a los proyectos, estos son de propiedad de la Empresa y son utilizados para fines del desarrollo integral de la empresa.

\subsection{Recopilación de datos, preparación y presentación de la factura.}


En este punto del proyecto, se hará mención de cómo es que La Empresa recolecta, prepara y presenta la información referente a sus Estados de Pago, que son los documentos y sustentos con los cuales traslada al Cliente, la factura legal por los servicios prestados para el desarrollo de la obra.

Este proceso es de suma importancia porque de él dependen los ingresos y ganancias de la empresa. También se tiene que tener mucha responsabilidad y cuidado en la consideración de los documentos a incluir, los cuales deben ser lo más claro y completos, incluir sustentos, comprobantes, cálculos y toda aquella información que haga que su presentación corresponda a los bienes adquiridos y recursos empleados exclusivamente para la obra.

El Estado de Pago se emite, para el caso de la Empresa (cada empresa debe tener sus propios procedimientos), uno por mes que por lo general se presenta al final del mes, de preferencia con días de anticipación para que el Cliente lo pueda revisar, analizar, evaluar y en caso estime conveniente y no esté de acuerdo con los cálculos o documentación presentada no cuente con los sustentos suficientes, pueda hacer las observaciones o correcciones pertinentes.

En este tipo de empresas que desarrollan proyectos EPCM, siempre tratándose del presente caso, el dinero con el que se trabaja o financia la obra es con el del Cliente, se emite una factura por el Adelanto (en términos internos de la empresa llamado “Advance"), por lo general durante los primeros días del mes con el cual se podrá financiar las necesidades de la obra hasta la presentación final del Estado de Pago del mes. En este adelanto sólo se considerará el cobro de un porcentaje la Mano de Obra de todos los empleados que están asignados en el proyecto, más un porcentaje de cargos o gastos aceptados que ya están acordados en el Contrato y un estimado de gastos reembolsables de acuerdo a aquellos en los que ya se hayan incurrido y de los cuales se tengan conocimiento certero a la fecha de emisión del Adelanto. Respecto al cobro de un porcentaje de la Mano de Obra, como sólo es un adelanto, por prudencia, no se considera el $100 \%$ ya que en el transcurso del mes puede haber ingresos o salidas de personal, cambios en los salarios de los empleados o alguna contingencia propia del proyecto, como por ejemplo, la paralización de la obra por acontecimientos ajenos al Cliente o a La Empresa, por lo cual dependiendo de la coyuntura, podría prescindirse de personal asignado a la obra o en para el caso de la empresa, los aumentos anuales en las remuneraciones a sus trabajadores que se da en el mes de Marzo y con ello cambiarán los importes de los salarios. 
Tal como se puede apreciar en la hoja de cálculo del Anexo 001, el Advance considera solo el cobro de la Labor o mano de obra de todo el personal asignado a la obra, por el cual solo toma en cuenta el $90 \%$ de su valor total, además se considera un porcentaje de cargos fijos del $15 \%$ de la misma mano de obra y un estimado de Gastos Reembolsables de acuerdo con gastos cobrados en meses anteriores. La columna Multiplicador, considera el cobro porcentaje que está determinado de acuerdo al Contrato con el Cliente y que equivale, para nuestro caso, al 95\% de la Mano de Obra considerada en el Adelanto. Este porcentaje toma en cuenta el cálculo de los beneficios sociales de los trabajadores tales como: CTS, Gratificaciones, Vacaciones, entre otros.

Los cálculos y explicaciones de los importes consignados se detallarán con la presentación del Estado de Pago final.

(Ver Solicitud de Adelanto Anexo 3.1).

El registro contable, como sólo es un asiento provisional hasta que se emita la factura final y se reconozcan los ingresos, es un asiento simple reconociendo el adelanto, los impuestos y la obligación generada hacia el Cliente por los servicios brindados. Al momento de la emisión de la factura final, se cancela la cuenta de Adelanto a Clientes y la cuenta por Ventas/Ingreso, se registrará por el integro de la factura.

\section{Registro Contable}

\begin{tabular}{|l|l|l|l|}
\hline CUENTA & CONCEPTO & DEBE & HABER \\
\hline 12 & Adelantos de Clientes & 353,716 & \\
\hline 40 & Impuesto General a las Ventas & & 53,957 \\
\hline 70 & Ventas & & 299,759 \\
\hline
\end{tabular}

El Estado de Pago (EDP), factura final por los servicios prestados (o también Progress en la interna de la empresa), se emite uno por mes, durante todo el desarrollo de la obra y es el documento donde se traslada al Cliente los bienes y servicios en los que incurrió la Empresa y van acompañados de la documentación sustentatoria y necesaria para que el Cliente cuente con información oportuna y confiable. Esta incluye todas las transacciones u operaciones realizadas durante el mes de presentación del EDP que están relacionadas con las compras de bienes o servicios recibidos, como por 
ejemplo: la mano de obra de los empleados, compra de materiales, servicios de subcontratistas para el desarrollo de la obra, entre otros.

El Estado de Pago es un documento muy detallado y explícito ya que el Cliente independientemente de constatar los servicios recibidos, le servirá como sustento para fines contables, tributarios, de auditorías y para toda aquella institución o interesados en la información presentada en ella.

Uno de los puntos de mayor importancia por el volumen y la materialidad dentro de la preparación del EDP es el cálculo de la mano de obra o la "labor". Pasaremos a desarrollar de manera breve los componentes del EDP:

(Ver Estado de Pago - $\underline{\text { Anexo 3.2) }}$.

- Salario o Labor: tal como su nombre lo indica corresponde al sueldo bruto recibido por cada colaborador perteneciente al proyecto, el cual incluye todos los beneficios de ley tales como: gratificaciones, CTS, Vacaciones, Essalud, EPS, LBS, entre otros beneficios sociales, en un componente denominado "burden" o "carga" y que se describirá posteriormente ya que para fines de presentación se distribuye entre otros conceptos que forman parte del EDP.

- Cargas Sociales o Burden: este es un componente que recoge los beneficios sociales que forman parte del salario o labor de los empleados y cuyo importe también se traslada al Cliente ya que como hemos mencionado anteriormente, en este tipo de contratos la empresa trata en lo posible de financiar el proyecto a través de los reembolsos recibidos por sus clientes..

El concepto de Burden representa aproximadamente un $60 \%$ de costo adicional al sueldo o labor y a excepción de algunas cargas sociales que pueden determinarse, los demás cobros se determinan de acuerdo al Contrato firmado entre ambas partes. La siguiente es la estructura relacionada con nuestro trabajo y proyecto, pero no es determinante, ya que como mencioné, dependerá mucho del acuerdo aceptado entre las partes. Los conceptos de las cargas sociales que se consideran en este rubro podemos mencionar: Gratificaciones, CTS, Essalud, Seguro Privado de Salud (EPS), Liquidación de Beneficios Sociales.

De estos dos componentes del salario, se desprende un promedio que es muy importante para determinar el costo salario hora/hombre o "bare rate", que se desarrollará a continuación. 
Costo Salario Hora/Hombre (Bare Rate): es el coeficiente que sirve como punto de partida sobre el cual se calcularán los demás conceptos o componentes del presente EDP y también reportes contables o financieros que necesite de este resultado.

Este coeficiente se obtendrá en base al sueldo, multiplicado por 12 meses del año y dividido entre 48 horas diarias de trabajo, determinadas por ley y multiplicado por 52 semanas por año.

\begin{tabular}{|c|c|}
\hline Costo & Sueldo $x 12$ meses \\
\hline $\begin{array}{c}\text { Hora/Hombre o } \\
\text { Bare Rate }\end{array}$ & $48 \mathrm{~h} / \mathrm{d} \times 52 \mathrm{sem}$ \\
\hline
\end{tabular}

Por ejemplo, para un sueldo de 8,000 Nuevos Soles, el costo por hora hombre o "bare rate" sería de:

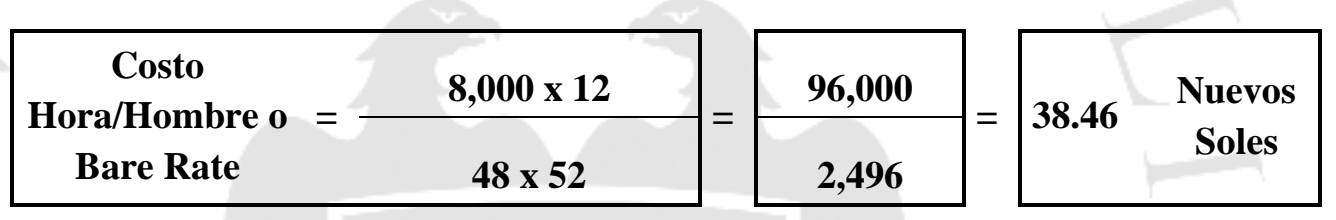

El "burden", para efectos de presentación, se distribuye como parte de los importes del salario y del multiplicador (que será desarrollado más adelante), en partes iguales, es decir, el salario más $30 \%$ de burden y el multiplicador más el $30 \%$ restante.

Coeficiente Base (Base Rate): cuyo valor se obtiene a partir del coeficiente del costo salario hora/hombre más un porcentaje adicional previamente acordado en el contrato y que para el caso del presente trabajo además incluyen el importe correspondiente a las gratificaciones y vacaciones. Se determinó como valor a considerar una compensación del 25\% (porcentaje determinado previamente en el Contrato y acordado por la partes) adicional al costo del salario hora/hombre.

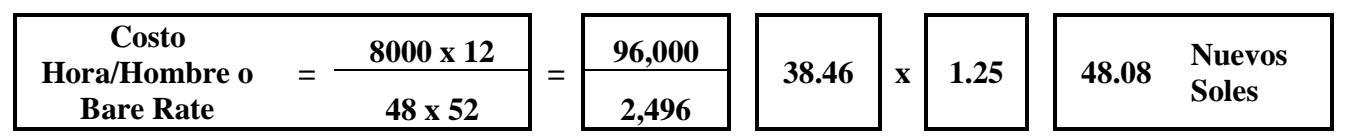

Multiplicador: es otro de los componentes del proceso de costeo de la empresa que significa un ingreso y cuyas condiciones se determinan a través cálculos matemáticos establecidos en el contrato con el Cliente y va de la mano con la 
envergadura del proyecto. Para nuestro caso el porcentaje a considerar es de un 95\% adicional aplicado al Coeficiente Base. Tal como se indicó líneas arriba, este valor está determinado por un porcentaje del burden (30\%) y un sobrecargo u overhead (50\%), relacionado con costos fijos administrativos que de manera individual no se pueden determinar y considerar como reembolsables directamente a la ejecución del proyecto, tales como: parte de los costos del salario del personal administrativo que cumplen funciones corporativas que indirectamente se vinculan al proyecto, el costo en los que incurre la empresa en útiles de oficina, papelería, alquiler de equipos como fotocopiadoras, las mismas fotocopias, entre otros. Por lo que el $95 \%$ considerado se obtiene de la siguiente manera:

$\begin{array}{|lr|}\text { Multiplicador }=\begin{array}{c}\text { Burden } \\ \text { Overhead }\end{array} \mathbf{5 0 \%}\end{array} \quad 1.30 \% \times 1.50 \%=1.95 \%=\mathbf{9 5 \%}$

$\underline{\text { Otros Costos Directos }(O D C):}$ : este componente ya no es un coeficiente, se trata de un precio determinado para cada tipo de empleado o colaborador del proyecto. El tipo está referido a que se tienen dos empleados, los que trabajan en oficinas corporativas y los que trabajan directamente en la misma obra o proyecto (campo o terreno). Para el caso del proyecto, para los colaboradores administrativos se considera un precio de US\$ 11.00 por hora y para aquellos que trabajan en la misma obra o terreno US\$ 7.50 por hora. La base a la que se aplican estos importes son las horas trabajadas mensualmente por los empleados. Se debe tener en cuenta que hay una diferencia en cuanto a las horas/hombre trabajadas por los colaboradores, se considerarán 48 horas para colaboradores que laboran en oficinas administrativas y 70 horas (las cuales pueden variar de acuerdo a los requerimientos de cada proyecto) para colaboradores que laboran en terreno.

\begin{tabular}{|lll|}
\hline $48 \mathrm{hrs} / \mathrm{sem}$ & $x$ & US\$ 11.30 \\
$60 \mathrm{hrs} / \mathrm{sem}$ & $x$ & US\$ 7.50 \\
\hline
\end{tabular}

\begin{tabular}{|l|}
542.40 \\
450.00
\end{tabular}


$\underline{\boldsymbol{F E E}}$ : este cargo es el último que para este caso se considerará para el costeo del EDP, como los anteriores componentes, está formado por un porcentaje calculado sobre la base de la sumatoria de los totales de: la labor, el multiplicador y el ODC. El porcentaje asignado para este caso es del 15\%. Este valor puede variar de acuerdo a las circunstancias del avance del proyecto, éste concepto fluctuó entre el $13 \%$ y $15 \%$, iniciándose con un porcentaje del 13\%, en momentos de crecimiento del proyecto llegó al 15\% y cuando se presentaron inconvenientes de tipo coyuntural en el Perú, como la paralización de proyectos mineros, la caída de los precios de los metales, lo que originó la paralización momentánea de la inversión en este proyecto y en general en la economía nacional, nuevamente se consideró vaya en disminución.

\begin{tabular}{|c|c|}
\hline$($ Labor + ODC $) \times \mathbf{1 5 \%}=$ & {$[[($ Labor $\times$ Base Rate $)+($ Multiplicador $)]+($ ODC $)] \times 15 \%$} \\
& {$[[(8,000 \times 1.25)+($ Labor $\times 95 \%)]+($ hrs $\times 11.3)] \times 15 \%$} \\
& $[[(10,000)+(10,000 * 95 \%)]+(172 \times 11.30)]] \times 15 \%$ \\
& {$[19,500+1,943.60] \times 15 \%$} \\
& $21,443.60 \times 15 \%$ \\
& $3,216.54$ \\
\hline
\end{tabular}

\subsection{Documentos soporte y/o entregables para afectos tributarios.}

En este acápite del proyecto, se presentarán algunos documentos o formatos que la empresa adjunta como soporte sustentatorio al momento de la presentación de los EDP al Cliente y que tienen carácter de oficiales para efectos de validación por parte de los entes fiscalizadores, son también auditables tanto por parte del Cliente, como de auditorías internas y externas. Junto con los documentos, se tratará en la medida de lo posible explicar: conceptos, finalidades o detalles que van de la mano con su presentación en los EDP's.

- Lista de Firmas Autorizadas: este documento, también conocido como: Authorized Signature List (ASL por sus siglas en Inglés), es uno de los más importantes a implementar en la ejecución de un proyecto y de cumplimiento obligatorio, porque en él se designa a las personas responsables para dar autorización a documentación relacionada al proyecto, las compras, contratos, viajes y en general, gastos que se necesite incurrir para la ejecución oportuna y ordenada 
del proyecto. En este formato, se puede apreciar los nombres del personal autorizado, las áreas a las que pertenecen y los límites de dinero autorizados a aprobar. Si bien es cierto se confecciona al inicio de la ejecución del proyecto, este puede sufrir modificaciones por distintos motivos, como, por ejemplo: cambios o relevos de los gerentes, inclusión de nuevos ítems relacionados con los gastos por las distintas etapas que se desarrollan en la obra o el término de las mismas, entre otros.

(Ver Lista Autorización de Firmas Anexo 3.3).

- Contrato Estudio de Factibilidad con Cliente: este documento, es el cual donde el Cliente da la autorización para iniciar y realizar los estudios de factibilidad en terreno donde se realizará la obra y que darán origen, una vez terminado los estudios, al proceso de construcción. Este acuerdo hace mención al importe que del costo considerado para el estudio y da la aprobación por parte del Cliente el inicio de las fases: IV y $\mathrm{V}$, que es donde se desarrollarán las dos últimas etapas del proyecto EPCM, es decir, las de Construcción (“C”) y la de Gerenciamiento o Administración ("M") de la obra. Además, también se hace referencia al importe aprobado para los Gastos Reembolsables, que es uno de los puntos importantes a considerar, ya que es sobre ese monto, que La Empresa, deberá realizar compras o adquisiciones en nombre del Cliente y que serán debidamente justificados con los soportes y documentos acordados, tanto para cumplir con fines legales, como fines de control de ambas partes. Se debe tener en cuenta que los importes consignados como parte de este acuerdo, no son definitivos, ya que independientemente que se trabaje con la mejor voluntad y cumpliendo los plazos establecidos, existen factores externos ajenos a las partes que pueden hacer que el tiempo de ejecución de la obra tenga inconvenientes y sufra retrasos o paralizaciones, lo que se reflejará en variaciones en el incremento, en la mayoría de ocasiones, pero no se puede descartar y en menor proporción, un avance dentro de los términos acordados en el contrato y no hayan cambios en los importes establecidos. En caso se presenten modificaciones a los importes acordados, estos serán analizados por ambas partes, se deberán presentar los sustentos convenientes que lo justifiquen por parte de La Empresa y serán observados y en su oportunidad aprobados por el Cliente y se reflejarán en Adendas (Amendments) o como también se les conoce internamente: Avisos para proceder (por su nombre en inglés: Notice to Proceed). 
(Ver Formato de Contrato Anexo 3.4).

En otra parte del contrato con el Cliente se especifica el detalle de las formas o formatos de los documentos a presentar para los distintos reportes, procedimientos a seguir o desarrollo de los avances de la obra que requieran de la revisión y aprobación formal, para proceder a emisión de documentos aprobatorios o desembolsos de dinero como retribución por los servicios de La Empresa al Cliente.

Dentro de los cuales se pueden presentar:

- Costos Estimados: el presente reporte financiero muestra los estimados de los costos totales del proyecto de sus 4 etapas (EPCM) en alguna de las fases de desarrollo del proyecto, para nuestro caso la fase final de la puesta en marcha. Se puede apreciar claramente la desagregación de los costos de manos de obra (labor) referidos a: ingeniería y procura o adquisiciones (E y $\mathrm{P}$ por sus siglas en inglés), construcción y gerenciamiento ( $\mathrm{C}$ y $\mathrm{M}$, también por sus siglas en inglés), costos reembolsables y otros gastos adicionales aceptados (FEE).

(Ver Cuadro Costos Estimados Iniciales - Anexo 3.5).

- Forma para presentación y solicitud de pago de los EDP's: esta forma requerida por el Cliente para la presentación de los estados de pago (EDP) por parte de La Empresa, requiere se considere información detallada referida a las actividades desarrolladas tales como la labor, los gastos incurridos, mostrados por lo presupuestado: actual y anterior y los costos reales actuales del periodo del EDP y los importes acumulados, las firmas de aprobación del EDP autorizadas por ambas empresas, entre otros conceptos no menos importantes como: número del EDP, fecha de presentación, periodo, referido al mes del EDP que es distinto al mes de fecha de presentación, etc.

(Ver Formato presentación y solicitud de pago de EDP's Anexo 3.6). 
- Relación de Gastos Aceptados: en el presente documento de puede observar el detalle de los gastos que de acuerdo con las condiciones de contrato serán aceptados. Como se puede apreciar, dependiendo del concepto del gasto, éste es clasificado como: parte del burden y se les aplica un multiplicador, reembolsables, gastos de oficina, otros costos directos y aquellos gastos que no estén incluidos dentro de esta relación, serán considerados como no reembolsables y serán asumidos por La Empresa.

(Ver Relación de Gastos Aceptados - Anexo 3.7).

- Adendas (o Notice to Proceed): en este documento las partes se ponen de acuerdo en aceptar variaciones, desviaciones que hayan ocurrido en alguna de las condiciones en los contratos que hayan pactado, sea del principal o de cualquiera de las áreas involucradas en el desarrollo de la obra y por el cual se requiera modificar términos contractuales o también importes pactados. En la adenda se tiene que detallar los motivos de su emisión, se menciona a la persona que hace la solicitud, los importes de dinero estimados, el nuevo importe por el cual se acepta la presente Adenda, inclusive se debe tener en cuenta el periodo de aplicación del nuevo acuerdo.

Luego, en el contenido del documento, se detallarán todas las áreas a cargo del desarrollo de las acciones necesarias para cumplir con los objetivos trazados, el nuevo alcance de los servicios prestados, las prácticas y procedimientos a utilizar, los cuales deben ser debidamente notificados y presentados al Cliente en boletines de trabajo, de acuerdo a lo establecido en los acuerdos del proyecto.

(Ver Formato de Adenda - Anexo 3.8).

- Contratos de Servicios: documentos contractuales firmados con los proveedores de servicios para proporcionar diferentes de tipos de servicios, en estos dos casos, de transporte y abastecimiento de combustible. En ellos se puede apreciar muy detalladamente las condiciones y obligaciones a asumir y cumplir por ambas partes, tales como:

- Razón Social de las empresas, fecha de la firma del contrato, los representantes legales de las mismas que son los firmantes, domicilio fiscal. 
- Descripción del servicio

- Programa de ejecución del servicio, es decir, el periodo de duración del contrato.

- Dónde ubicar (dirección) y qué personas serán los contactos para circular las comunicaciones cuando sea pertinente.

- Precios acordados de los servicios.

- Condiciones, fechas y plazos de los pagos.

- En general, términos y obligaciones legales y contractuales a las cuales las partes se encuentran sujetas para el buen desarrollo y cumplimiento de la prestación del servicio.

Los Contratos son gestionados por el área específica de Contratos y en coordinación todas las áreas que intervienen en el desarrollo del proyecto ya que todas en algún momento requieren de servicios prestados por terceros, pero tienen una comunicación y relación más directa con las áreas de Control de Proyectos que son los que tienen el conocimiento de las necesidades de los servicios en los cuales se tienen que recurrir de acuerdo a las etapas y avances del proyecto. También se puede considerar como contacto importante con las áreas de Contabilidad y Finanzas, en lo referido a el control contable que se lleva en paralelo a través de los sistemas integrados de gestión y con el área de Finanzas en cuanto a los desembolsos para el pago oportuno a los proveedores, de acuerdo a las condiciones y plazos establecidos en el contrato de servicio. Para un mejor control de los Contratos, cada uno de ellos que un proveedor puede tener más de un contrato con La Empresa y para ello el número de contrato asignado, se distingue en primer lugar porque lleva el nombre del proyecto, el cual lo hemos mencionado en su momento y que también es conocido como: Project Definition.

(Ver Contrato Servicio De Transporte ACD - $\underline{\text { Anexo 3.9). }}$.

- Órdenes de Compra: en general consignan las mismas condiciones y obligaciones a las que las partes se comprometen para el cumplimiento de lo estipulado en la orden de compra.

A diferencia de los Contratos, las Órdenes de Compra están bajo la gestión y el control del área de Adquisiciones (o Procura), pero tiene el mismo contacto con las 
demás áreas de La Empresa y también está en coordinación directa con el área de Control de Proyectos en el referente a las necesidades de la solicitud y pedido de los materiales, que depende de las etapas y avance de la obra.

(Ver Orden de Compra Intech S.A. - Anexo 3.10).

- Reporte Gastos de Viaje: este es uno de los reportes más utilizados por los colaboradores asignados a los proyectos (también los corporativos) en La Empresa y que es de presentación obligatoria y oportuna después de haber realizado alguna comisión encargada como parte del desarrollo de la obra. Se presentan en caso de viajes o de algún gasto que tenga que sustentarse para ser reembolsado como parte del gasto del proyecto o también por colaboradores corporativos.

Este formato debe ser presentado en un plazo determinado de acuerdo al procedimiento de gastos de viaje y para que sea admitido como reembolsable para el caso de un proyecto, debe estar acompañado de los sustentos adecuados y aceptados legalmente, tales como: facturas, tickets aéreos, boletas de venta, tickets emitidos por máquinas registradoras, entre otros, todos estos documentos debidamente emitidos conforme a ley de comprobantes de pago. Además son aceptados en casos excepcionales por el desarrollo de actividades en proyectos instalados en zonas alejadas de las ciudades y se haya solicitado algún servicio o realizado alguna compra y no se cuente con comprobantes admitidos legalmente, declaraciones juradas hechas por el colaborador.

Estos reportes de gastos son preparados por la persona que realizó la comisión, aprobada por el gerente del área respectiva, luego es revisada y aprobada por el área de contabilidad y la aprobación final para proceder al pago por el gerente de finanzas del proyecto.

(Ver Reporte Gastos de Viaje - Anexo 3.11).

- Documentación Requerida para Presentación de Valorizaciones Contratistas: para el buen cumplimiento y aceptación en la preparación y presentación de los EDP's por parte de La Empresa al Cliente y cumplir con los acuerdos del Contrato entre ambas partes, asi como procedimientos administrativos, tanto internos, como externos, llámese cumplir con revisiones por parte de entes fiscalizadores como SUNAT, auditorías externas, entre otros, se implementó éste formato que detalla los 
documentos que deben incluir los proveedores o subcontratistas que tengan contrato de servicios y que para su ejecución, involucren labor su propio personal, para que la prestación de sus servicios sean aceptados como válidos por La Empresa y a su vez por el Cliente.

Entre los documentos que se solicitan presentar, podemos encontrar desde los relacionados con el contrato de servicios, como por ejemplo: referencia al número del contrato, documentación sustentatoria del mismo y relación del personal involucrado a realizar el servicio. Y/ con la finalidad de confirmar que los proveedores o subcontratistas cumplan con sus obligaciones al fisco del pago de sus obligaciones salariales y de pensiones, se les exige la presentación de formularios de pago presentados a SUNAT, como el 601 referidos al pago de la planilla electrónica mensual, el 600 a pagos de Essalud, LBS, CTS, SNP, Renta de 5ta Categoría relacionados a la planilla, pago de pólizas de los distintos tipos de Seguros, entre ellos los relacionados al Seguro Complementario de Trabajo de Riesgo (SCTR) y de mucha importancia, ya que solo con éste documento, es que los empleados asignados al proyecto, es que pueden ingresar, con el permiso del Cliente y a través de las respectivas identificaciones, a desarrollar sus labores al campamento o áreas donde se ejecutan las obras.

- Relacionados a la seguridad y que es uno de los pilares de La Empresa, se solicita la presentación de un reporte de Accidentabilidad, que está referido a informar mensualmente en caso hayan tenido algún accidente en la ejecución de las labores por parte de sus empleados. Esto formará parte del record para la buena reputación de La Empresa, ya que se dedica e invierte mucho tiempo en la educación e inducción para el buen desarrollo de las actividades laborales y evitar accidentes.

- (Ver Formato Documentación Requerida para Presentación de Valorizaciones Contratistas - Anexo 3.12). 


\section{CONCLUSIONES}

Después de haber desarrollado el proceso de costeo para la facturación, tema del presente proyecto, es posible llegar a enunciar algunas conclusiones de tal forma que se puedan tener ideas generales del presente proceso de costeo:

- El proceso de costeo desarrollado, tiene por finalidad mostrar la utilización y aplicación de éste modelo en empresas del mismo rubro o de rubros similares. La correcta elaboración en base al uso de controles específicos y detallados para cada uno de los componentes del costeo: mano de obra directa, materiales directos y costos indirectos, relacionados con el cumplimiento de las especificaciones técnicas y plazos determinados en los contratos, han permitido a la gerencia de la organización contar con una fuente de información relevante de los servicios que presta en cuanto a la determinación de los costos e ingresos que generan, para ser tomados en cuenta en la toma de decisiones y un control adecuado de las operaciones, tanto de manera interna (dentro de la misma empresa), como de manera externa (clientes e interesados en los servicios de la organización).

- Debido a la estrecha relación entre el contratista y el cliente y también, la relación de las áreas involucradas dentro de la misma empresa, cabe resaltar la importancia de la comunicación e intercambio de información durante todo el proceso de ejecución de las obras, desde las etapas iniciales hasta la culminación total del proyecto. Mediante el presente proceso de costeo, los trabajos realizados se hacen a través de una adecuada planificación de las obras, así como también de los procesos acordados e implementados, de la selección del personal adecuado y calificado, de la elección de los mejores proveedores de materiales y servicios y con ello lograr la optimización de las actividades a través de seguimientos y controles periódicos de las labores para prevenir y en la medida de lo posible, evitar posibles desviaciones y riesgos que redunden en el aumento de la inversión presupuestada, de los plazos establecidos y de la rentabilidad proyectada que permiten a la organización y sus clientes, el logro de los objetivos y metas programadas durante la ejecución de los proyectos. 
- Junto con la presentación e ideas expuestas en el presente trabajo, que están siendo de utilidad a la empresa materia de la implementación, existe la firme intención de brindar un pequeño aporte a la contabilidad, tanto a la financiera, mediante la revisión de hechos del pasado a través de los costos y en base a la información histórica registrada de éstos para poder obtener y formular reportes, para el presente caso llámense, estados de pago (en general, formulación de estados financieros), que se reflejen en la obtención de mayores ingresos, relacionados con un adecuado manejo y reducción de costos de la empresa, así como también brindar soporte a la contabilidad administrativa, analizando la información que le brinda la contabilidad financiera, revisando y actualizando las estimaciones de los presupuestos y también información no financiera, desarrollando, formulando y aplicando estrategias adecuadas que ayuden a la gerencia de la empresa en la toma de decisiones encaminadas a dar un mejor uso a los recursos de la empresa y proporcionar al cliente un valor agregado que se refleje en el cumplimiento de metas y la consecución del éxito en el desarrollo de los trabajos acordados en los contratos.

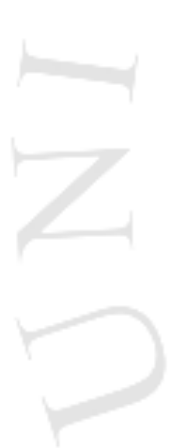




\section{RECOMENDACIONES}

- Establecer en base a las especificaciones contractuales, controles internos orientados al correcto cumplimiento de los procesos establecidos en cada uno de los estamentos que participan en la ejecución de los proyectos, desde la gerencia en cuanto a la toma de decisiones, hasta las áreas operativas y administrativas. La gerencia como órgano directriz de la organización tendrá como responsabilidad hacer de conocimiento de sus colaboradores los beneficios de la aplicación, cumplimiento y revisiones periódicas de los procedimientos establecidos para la consecución exitosa de los objetivos en la ejecución de sus proyectos.

- Establecer, una vez determinada la viabilidad del o los proyectos, los medios más adecuados para lograr una comunicación fluida y directa entre todos los actores que participan en el desarrollo de las obras, principalmente dentro de la organización, teniendo en cuenta que es la manera de organizar y coordinar el mejor cumplimiento y ejecución de todas las etapas y tareas establecidas en la etapa contractual, de forma tal que se puedan atender eficaz y oportunamente las necesidades de todas las áreas que se presenten a medida que se avance con los proyectos, tanto dentro de la empresa, como de los requerimientos que puedan solicitar el o los clientes. Asimismo, en las etapas previas determinar los procedimientos de prevención accidentes o riesgos personales o materiales para evitar dilatar los plazos en la ejecución de las obras y en consecuencia tener que modificar los presupuestos establecidos lo que ocasionaría una afectación en los márgenes de ingresos y costos para la empresa y también para el cliente.

- Para la consecución de los objetivos de parte de la empresa y la plena satisfacción del o los clientes al recibir finalmente el proyecto de acuerdo a lo pactado contractualmente, se recomienda la implementación, aplicación y ajustes progresivos de controles internos a medida que se avance con la obra, se definan políticas y procedimientos de: ingeniería, construcción, financieros, recursos humanos, durante el desarrollo del proyecto, pudiendo estos ser perfectibles en la medida que cada fase de la obra presenta retos a rebasar. Los órganos gerenciales y de dirección deben ser los encargados de establecer, interiorizar y evaluar periódicamente sus procesos dentro de la organización y de sus miembros para 
asegurar del fiel cumplimiento de los principios establecidos con la finalidad de mantener un alto estándar de especialización en la ejecución de los proyectos que vaya acorde con la eficacia, eficiencia, economía, presupuestos y los plazos programados para la obtención de las metas y objetivos de la empresa. 


\section{REFERENCIAS}

Instituto de Ingenieros del Perú (2011). Minería Peruana: Contribución al Desarrollo Económico y Social. Lima: Autor.

Instituto de Gobierno y de Gestión Pública. Universidad San Martín de Porres (2012). Minería, Impuestos e Inversión. Lima. Recuperado de http://www.minem.gob.pe/detalle.php. Lima: Autor.

Consejo Superior de Contrataciones y Adquisiciones del Estado (OSCE) (2007), Texto Unico Ordenado de la Ley de Contrataciones y Adquisiciones del Estado.

(Aprobado mediante D.S. N 083-2004-EPCM). Modificado por Ley $\mathrm{N}^{\circ} 28267$. Lima: OSCE.

Echevarría, F. (2007), Asegurando el valor en proyectos de construcción: una guía estratégica para la selección y contratación del equipo del proyecto. Tesis para optar título de Ingeniero Civil. Perú. Recuperado de http://tesis.pucp.edu.pe/repositorio/handle/123456789/975. Lima: Autor. 


\section{BIBLIOGRAFÍA}

Construction Owners Association of Alberta (2008). Orientación EPCM, Estructura del Contrato EPCM. Alberta. Recuperado de http://www.coaa.ab.ca/Home.aspx. Alberta: Autor.

Universidad ESAN (2010). Características de empresas mineras. Marco Normativo y generación de valor en empresas mineras. Análisis Comparativo entre el Perú y Chile. Lima: ESAN Publicaciones.

Sebastián R., Arancibia, F. (2012). Análisis de Indices de Accidentabilidad en la Construcción de Proyectos EPCM para La Minería: recomendaciones. Proyecto de Tesis. Santiago de Chile: Repositorio Universidad de Chile.

Pinilla, A. Estrategias contractuales para el desarrollo de Proyectos (EPCM). Recuperado de http://www.indemipe.com/indemipe/Antonio-Pinilla.pdf. Lima: Autor.

Santacruz, C. (2009). Los Contratos Llave en Mano. Taller-Seminario C.A.F. Recuperado de https://www.caf.com/media/3304/Conferenciasobrecontratosllaveenmano(bolivi a).pdf. La Paz: Autor.

Schwarz, M. (2013), Licencias y permisos generales para operar una mina. Recuperado de http://max-schwarz.blogspot.com/2013/04/licencias-y-permisosgenerales-para.html. Lima: Autor.

Guzmán, J. (2014), Contratos de Costes Reembolsables. Recuperado de http://www.obcp.es/index.php/mod.opiniones/mem.detalle/id.159/relcategoria.2 08/relmenu.3/chk.7b21f20261cfaeb6de1b59da6a01d533. Madrid: Autor.

Torres, S. El área de compras en la empresa constructora. Recuperado de http://www.monografias.com/trabajos90/area-compras-y-su-proceso-empresaconstructora/area-compras-y-su-proceso-empresa-constructora.shtml:Autor.

Torres, S. Modelo de administración para empresas constructoras. Recuperado de http://www.monografias.com/trabajos90/modelo-administracion-empresasconstructoras-mac4dv/modelo-administracion-empresas-constructorasmac4dv2.shtml: Autor.

Project Management Institute, Project Management. Recuperado de: http://www.pmmlearning.com/principal/project-management: Autor.

Estudio Caballero Bustamante (2011), Normas Internacionales de Contabilidad (Tomo 1 NIC 1 a NIC 15). Lima: Biblioteca Universidad de Lima; CB20 / 657.028/L95. Lima: Autor.

La Torre, G. (2008). Rentas de fuente peruana, Concepto asistencia técnica, Jornadas Laborales en Derecho Tributario. Recuperado de http://www.ipdt.org/editor/docs/07_XJorIPDT_GLTO.pdf. Lima: Autor. 
Castillo, J. (2014). Los Contribuyentes no domiciliados en el Perú: comentarios a la ley del impuesto a la renta. Recuperado de file:///C:/Users/Usuario/Downloads/DialnetLosContribuyentesNoDomiciliadosEnElPeru-5109639.pdf. Lima: Autor.

Estudio Caballero Bustamante. Persona no domiciliada, 183 días no domiciliados. Recuperado de http://www.caballerobustamante.com.pe/plantilla/profe/personadomiciliada.pdf / 183 días no domiciliados (2). Lima: Autor.

SUNAT. Sistema de detracciones (SPOT), Recuperado de http://orientacion.sunat.gob.pe/index.php?option=com_content\&view=category\&layout=blog\&id=173\&Itemid=351. Lima: Autor.

Ministerio de Energía y Minas (2015). Memorias de La Empresa. Boletín Estadístico del Subsector Minero. Recuperado de http://www.minem.gob.pe/_publicacion.php?idSector=1\&idPublicacion=500. Lima: Autor.

Actualidad Minera (2015). Boletín Junio 2015. Recuperado de: http://cooperaccion.org.pe/main/images/pdf/ACTUALIDAD_MINERA_JUNIO _2015. Lima: Autor.

Red de Justicia Fiscal de América Latina y El Caribe (2015). Tratamiento Tributario a las Inversiones Extractivas (1ra. Ed.). Lima: Autor.

BBVA Research (2016). Informe Situación Perú-1er Trimestre de 2016. Unidad de Perú. Lima: Autor. 


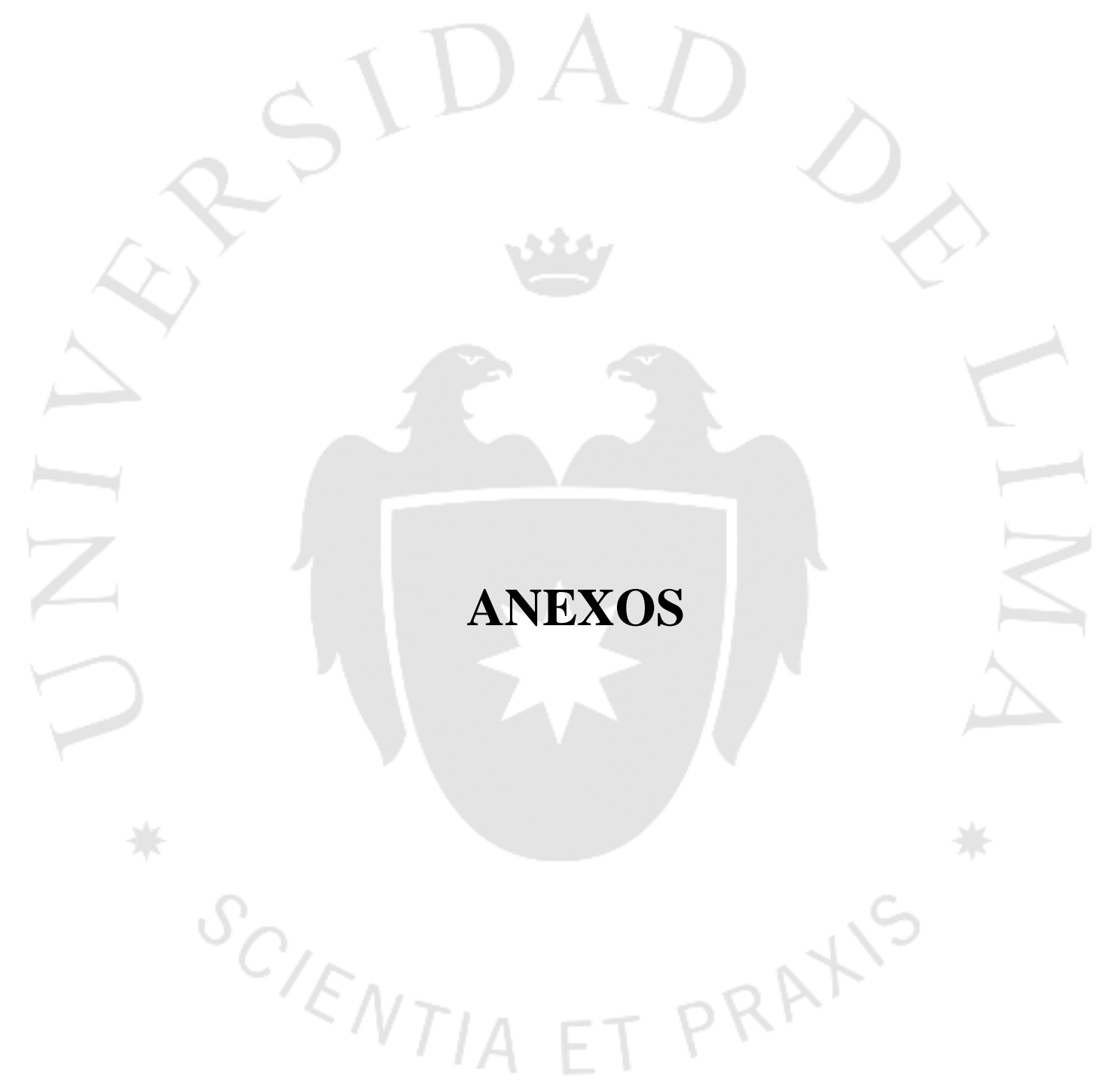




\section{Anexo 3.1: Solicitud de Adelanto ADELANTO (ADVANCE) POR SERVICIOS}

(En US\$ Dollars)

\begin{tabular}{|c|c|c|c|c|c|c|c|c|}
\hline \multicolumn{2}{|c|}{} & \multicolumn{1}{|c|}{ A } & B & C & D & E & F \\
\hline \multirow{2}{*}{ Código } & \multirow{2}{*}{ Nombre Empleado } & & $\begin{array}{c}\text { Mes/Año } \\
\text { Hrs }\end{array}$ & $\begin{array}{c}\text { Tarifa X } \\
\text { Hora } \\
\text { US } \$ / H r\end{array}$ & $\begin{array}{c}\text { Importe } \\
\text { Labor } \\
\text { USD }\end{array}$ & $\begin{array}{c}\text { Multiplica } \\
\text { dor } \\
\mathbf{0 . 9 5}\end{array}$ & $\begin{array}{c}\text { ODC } \\
7.50\end{array}$ & $\begin{array}{c}\text { Costos } \\
\text { Directos }\end{array}$ \\
\hline
\end{tabular}

\section{CONSTR UCCION}

501 - Construcción

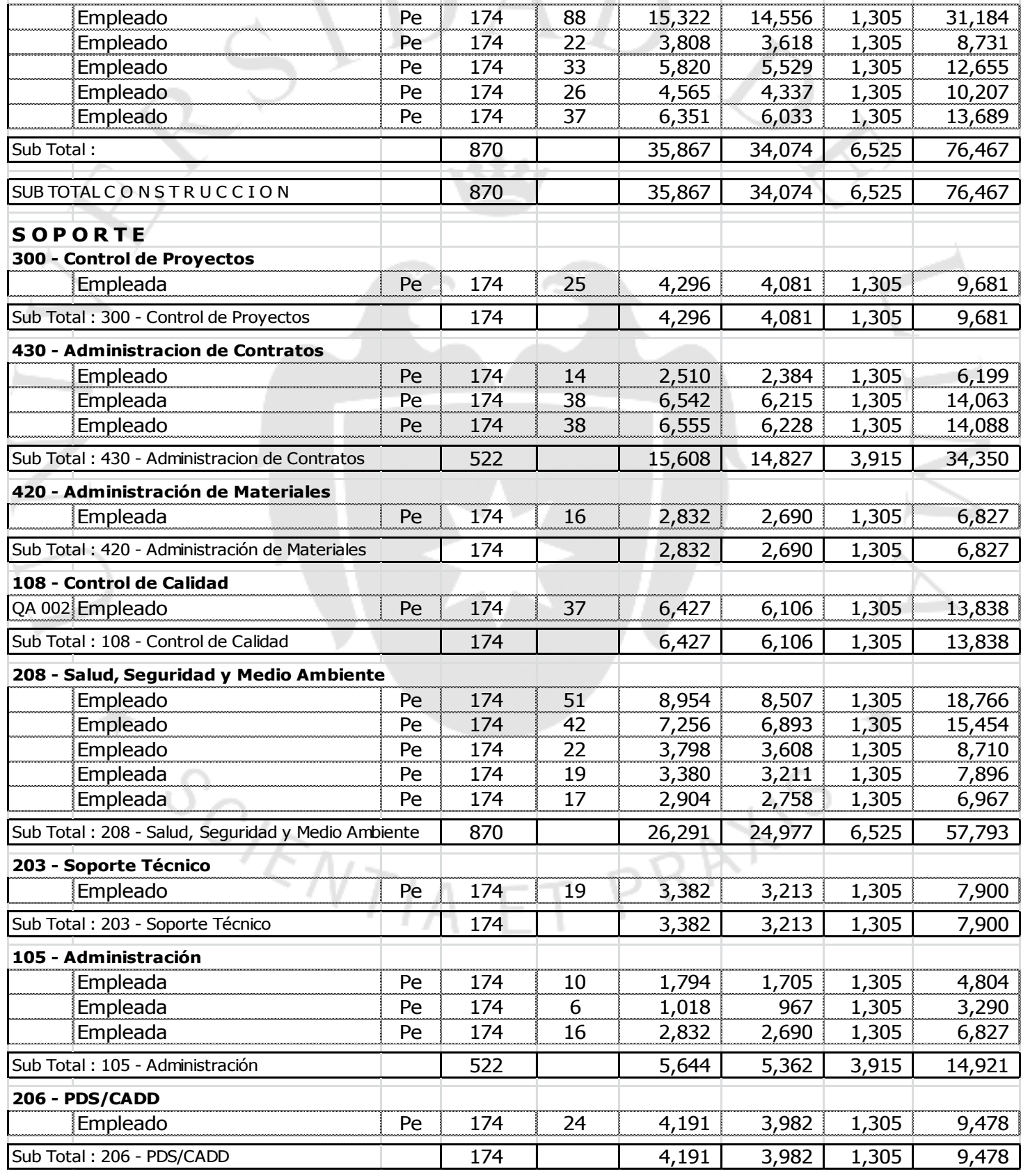


340 - Servicios de Negocios de Proyectos

\begin{tabular}{|l|l|l|l|r|r|r|r|}
\hline Empleado & $\mathrm{Pe}$ & 174 & 22 & 3,767 & 3,579 & 1,305 & 8,651 \\
\hline Empleado & $\mathrm{Pe}$ & 174 & 15 & 2,638 & 2,506 & 1,305 & 6,450 \\
\hline Empleada & $\mathrm{Pe}$ & 174 & 8 & 1,451 & 1,378 & 1,305 & 4,134 \\
\hline Sub Total : 340 - Servicios de Negocios de Proyectos & 522 & & 7,856 & 7,463 & 3,915 & 19,234 \\
\hline SUB TOTAL EQUIPO DE SOPORTE & 3,306 & & 76,527 & 72,701 & 24,795 & 174,023 \\
\hline TOTAL GERENCIAMIENTO DE CONSTRUCCIÓN & 4,176 & & 112,395 & 106,775 & 31,320 & 250,490 \\
\hline TOTAL LABOR & $\mathbf{4 , 1 7 6}$ & & $\mathbf{1 1 2 , 3 9 5}$ & $\mathbf{1 0 6 , 7 7 5}$ & $\mathbf{3 1 , 3 2 0}$ & $\mathbf{2 5 0 , 4 9 0}$ \\
\hline TOTAL LABOR 90\% & $\mathbf{1 0 1 , 1 5 5}$ & $\mathbf{9 6 , 0 9 8}$ & $\mathbf{2 8 , 1 8 8}$ & $\mathbf{2 2 5 , 4 4 1}$ \\
\hline FEE (15\% LABOR + ODC) & $\mathbf{1 5 \%}$ & $\mathbf{1 5 , 1 7 3}$ & $\mathbf{1 4 , 4 1 5}$ & $\mathbf{4 , 2 2 8}$ & $\mathbf{3 3 , 8 1 6}$ \\
\hline GASTOS REEMBOLSABLES (USD) & & & & & $\mathbf{4 0 , 0 0 0}$ \\
\hline TOTAL USD & & & & & $\mathbf{2 9 9 , 2 5 7}$ \\
\hline
\end{tabular}




\section{Anexo 3.2: Estado De Pago}

Nombre de Proyecto:

Numero de Proyecto: A\#BC

ESTADO DE PAGO $N^{\circ} \mathrm{XX}$

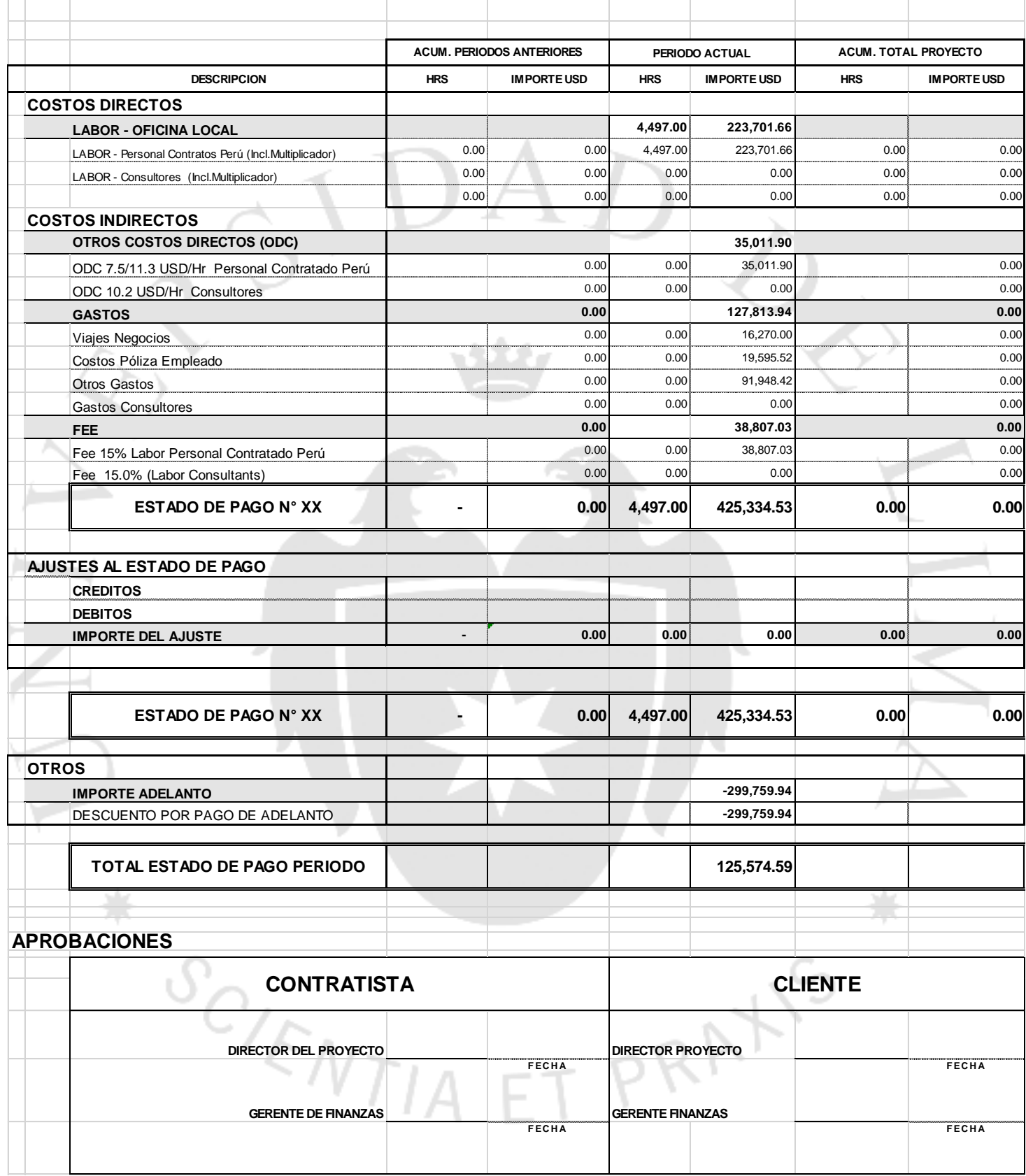




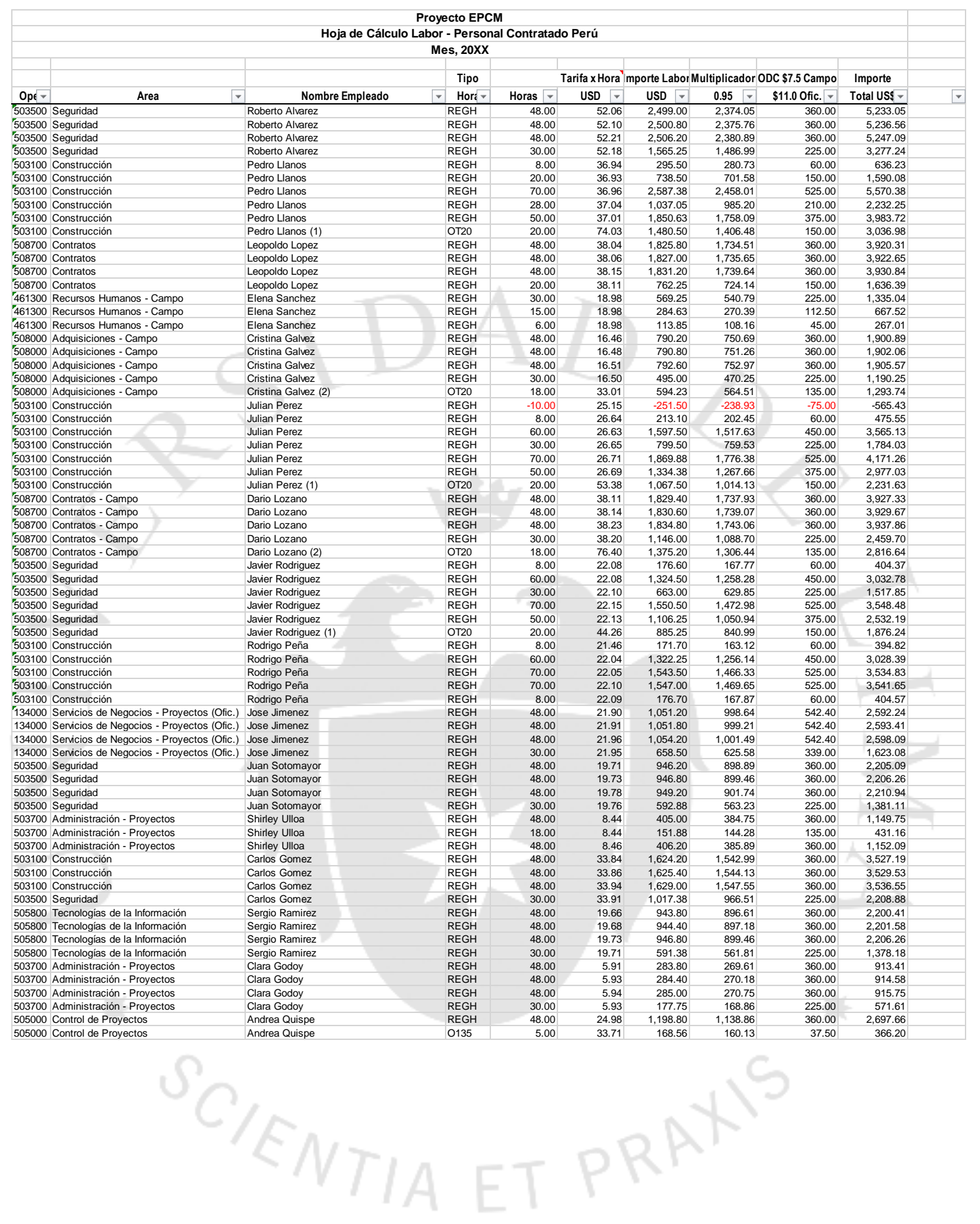




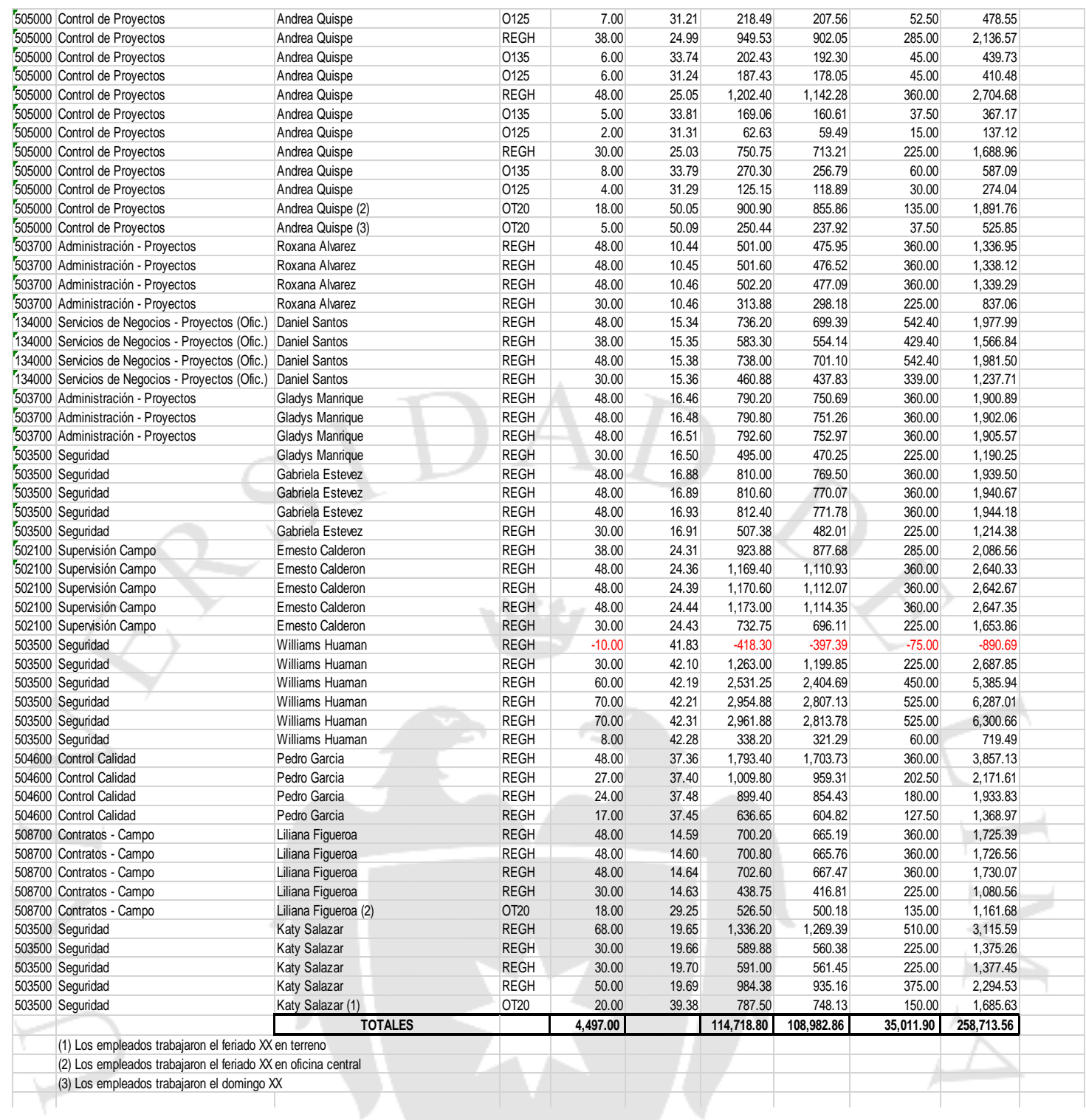




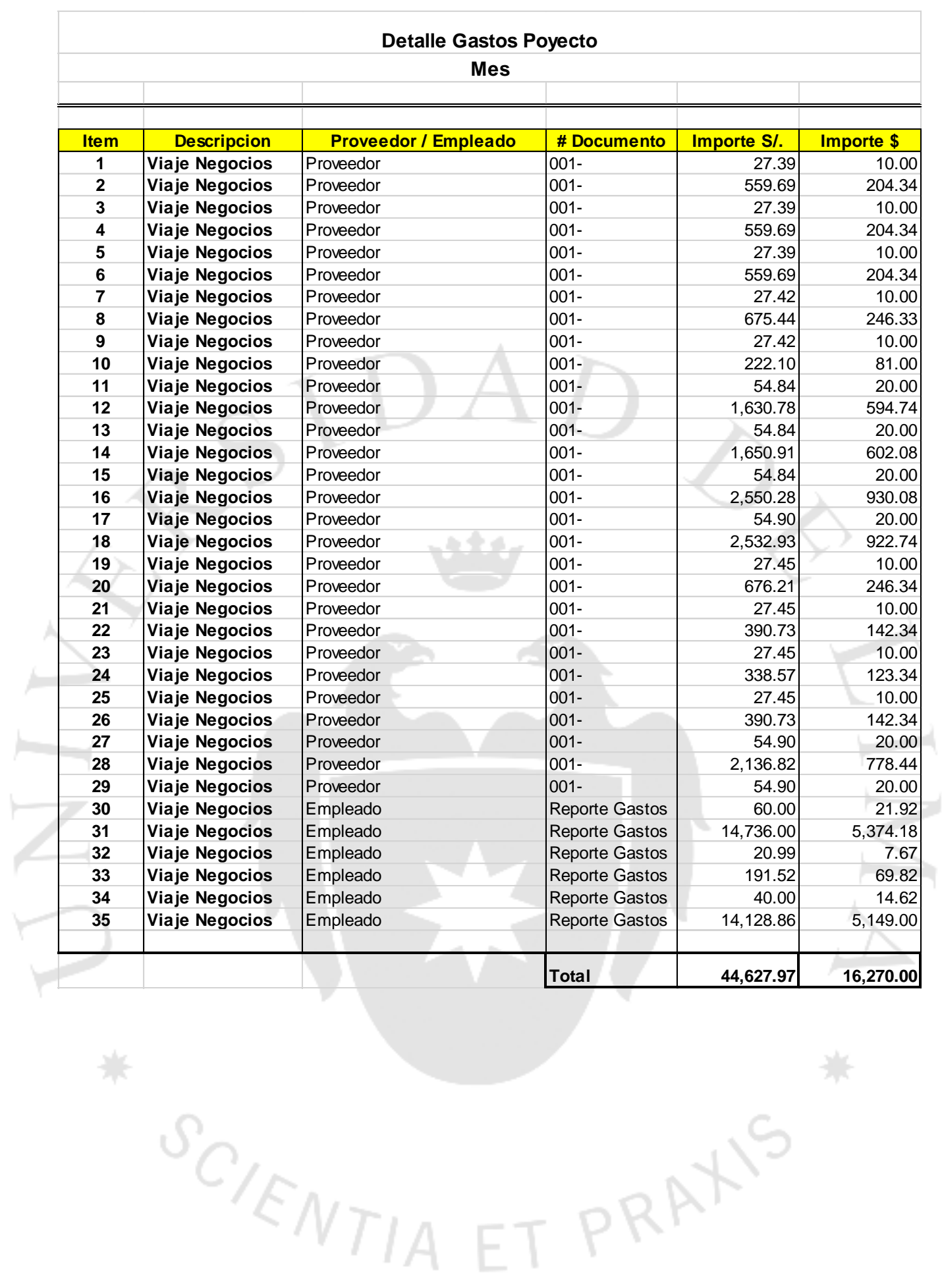




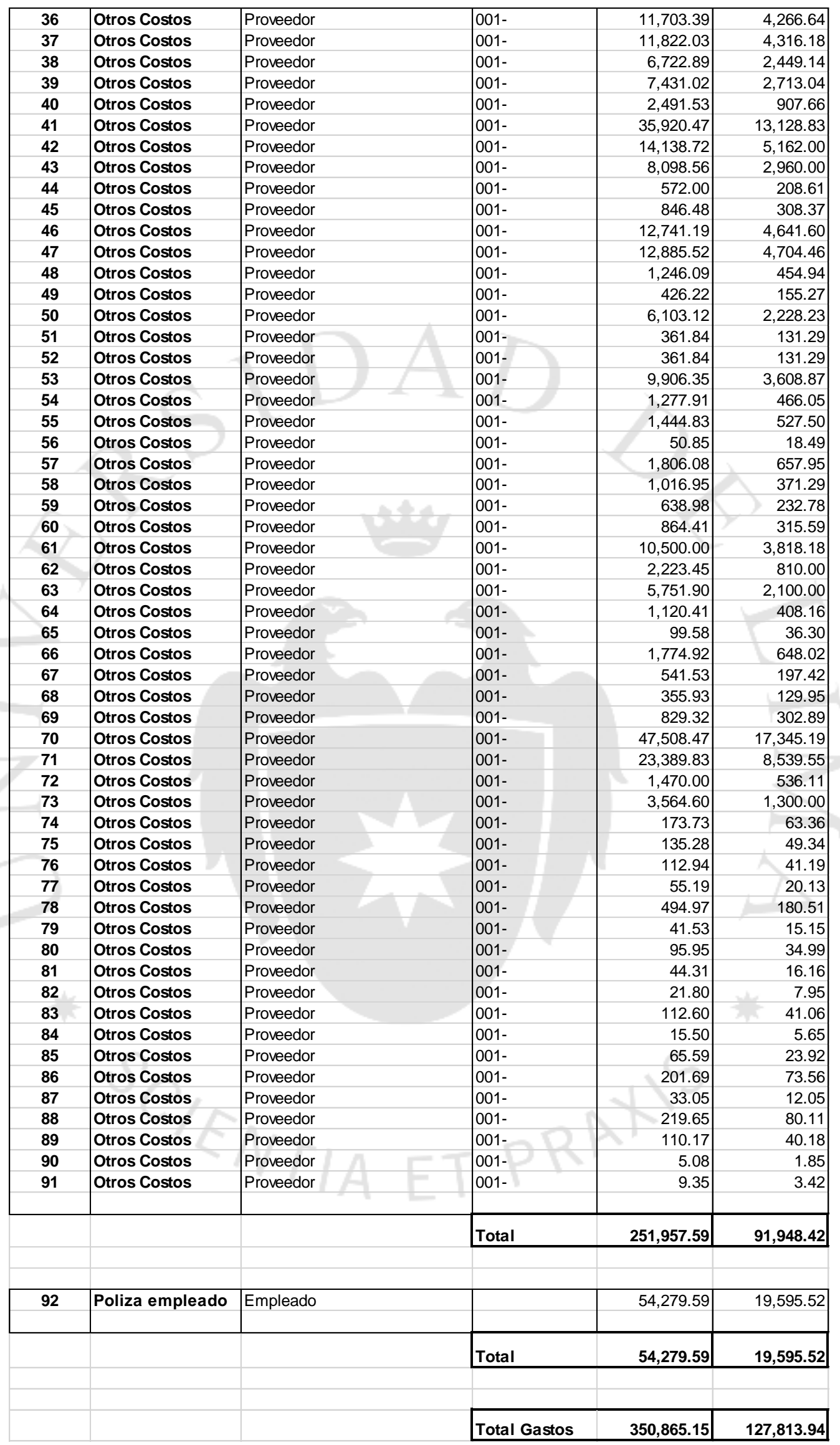


Anexo 3.3: Lista Autorización De Firmas

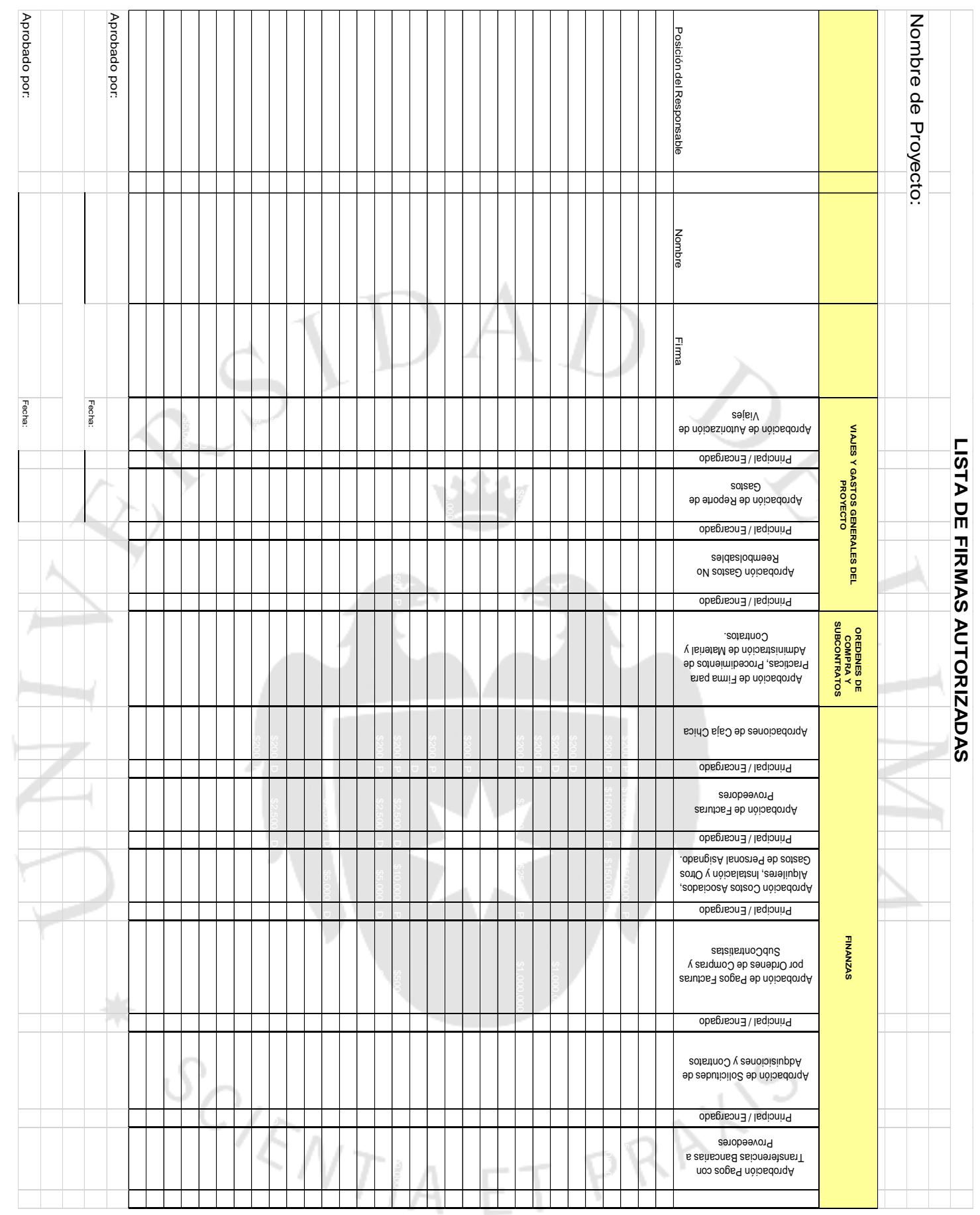




\section{Anexo 3.4: Formato De Contrato}

\section{Contrato Estudio de Factibilidad con Cliente}

A\&SC-177-09

Lima, __ de de 20

Señores: El Contratista

Atte:

Nombre: $\mathrm{Sr}$.

Cargo: Gerente General

Unidad de Negocio: Minería

Ref: CONTRATO $\mathrm{N}^{\circ}$ XXX.XX.0083-INGENIERIA OPTIMIZACIÓN DEL ESTUDIO DE FACTIBILIDAD DEL PREYECTO (Nombre del Proyecto)

En relación con el contrato de la referencia, confirmamos lo siguiente:

1. El Cliente, está de acuerdo con la propuesta Técnico Económico de El Contratista, en adelante el INGENIERO, del DD de MM del AA; completada con su revisión $\mathrm{N}^{\circ}$ BD/L/055/09 del DD de MM de AA y revisión N BD/L/006/09 del DD de MM de AA, en adelante la PROPUESTA. El monto total estimado para el CONTRATO a tres millones cuatrocientos sesenta y tres mil doscientos nueve dólares de los Estados unidos de América (US\$ 3,463,209). Dicho monto está compuesto por los siguientes 2 conceptos: 
a. Fase IV y Fase V, la cual considera la coordinación y administración por parte de la gerencia del proyecto, de todas las actividades relacionadas con estas faces que se encuentran dentro del alcance del trabajo del INGENIERO así como, las funciones de control de costos programación, pronóstico, administración de cambios y presentación de informes de avance y finalización y emisión del Informe de Estudio de Factibilidad por un monto total estimado de tres millones ciento noventa y un mil novecientos cuarenta y seis dólares de los Estados Unidos de América (US\$3,191,946).

b. Gastos Reembolsables, los cuáles solo serán utilizados, a solicitud expresar del Cliente por un monto total estimado de doscientos setenta y un mil doscientos sesenta y cuatro dólares de los Estados Unidos de América (US\$271,264).

Las condiciones relativas al avance y descripción de los servicios , plan de prestación, programación ,organización, personal clave, etc, están contenidas en los documentos indicados en este numeral, las que serán establecidas en detalle con la suscripción del acuerdo definitivo por los servicios de la referencia en adelante el CONTRATO.

2. La estimulación de horas y planos y documentos para la realización del proyecto, durante las fases IV Y V, será llevada por el área de Control de Proyectos del CONTRATISTA, quienes constantemente estarán informando a EL CLIENTE de las desviaciones tanto positivas como negativas. Será el Gerente del proyecto del CONTRATISTA quien deberá indicar y defender cualquier desviación al precio originalmente ofrecido, es decir, cualquier variación de las horas hombre.

3. Mientras se suscribe al Contrato y con el objetivo de progresar con el desarrollo de los trabajos del proyecto, EL CLIENTE está de acuerdo en comprometer con el CONTRATISTA, mediante el presente instrumento, el inicio de los trabajos del 
CONTRATO, El pago se hará contra los servicios y trabajos realmente prestados, previa conformidad de EL CLIENTE y de acuerdo con los precios de la PROPUESTA.

4. Hasta la firma del CONTRATO, esta carta y los documentos indicados en el numeral 1 precedente, constituirán el acuerdo entre las partes. EL CONTRATO se firmará a más tardar dentro de treinta (30) días .calendario contado desde la fecha de este documento.

5. Durante el periodo antes mencionado, las observaciones hechas por el CONTRATISTA y las que EL CLIENTE presente, serán consideras y definidas de común acuerdo por las partes antes de suscribir el CONTRATO.

6. La coordinación técnica y administrativa por EL CLIENTE la efectuará el Gerente de Ingeniería.

7. Los servicios de la fase IV se iniciarán el DD de MM del AA y el CONTRATISTA realizará sus mejores esfuerzos para entregar los servicios comprometidos en la PROPUESTA, completamente terminados y correctamente prestados/ejecutados a satisfacción de EL CLIENTE, a más tardar el DD de MM de AA.

8. Condición esencial: Sin perjuicio de lo señalado precedentemente las partes dejan expresamente establecido y elevan a la cantidad de esencial, la condición que el CONTRATO solo se suscribirá y producirá sus efectos, una vez que las partes hayan perfeccionado el convenio en todos sus aspectos.

9. De no lograrse acuerdo, EL CONTRATISTA y EL CLIENTE renuncian expresamente desde ya, a cualquier acción o reclamación que pudieren entablase la una contra la otra para estos efectos $\mathrm{y}$ en ese sentido, excepto con respecto al derecho del CONTRATISTA de recibir el pago por los servicios y trabajos realmente prestados según el párrafo siguiente. Por lo tanto, EL CONTRATISTA y EL CLIENTE renuncia a su derecho de solicitar indemnización y/o compensación de cualquier especie. 
10. En el evento de producirse la situación descrita, sólo corresponderá a EL CLIENTE, el pago de los trabajos y servicios realmente ejecutados/prestados por EL CONTRATISTA, siempre que estén relacionados, directamente con los servicios/trabajos de que da cuenta esta carta y estén de acuerdo con la PROPUESTA.

11. Rigen las mismas disposiciones sobre prevención de riesgos, políticas sobre ética en los negocios, conflicto de intereses, consumo de alcohol y drogas, confidencialidad, propiedad de la Ingeniería y Planos, y otros estándares aplicables ya suscritos por ustedes en otros contratos celebrados con anterioridad.

En señal de conocimiento y aceptación, agradeceremos confirmar su acuerdo mediante la firma del representante legal de su compañía al pie de esta carta y una vez hecho devolveremos un ejemplar.

Saluda atentamente a Ustedes,

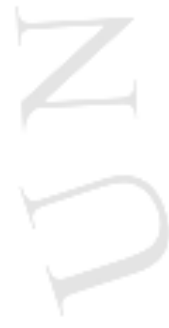

Por:

El Cliente

Por:

El Contratista 
Anexo 3.5: Costos Estimados Iniciales
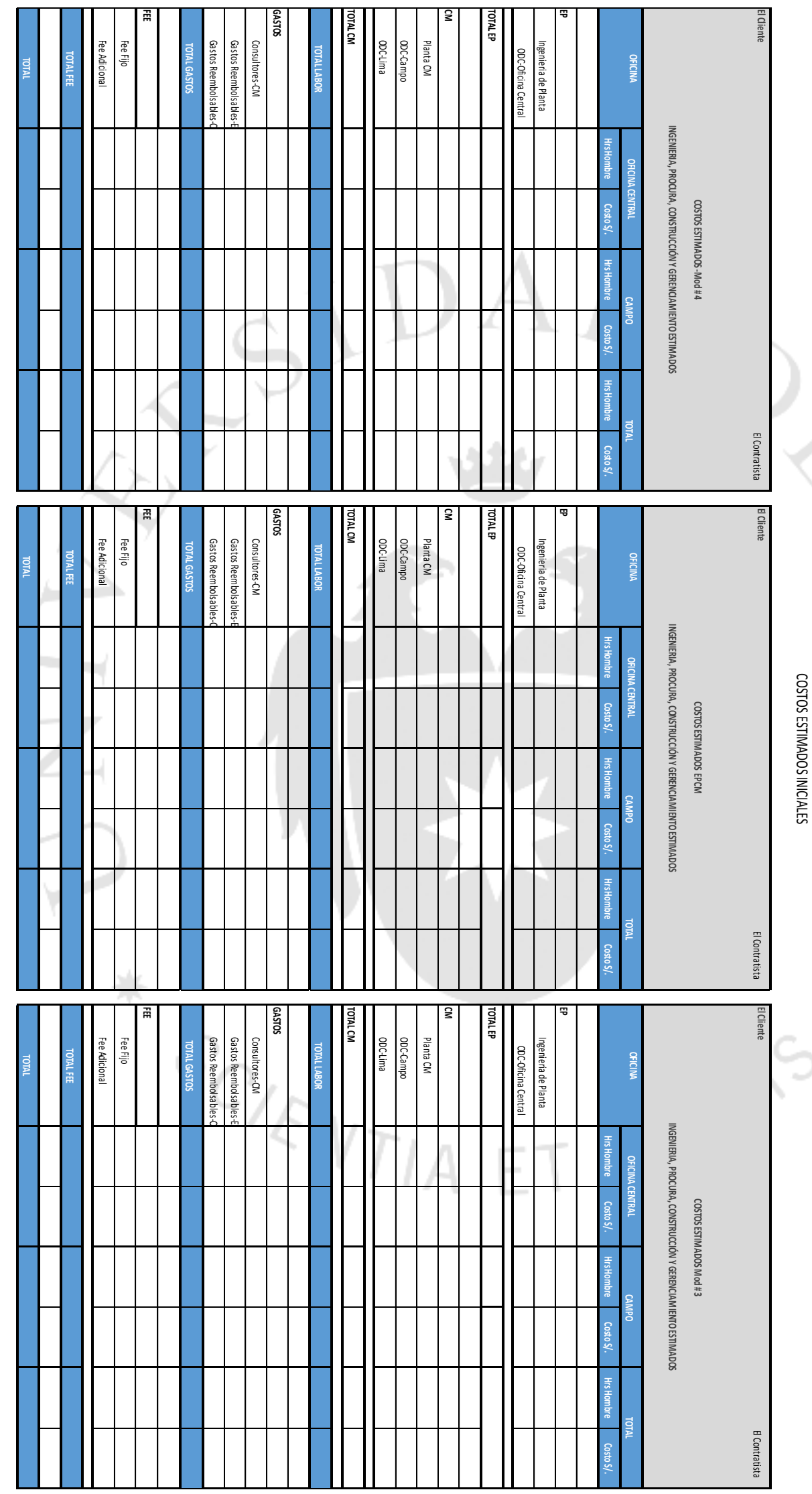
Anexo 3.6: Formato Presentación Y Solicitud De Pago De Edp's

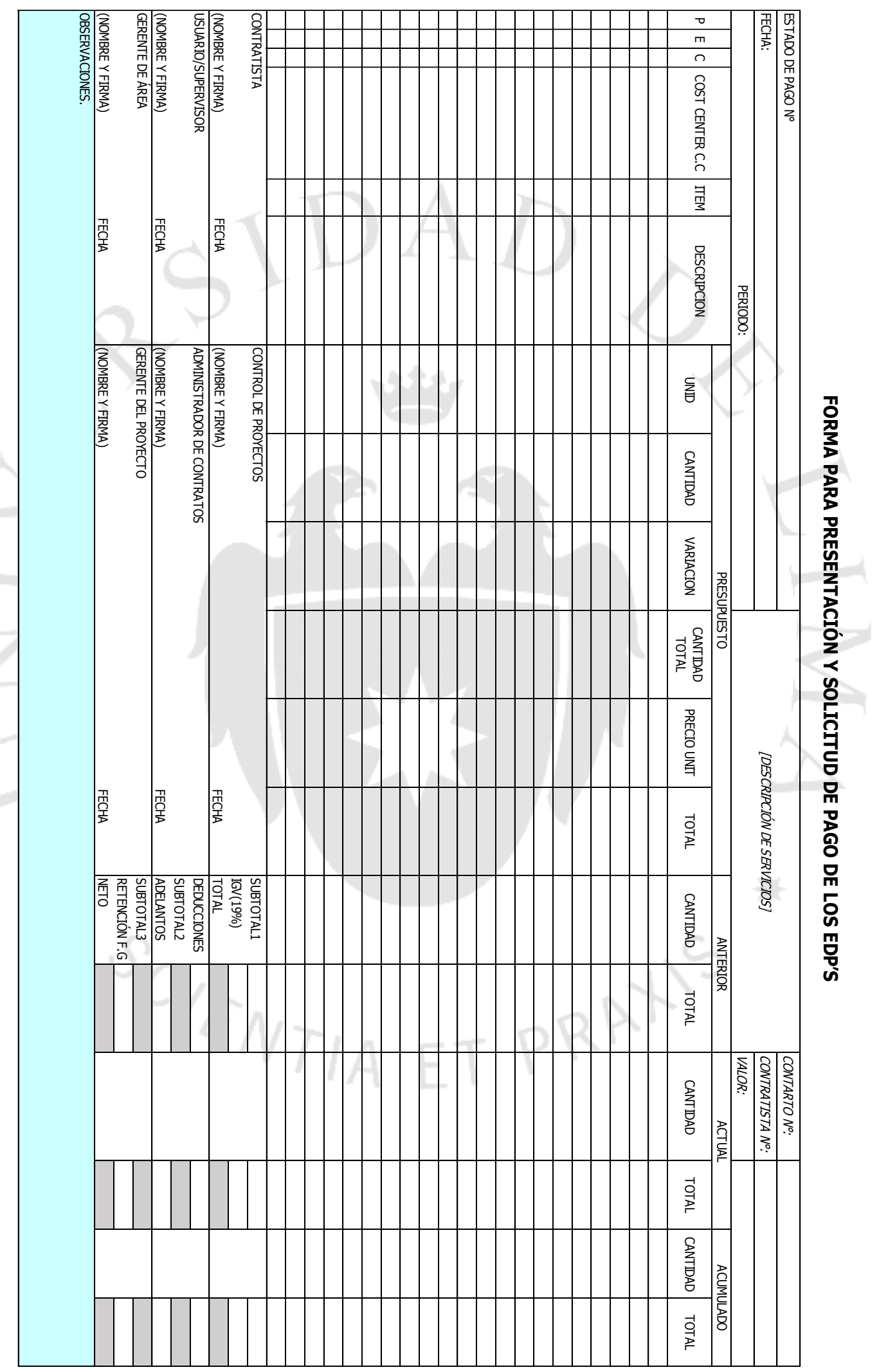




\section{Anexo 3.7: Relación De Gastos Aceptados}

Project - Services

'X' CHART

\begin{tabular}{|c|c|c|c|c|c|c|}
\hline $\mathrm{L}$. & Home Omce Costs & $\begin{array}{c}\text { Burden } \\
\text { Mutpler }\end{array}$ & $\begin{array}{l}\text { Relmbursable } \\
\text { employment } \\
\text { cocts }\end{array}$ & \begin{tabular}{|l|} 
Relmbursable \\
Expenses (as \\
per paragraph \\
4)
\end{tabular} & $\begin{array}{l}\text { Overheasd } \\
\text { Mutlipiler }\end{array}$ & $\begin{array}{c}\text { Other Direct } \\
\text { Cost }\end{array}$ \\
\hline $1 \mathrm{~A}$ & $\begin{array}{l}\text { All salaries, wages, compensation, benefits, and on-costs } \\
\text { of all categories of Consultant personnel (but not } \\
\text { including corporate officers) for the actual time expended } \\
\text { in performance and support of the Services. }\end{array}$ & & - & & & \\
\hline $1 \mathrm{~B}$ & $\begin{array}{l}\text { The time of Consultant personnel while on sick leave, } \\
\text { vacation, holiday. or while otherwise excused from } \\
\text { work (TOWP) }\end{array}$ & & $\cdot$ & & & \\
\hline 2 & Payroll burdens & - & & & & \\
\hline 3 & \begin{tabular}{|l} 
Corporate overhead - Consultant labour and general \\
corporate expenses not project related
\end{tabular} & & & & • & \\
\hline 4 & $\begin{array}{l}\text { Project support by Consultant Executive and Project } \\
\text { Sponsors (labour and expenses) }\end{array}$ & & & & $\cdot$ & \\
\hline $5 \mathrm{~A}$ & $\begin{array}{l}\text { Consultant office lease, maintenance, utilities, and } \\
\text { housekeeping services (Consultant facilities) }\end{array}$ & & & & & $\cdot$ \\
\hline $5 B$ & $\begin{array}{l}\text { Project office lease, maintenance, utilities, and } \\
\text { housekeeping services (outside Consultant facilities) }\end{array}$ & & & $\cdot$ & & \\
\hline $6 \mathrm{~A}$ & $\begin{array}{l}\text { Consultant office furniture and equipment, including } \\
\text { purchase, lease, maintenance, repair, and cleaning } \\
\text { (Consultant facilities) }\end{array}$ & & & & & $\cdot$ \\
\hline $6 \mathrm{~B}$ & $\begin{array}{l}\text { Project office furniture and equipment, including } \\
\text { purchase, lease, maintenance, repair, and cleaning } \\
\text { (outside Consultant facilities) }\end{array}$ & & & $\cdot$ & & \\
\hline 7 & General office supplies and consumables & & & & & $\cdot$ \\
\hline 8 & Solid model building and model supplies & & & $\cdot$ & & \\
\hline 9 & $\begin{array}{l}\text { Local telephone service within city limits of city where } \\
\text { Consultant Project office is located }\end{array}$ & & & & & - \\
\hline 10 & $\begin{array}{l}\text { Long distance telephone service outside of limits of city } \\
\text { where Consultant Project office is located and } \\
\begin{array}{ll}\text { international, including teleconferencing and } \\
\text { videoconferencing }\end{array}\end{array}$ & & & $\cdot$ & & \\
\hline 11 & Cost of Subconsultants & & & $\cdot$ & & \\
\hline 12 & $\begin{array}{l}\text { Consultant computers and standard Consultant computer } \\
\text { programs, Projects OnLine }{ }^{3 M} \text {, and tools including PDS } \\
\text { (toolkit system, software) }\end{array}$ & & & & & - \\
\hline 12.A & Payroll system (HO) & & & & & $\cdot$ \\
\hline 13 & $\begin{array}{l}\text { Specialty software required for the Project not included in } \\
\text { the standard Consultant systems }\end{array}$ & & & $\cdot$ & & \\
\hline 14 & $\begin{array}{l}\text { Job-related travel and living expenses for all personnel } \\
\text { (and approved by Client) while travelling away from their } \\
\text { home bases on the Project, as per Consultant policies }\end{array}$ & & & $\cdot$ & & \\
\hline
\end{tabular}


Project - Services

\begin{tabular}{|c|c|c|c|c|c|c|}
\hline L. & Home Ornoe Costs & $\begin{array}{c}\text { Burden } \\
\text { Muttepller }\end{array}$ & $\begin{array}{l}\text { Relmbursable } \\
\text { employment } \\
\text { costs }\end{array}$ & \begin{tabular}{|c|} 
Relmbursable \\
Expenses (as \\
per paragraph \\
4
\end{tabular} & $\begin{array}{l}\text { Ovemead } \\
\text { Multipler }\end{array}$ & $\begin{array}{c}\text { Other Direct } \\
\text { Cost }\end{array}$ \\
\hline 15 & $\begin{array}{l}\text { Local (within city limits of city where Consultant Project } \\
\text { office is located) postage, express mail, and courier } \\
\text { services }\end{array}$ & & & & & $\cdot$ \\
\hline 16 & $\begin{array}{l}\text { Postage, express mail, and courier services to locations } \\
\text { outside of Santiago city limits and international }\end{array}$ & & & $\cdot$ & & \\
\hline 17 & $\begin{array}{l}\text { Compact discs (CDs) and other electronic reproduction } \\
\text { and reprographics }\end{array}$ & & & & & $\cdot$ \\
\hline 18 & $\begin{array}{l}\text { Cost of day-to-day in-house printing and binding of small } \\
\text { documents and reports within the Project office, including all } \\
\text { equipment and supplies }\end{array}$ & & & & & - \\
\hline 19 & $\begin{array}{l}\text { Cost of large printing runs and binding of large } \\
\text { documents and reports undertaken externally }\end{array}$ & & & $\cdot$ & & \\
\hline 20 & $\begin{array}{l}\text { General corporate and company branch office personnel, } \\
\text { such as guards, receptionists, telephone operators, mail } \\
\text { clerks, messengers, and others not assigned or working } \\
\text { on the Project }\end{array}$ & & & & $\cdot$ & \\
\hline 21 & $\begin{array}{l}\text { Customs, duties, fees, consular charges, and custom } \\
\text { brokers fees }\end{array}$ & & & $\cdot$ & & \\
\hline 22 & Charges of commercial testing and inspection agencies & & & $\cdot$ & & \\
\hline 23 & $\begin{array}{l}\text { Freight forwarding, demurrage, boxing. storage, and } \\
\text { warehousing }\end{array}$ & & & $\cdot$ & & \\
\hline 24 & $\begin{array}{l}\text { Office services to Client's resident representatives in } \\
\text { Consultant offices up to a maximum of five (5) furnished } \\
\text { work locations for Client staff, including up to two (2) } \\
\text { offices and the remainder open work stations. }\end{array}$ & & & $\cdot$ & & \\
\hline & (a) Local telephone service & & & & & - \\
\hline & (b) Long distance telephone services & & & $\cdot$ & & \\
\hline & $\begin{array}{l}\text { (c) Mail, express mail, and courier services out of } \\
\text { Santiago and international }\end{array}$ & & & - & & \\
\hline 25 & $\begin{array}{l}\text { Office services to Client's resident representatives in } \\
\text { Consultant offices - over and above the first five (5) work } \\
\text { locations }\end{array}$ & & & $\cdot$ & & \\
\hline & (a) Office Rental @ US\$25 per sqm per Month & & & $\cdot$ & & \\
\hline & (b) Local telephone service & & & $\cdot$ & & \\
\hline & (c) Long distance telephone services & & & $\cdot$ & & \\
\hline & $\begin{array}{l}\text { (d) Mail, express mail, and courier services out of } \\
\text { Santiago and international }\end{array}$ & & & $\cdot$ & & \\
\hline
\end{tabular}

\begin{tabular}{|c|c|c|c|c|c|c|}
\hline II. & Field Costs & $\begin{array}{l}\text { Burden } \\
\text { Multepller }\end{array}$ & \begin{tabular}{|l} 
Relmbursable \\
employment \\
costs
\end{tabular} & \begin{tabular}{|l|} 
Relmbursable \\
Expenses (as \\
per paragraph \\
$4)$
\end{tabular} & $\begin{array}{l}\text { Overhead } \\
\text { Multipier }\end{array}$ & $\begin{array}{l}\text { Other Direct } \\
\text { Cost }\end{array}$ \\
\hline $1 \mathrm{~A}$ & $\begin{array}{l}\text { All salaries, wages, compensation, and benefits of all } \\
\text { categories of Consultant personnel (but not including } \\
\text { corporate officers) for the actual time expended in } \\
\text { performance and support of the Services. }\end{array}$ & & - & & & \\
\hline $1 \mathrm{~B}$ & $\begin{array}{l}\text { The time of Consultant personnel while on sick leave, } \\
\text { vacation, holiday, or while otherwise excused from } \\
\text { work (TOWP) }\end{array}$ & & - & & & \\
\hline
\end{tabular}




\begin{tabular}{|c|c|c|c|c|c|c|}
\hline II. & Fleld Costs & $\begin{array}{l}\text { Burden } \\
\text { Multipler }\end{array}$ & $\begin{array}{l}\text { Relmbursable } \\
\text { employment } \\
\text { costs }\end{array}$ & $\begin{array}{l}\text { Relmbursable } \\
\text { Expenses (as } \\
\text { per paragraph }\end{array}$ & $\begin{array}{l}\text { Overhead } \\
\text { Mutiplier }\end{array}$ & $\begin{array}{c}\text { Other Direct } \\
\text { cost }\end{array}$ \\
\hline 2 & Payroll burdens & $\cdot$ & & & & \\
\hline 3 & $\begin{array}{l}\text { Corporate overhead - Consultant labour and general } \\
\text { expenses not project related }\end{array}$ & & & & $\cdot$ & \\
\hline 4 & $\begin{array}{l}\text { Travel costs of all project related personnel according } \\
\text { to project policies }\end{array}$ & & & $\cdot$ & & \\
\hline 5 & $\begin{array}{l}\text { Establishment, maintenance, and operation of field } \\
\text { offices, warehouses, change houses, and other } \\
\text { facilities required to perform the Services and complete } \\
\text { the work at the Project Site, including rental costs, } \\
\text { furniture, fixtures, and utilities to the extent these } \\
\text { facilities are not provided free-of-charge by the Client } \\
\text { and are approved by the Client }\end{array}$ & & & $\cdot$ & & \\
\hline 6 & $\begin{array}{l}\text { Incidental contracted labour and services as approved } \\
\text { by the Client }\end{array}$ & & & $\cdot$ & & \\
\hline 7 & $\begin{array}{l}\text { Printing, compact discs (CDs), and other paper and } \\
\text { electronic reproduction done externally }\end{array}$ & & & $\cdot$ & & \\
\hline $8 . \mathrm{A}$ & $\begin{array}{l}\text { Consultant computers/workstations (laptops, desktops } \\
\text { and printers) provided to staff }\end{array}$ & & & & & $\cdot$ \\
\hline $8 . \mathrm{B}$ & Constructions toolkit systems software & & & & & $\cdot$ \\
\hline $8 . \mathrm{C}$ & Payroll systems & & & & & $\cdot$ \\
\hline 9 & $\begin{array}{l}\text { Establishment (and disestablishment) of computer } \\
\text { network and access/ international links (network, } \\
\text { communication, television, cable, cell, radio, etc), } \\
\text { including any associated sub-contracted or purchased } \\
\text { labour, equipment, and services }\end{array}$ & & & $\cdot$ & & \\
\hline 10 & $\begin{array}{l}\text { Standard Consultant suite of software load for Consultant } \\
\text { personnel }\end{array}$ & & & & & $\cdot$ \\
\hline 11 & Office furniture, equipment, and supplies & & & $\cdot$ & & \\
\hline 12 & Local telephone service, facsimiles, and postage & & & & & $\cdot$ \\
\hline 13.A & $\begin{array}{l}\text { Long distance and international telephone calls, including } \\
\text { teleconference and videoconference }\end{array}$ & & & $\cdot$ & & \\
\hline $13 . \mathrm{B}$ & Communications excluding long distance & & & & & $\cdot$ \\
\hline 14 & Cellular phones and site communications (radio, etc.) & & & $\cdot$ & & \\
\hline 16 & $\begin{array}{l}\text { Approved purchases or rental of tools and equipment } \\
\text { used for the Project, including maintenance, repair, } \\
\text { insurances, and freight and handling to and at the Project } \\
\text { Site and return, if required }\end{array}$ & & & $\cdot$ & & \\
\hline 18 & $\begin{array}{l}\text { Temporary jobsite construction materials and labour, } \\
\text { including construction utilities, telephone equipment, } \\
\text { power, water, light, compressed air, buildings, access } \\
\text { roads, and the like }\end{array}$ & & & $\cdot$ & & \\
\hline 19 & Consumable supplies used at the Project Site & & & $\cdot$ & & \\
\hline 20 & $\begin{array}{l}\text { Travel and living expenses for Project Site-based } \\
\text { personnel required and approved by Client to travel away } \\
\text { from the Project Site in connection with the Project }\end{array}$ & & & $\cdot$ & & \\
\hline
\end{tabular}


Project - Services

\begin{tabular}{|c|c|c|c|c|c|c|}
\hline il. & Field Costs & $\begin{array}{c}\text { Burden } \\
\text { Mutlepller }\end{array}$ & $\begin{array}{l}\text { Relmbursable } \\
\text { employment } \\
\text { costs }\end{array}$ & \begin{tabular}{|l|} 
Relmbursable \\
Expenses (as \\
per paragraph \\
$4)$
\end{tabular} & \begin{tabular}{l|l} 
Overthead \\
Multipler
\end{tabular} & $\begin{array}{l}\text { Other Direct } \\
\text { Cost }\end{array}$ \\
\hline 21 & $\begin{array}{l}\text { Cost of any materials necessary for the Project, including } \\
\text { freight, duty (if any), insurances, sales, use and gross } \\
\text { receipt taxes, loading, unloading, express, demurrage, } \\
\text { packing. crating. and related charges }\end{array}$ & & & - & & \\
\hline 22 & $\begin{array}{l}\text { Progress photographs and any related third-party } \\
\text { services }\end{array}$ & & & $\cdot$ & & \\
\hline 23 & $\begin{array}{l}\text { Charges of manufacturer's service for manufacturer's } \\
\text { engineers, supervisors, and technicians, approved by } \\
\text { Client }\end{array}$ & & & $\cdot$ & & \\
\hline 24 & Costs of sub-contracts, consultants, and purchase orders & & & $\cdot$ & & \\
\hline 25 & $\begin{array}{l}\text { Project Site vehicles and equipment (purchased or } \\
\text { leased), including fuel, lubricants, repair, and } \\
\text { maintenance costs }\end{array}$ & & & $\cdot$ & & \\
\hline 26 & Construction camp costs, if any & & & $\cdot$ & & \\
\hline 27 & $\begin{array}{l}\text { Supply of any construction consumables (e.g., welding } \\
\text { rods, oxygen, acetylene, etc.) and equipment as may be } \\
\text { required }\end{array}$ & & & $\cdot$ & & \\
\hline & General Costs (Home omce and Prolect Stte) & $\begin{array}{c}\text { Burden } \\
\text { Muttoler }\end{array}$ & $\begin{array}{l}\text { Relmbursable } \\
\text { employment } \\
\text { costs }\end{array}$ & \begin{tabular}{|l|} 
Relmbursable \\
Expenses (as \\
per paragraph \\
4 4)
\end{tabular} & $\begin{array}{l}\text { Overhead } \\
\text { Muttinler }\end{array}$ & $\begin{array}{c}\text { Other Direct } \\
\text { Cost }\end{array}$ \\
\hline 1 & Except as otherwise provided in the Agreement, bonds & & & $\cdot$ & & \\
\hline 2 & $\begin{array}{l}\text { Legal, financial, and business expenses for procurement } \\
\text { documents, litigation, settlement of claims, etc., specific } \\
\text { to the Project (except only in the case of dispute between } \\
\text { the Client and the Consultant) }\end{array}$ & & & $\cdot$ & & \\
\hline 3 & Royalties on processes or equipment & & & $\cdot$ & & \\
\hline 4 & $\begin{array}{l}\text { Permits, licenses, visas, and authorisations required for } \\
\text { the Project }\end{array}$ & & & $\cdot$ & & \\
\hline 5 & $\begin{array}{l}\text { Project-specific insurances but only if specifically } \\
\text { requested by the Client to be procured by the Consultant } \\
\text { for this Project and further, other than those required by } \\
\text { this Agreement }\end{array}$ & & & $\cdot$ & & \\
\hline 6 & $\begin{array}{l}\text { Charges of contractors, sub-contractors, and Suppliers } \\
\text { engaged with the Client's permission }\end{array}$ & & & $\cdot$ & & \\
\hline 7 & $\begin{array}{l}\text { Outside services, consultants, special printing/brochures, } \\
\text { laboratory tests, surveys, soil tests, at actual billings }\end{array}$ & & & $\cdot$ & & \\
\hline 8 & $\begin{array}{l}\text { Cost of any temporary and permanent materials, } \\
\text { equipment, supplies, and buildings which are purchased } \\
\text { for the Project and approved by the Client }\end{array}$ & & & $\cdot$ & & \\
\hline 11 & $\begin{array}{l}\text { Recruiting expenses, including advertising, interviews, } \\
\text { agency recruitment fees, hire-on charges, and } \\
\text { relocation expenses relative to employment of } \\
\text { personnel as they directly relate to the Project }\end{array}$ & & & $\cdot$ & & \\
\hline 12 & $\begin{array}{l}\text { Functions, team building, events, and entertainment } \\
\text { related to the Project and approved by the Client }\end{array}$ & & & - & & \\
\hline 13 & \begin{tabular}{|l|} 
Project-related training and general personnel services, \\
including facilitation and Consultant training programs \\
relevant to a person's job and development on the \\
Project, including training in Client and/or Consultant
\end{tabular} & & & $\cdot$ & & \\
\hline
\end{tabular}


Project - Services

\begin{tabular}{|c|c|c|c|c|c|c|}
\hline III. & General Costs (Home ofmoe and Propect Site) & $\begin{array}{l}\text { Burden } \\
\text { Muttoller }\end{array}$ & $\begin{array}{c}\begin{array}{c}\text { Rembursable } \\
\text { employment } \\
\text { costls }\end{array} \\
\end{array}$ & \begin{tabular}{|c|} 
Relmbursable \\
Expenses (as \\
per paragraph \\
$4)$
\end{tabular} & $\begin{array}{l}\text { Overhead } \\
\text { Multipler }\end{array}$ & $\begin{array}{c}\text { Other Direct } \\
\text { Cost }\end{array}$ \\
\hline & $\begin{array}{l}\text { practice (excluding always any training of Consultant's } \\
\text { personnel to comply with any of the Consultant's own } \\
\text { policies and/or systems, all of which cost(s) shall be } \\
\text { deemed included within the Overhead) }\end{array}$ & & & & & \\
\hline 14 & $\begin{array}{l}\text { Contributions, donations, sales, and advertising not } \\
\text { related to the Project }\end{array}$ & & & & $\cdot$ & \\
\hline 15 & $\begin{array}{l}\text { Contributions, donations, sales, and advertising related } \\
\text { to the Project, approved by the Client }\end{array}$ & & & $\cdot$ & & \\
\hline 16 & $\begin{array}{l}\text { Consultant (and/or partners) corporate property, real } \\
\text { estate, gross receipts, franchise, business, income, or } \\
\text { other related business taxes not related to the Project }\end{array}$ & & & & $\cdot$ & \\
\hline 17 & Non-project employee cash bonuses & & & & - & \\
\hline 18 & $\begin{array}{l}\text { Project-specific employee benefits and cash bonuses } \\
\text { as approved by the Client }\end{array}$ & & $\cdot$ & & & \\
\hline 19 & $\begin{array}{l}\text { Cost of Client project audits and Consultant assistance } \\
\text { to Client's auditors and other than those costs of the } \\
\text { Consultant provided for in clause } 47.3\end{array}$ & & & & $\cdot$ & \\
\hline 20 & $\begin{array}{l}\text { Cost of storage and retention of documents created } \\
\text { and/or required for the Project }\end{array}$ & & & & & $\cdot$ \\
\hline
\end{tabular}

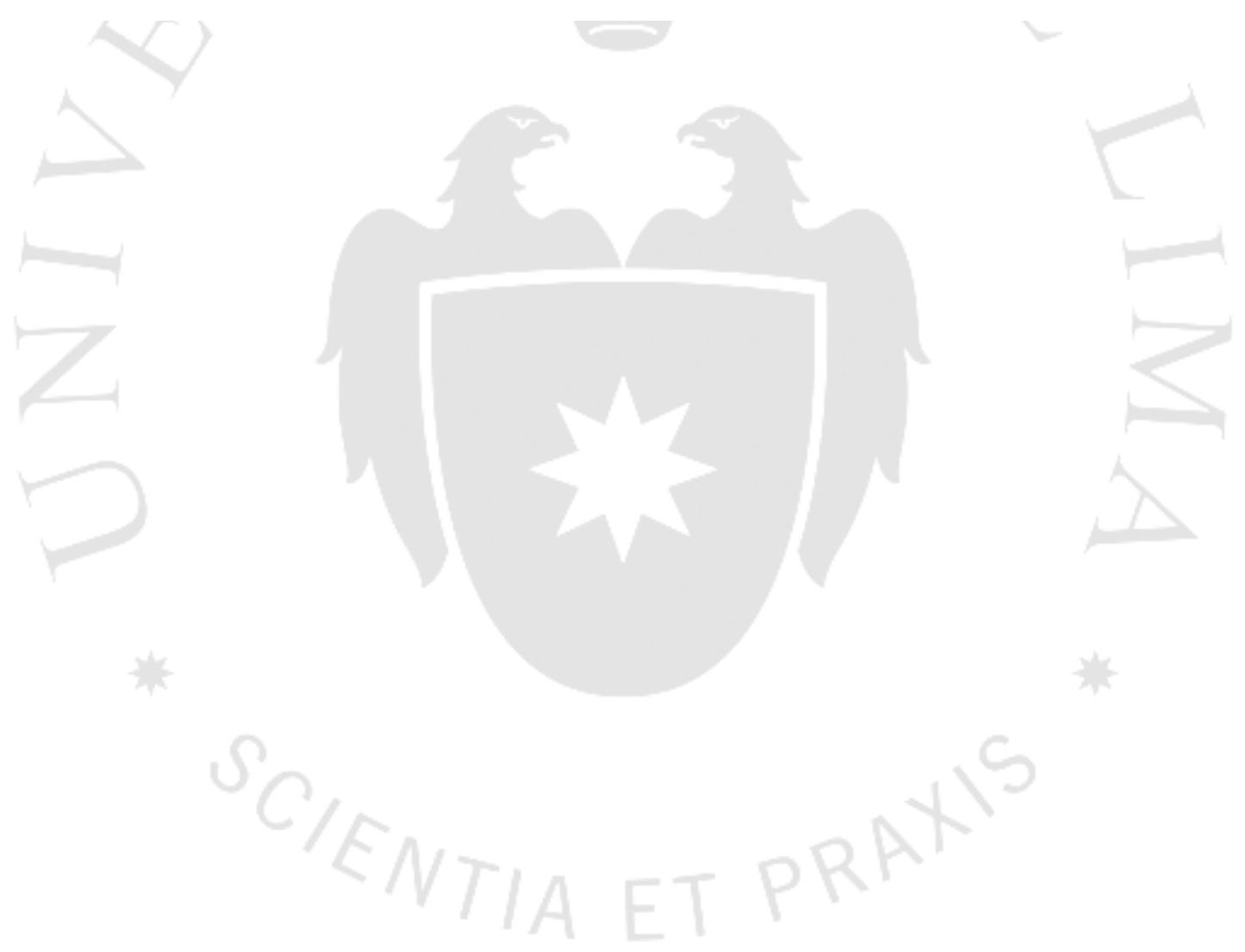




\section{Anexo 3.8: Formato De Adenda}

Numeración Correlativa

El Cliente

Dirección:

El Contratista

Dirección:

Fecha:

Atención: $\mathrm{Sr}$.

Gerente de Proyecto

\section{Asunto:}

\section{Referencia: Contrato Principal Proyecto EPCM}

De nuestra consideración:

Por la presente me es grato dirigirme a usted, para hacerles llegar Dos (02) originales de la Adenda $\mathrm{N}^{\circ} 1$ al LNTP $\mathrm{N}^{\circ} 1$ por los servicios del EPCM del Proyecto .................... agradecemos que una vez firmados por vuestras personas ambos originales, Uno (01) de ellos nos sean devueltos a vuestras oficinas de calle ................, Lima -Perú, para nuestro registro.

Sin otro particular quedamos de ustedes.

Atentamente,

Administrador Senior de Contratos

El Cliente

Proyecto 


\section{NOTICE TO PROCEED}

AMENDEMENT No.1,

To:

The Client (Legal Information: Address, RUC and Commercial Name)

Issue Date:

ENGINEERING, PROCUREMENT AND CONTRUCTION MANAGEMENT SERVICES AGREEMENT FOR (PROJECT NAME) BETWEEN “THE CLIENT" AND THE CONSULTANT DATED: MM, DD, YY (the "Agreement")

By this Notice to Proceed (the "Notice"). The Client hereby authorizes and instructs the Consultant to proceed forthwith the Services detailed in the Schedule to this Notice, subject to and in accordance with the provisions of the Agreement and this Notice (and, in the event of any conflict, discrepancy or divergence between this Notice an $\mathrm{d}$ any of the other Contract Document, the provisions of clause 2.4 of the Agreement shall apply).

The Issue Date shall be deemed to be /the commencement Date save where a different Commencement Date is stated in the Schedule to this Notice.

\section{INTERPRETATION}

In this Notice:

1.1 unless defined elsewhere in this Notice or the context requires otherwise, capitalized terms shall have the same meaning as ascribed to them in the Agreement;

1.2 references to this Notice and any provisions of this Notice or to any other document or agreement (including the Agreement) are to be construed as references to this Notice, those provisions or that document or agreement in force for the time being and as amended, varied, supplemented, substituted or novated from time to time;

1.3 words importing the singular are to include the plural and vice versa;

1.4 references to a person are to be construed to include that person's assignees or transferees or successors in title, whether direct or indirect;

1.5 in construing this Notice, the ejusdem generis rule shall not apply nor shall any similar rule or approach to the construction of this Deed and accordingly any phrase introduced by the words "including", "includes", "in particular", "for example" or similar shall be construed as illustrative and without limitation to the generality of the related general words; and

1.6 paragraph headings are for ease of reference only and are not to affect the interpretation of this Notice.

\section{SCHEDULE TO THE NOTICE}

The terms of this Notice include the following, the detail of which is more particularly set out in the Schedule to this Notice: 
2.1 the Phase and/or scope of the Services to be performed under and in accordance with this Notice, as the same may be more particularly described in the applicable sections of Appendix A(Scope of Services);

2.2 the Commencement Date if different from the Issue Date;

2.3 the Times for Completion (if any) relevant to such Services;

2.4 the maximum amount to which the Consultant may be entitled to reimbursement in respect of the Services in question (the "Maximum Amount"), subject to clause 37.1.2@ of the Conditions;

2.5 details of the requirements for any Consultant Collateral Warranty and/or any Subconsultant Collateral Warranty, insofar as applicable;

2.6 any Personnel requirements including in relation to the Key Proyect Personnel, insofar as applicable and including any changes in Appendix I (Key Project Personnel) to the commencement and cessation dates in respect of the Key Project Personnel;

2.7 the Consultant's Affiliates and Named Subconsultants, if applicable;

2.8 the personnel, equipment, facilities and services of others to be provided by the Client (if any), as more particularly described in Appendix B.

2.9 the Client's Information within the timeframes (if any) stated in the Schedule or, if no timeframe is so stated, within a reasonable period having regard to the Consultant's obligations; and

2.10 any other requirements of the Client subject always to the terms of the Agreement, including any proposed Variations thereto in accordance with clause 38 (Variations).

\section{CONDITIONS PRECEDENT}

3.1 It shall be a condition precedent to the effectiveness of the Notice that the Consultant shall provide to the Client:

3.1.1 Written confirmation signed by a duly authorized officer of the Parent Company that the Parent Company acknowledges the Parent Company Guarantee remains in full force and effect and in accordance with clause 15 of the Agreement shall be legally valid and enforceable in respect of the Services including the Phase of the Services instructed under this Notice; and

3.1.2 Documentary evidence (to the satisfaction of the Client) that the relevant Insurances required by clause 34 are being maintained,

All at the same time as or immediately following the Issue Date and in any event within ten (10) Business Days of the Issue Date

3.2 The Client shall promptly confirm to the Consultant the date on which all these conditions are satisfied. If any of the conditions in paragraphs 3.1.1 to 3.1.2 have not been satisfied within ten (10) Business Days after the Issue Date, at the Client's sole election this Notice shall lapse and become void and ineffective in respect of the Phase of the Services detailed in the Schedule to this Notice and shall be treated as if it had never been issued. 
4.1 Subject to the Consultant's compliance with the conditions of this Notice and the Agreement, the Client shall pay the Consultant for all Services provided pursuant to this Notice to the Client's reasonable satisfaction in accordance with the Agreement, up to a limit of the Maximum Amount. The amount payable for such Services shall be calculated in accordance with Appendix $\mathrm{C}$ (Remuneration and Payment) of the Agreement.

4.2 The Consultant shall not be required to provide Services exceeding in value the Maximum Amount, and if that limit is reached before the Parties agree in writing to increase it, the Consultant shall be entitled to cease performance of the Services and (if relevant) to demobilize and to vacate the Project Site. 
Anexo 3.9: Contrato Servicio De Transporte ACD

\section{CONTRATO SERVICIO DE TRANSPORTE ACD}

Proyecto: $\underline{A 1 B C}$

Contrato $\mathbf{N}^{\circ}$ : A1BC CS-300

Transporte de Personal

INDICE

1.0 DESCRIPCION DEL SERVICIO

2.0 PROGRAMA DE EJECUCION

3.0 COMUNICACIONES

4.0 INFORMES

5.0 PRECIOS DE LOS SERVICIOS

6.0 FACTURACION Y PAGOS

7.0 GARANTIAS

8.0 CASO FORTUITO O FUERZA MAYOR

9.0 OBLIGACIONES Y RESPONSABILIDADES

10.0 DECLARACIONES Y OBLIGACIONES DE LA EMPRESA 


\section{CONTRATO DE SERVICIO DE TRANSPORTE DE PERSONAL}

Este Contratos de Servicios de Transporte de Personal ("Contrato") celebrado el DD de MM de "AAAA" entre "La Empresa", RUC: 1000234567, en lo sucesivo denominada "La Compañía" y representada por Don "Representante Legal" de nacionalidad peruana, con DNI $\mathrm{N}^{\circ}$ : XXXXXXXX con domicilio para estos efectos en: "Dirección Legal de la Empresa", por una parte y por la otra, Don "Representante Legal Empresa brinda servicio", con RUC: 1000345678, con domicilio en "Dirección Legal" (en lo sucesivo denominado "La Empresa"), se ha convenido el siguiente Contrato de Servicio:

En adelante, tanto La Empresa, como la Empresa serán denominadas en forma individual como la "Parte" o en forma colectiva como las "Partes".

Considerando los términos y condiciones den el presente, las Partes convienen y acuerdan lo siguiente:

\subsection{DESCRIPCION DEL SERVICIO}

1.1 La Empresa deberá proporcionar toda la mano de obra, los servicios y recursos necesarios para el transporte de personal de La Empresa. El transporte de personal de la Compañía (en adelante el "Servicio") se presta para o en conexión con el Proyecto: (Nombre del Proyecto) denominado en lo sucesivo el "Proyecto". El Servicio que será prestado por la Empresa incluye, aunque no se limita, a lo siguiente:

Servicio de transporte de personal desde y hacia las siguientes ciudades y localidades: (detalle de las ciudades y localidades) 
1.2 La Empresa declara que se ha informado adecuadamente respecto a la naturaleza, tipo y magnitud de los Servicios contratados; la ubicación, clima, condiciones de operación y demás peculiaridades del lugar en que ellos serán prestados o ejecutados; de la clase, cantidad y calidad de los equipos y demás elementos necesarios para prestarlos; y de la especialidad, cantidad y calidad de personal necesario para cumplir con el Contrato en forma completa, correcta y oportuna, de modo que la Compañía pueda alcanzar los objetivos perseguidos por ella en la contratación de los Servicios.

1.3 La Empresa no prestará Servicios que no hayan sido previamente autorizados mediante una Modificación de Contrato.

\subsection{PROGRAMA DE EJECUCION}

2.1 La Empresa deberá comenzar los Servicios a contar de la fecha del presente Contrato. Este Contrato tendrá una duración de 3 meses, contado desde la fecha del mismo. Este Contrato se renovará automáticamente por el mismo periodo si ninguna de las partes comunica su intención de ponerle término con 15 días de anticipación a la fecha de su vencimiento.

\subsection{COMUNICACIONES}

\subsection{INFORMES}

\subsection{PRECIOS DE LOS SERVICIOS}

8.1 Servicio de transporte de personal de (lugar inicio) hasta (lugar destino) S/. XX.XX

8.2 Servicio de transporte de personal de (lugar inicio) hasta (lugar destino) S/. XX.XX

Los precios no incluyen el 18\% de Impuesto IGV

Los precios detallados en esta cláusula son por viaje en vehículos tipo Couster 
El monto del Contrato no debe exceder los S/. (importe total del Contrato)

\subsection{FACTURACION Y PAGO}

6.1 Cada 15 días, durante la ejecución del Contrato, la Empresa deberá enviar al Administrador del Contrato de la Compañía el Estado de Pago quincenal correspondiente.

6.2. Las facturaciones se efectuarán cada 15 días y se pagarán contra recepción de la factura, del detalle valorizado de los servicios prestados y de los comprobantes de servicios prestados; todo ello previamente aprobado por el Administrador del Contrato de la Compañía. El plazo para el pago de las facturas será de 15 días hábiles máximo, contados desde la fecha de recepción de cada factura junto con todos sus informes y comprobantes de servicios aprobados por la Compañía.

6.3 Las facturas deberán enviarse, junto con la documentación de respaldo previamente aprobada por el área de Contratos de la Compañía, mediante servicio de mensajería certificada, a la siguiente dirección:

Av. Lima

Atención: Trámite Documentario

6.4 Las facturas giradas a nombre de la Companía deberán incluir la siguiente información:

Nombre:

RUC:

Dirección: Lima-Perú. 
6.5 El plazo de la Compañía para objetar las facturas de la Empresa será de cinco (5) días hábiles contados desde la fecha de recepción de dicho documento por parte de la Compañía. A dicha factura deberá adjuntarse una copia del Estado de Pago correspondiente, aprobado por el Administrador del Contrato de la Compañía.

6.6 Aquellas facturas emitidas que infrinjan la ley o que no adjunten los documentos de respaldo correspondientes, o que incluyan un monto distinto del monto aprobado, serán devueltas de inmediato a la Empresa para su corrección, acordándose que la fecha límite para este pago se contará desde la fecha de emisión de la nueva factura emitida y entregada según lo estipulado en el Contrato, sin que la Empresa esté facultada a entablar demandas por ajustes, intereses o indemnizaciones de ningún tipo por el posible retraso en el pago y renunciando a acciones que pudiese ejercer en este sentido.

6.7 Con la primera factura, la Empresa deberá adjuntar la información necesaria para la emisión del pago y/o transferencia bancaria, como: nombre de la entidad bancaria, nombre de la cuenta, número de cuenta y otras del caso.

\subsection{GARANTIAS}

La Empresa acuerda prestar los servicios según los más altos niveles profesionales. Mediante el presente Contrato, la Empresa es informada que la Compañía confiará en la precisión, competencia y completitud de los servicios de la Empresa objeto de este Contrato.

\subsection{CASO FORTUITO O FUERZA MAYOR}

8.1 En los casos que algunas de las partes de vea impedida de cumplir con las obligaciones a su cargo, por caso fortuito o evento de fuerza mayor, las partes 
convienen en aplicar lo establecido en esta cláusula y supletoriamente, las reglas establecidas para esos efectos en el Código Civil que corresponda.

Atendiendo a ello, se acuerda que ante un incumplimiento por caso fortuito o fuerza mayor, se suspenderán únicamente los derechos y obligaciones de las partes, que hayan sido afectados directamente por el caso fortuito o evento de fuerza mayor.

8.1.1 En caso de presentarse un caso fortuito o evento de fuerza mayor que impida a una o ambas partes el cabal cumplimiento (total o parcial) de sus obligaciones bajo el Contrato, las partes procurarán acordar los términos y condiciones para reanudar el cumplimiento o resolver el Contrato.

8.1.2 Si una parte viese afectado el cumplimiento de sus obligaciones por caso fortuito o evento de fuerza mayor, dará aviso por escrito a la otra lo más pronto posible y, en todo caso, dentro de los cinco (5) días calendario siguientes de ocurrido o conocido el caso fortuito o fuerza mayor.

8.1.3 La Compañía mantendrá su obligación de pagar a la Empresa la contraprestación reflejada en aquellos Estados de Pagos que se encontraran aprobados al momento en el que se produjo el caso fortuito o evento de fuerza mayor, quedando liberado de pagar cualquier otro importe.

8.1.4 Constituyen casos fortuitos o eventos de fuerza mayor, aquellas circunstancias que se encuentren fuera del control de las partes y que haya sido imprevisible e irresistible para ellas y que no hubiera podido ser evitado incluso si la parte afectada hubiese actuado con la previsión 
y diligencia. Entre otros serán considerados casos fortuitos o eventos de fuerza mayor los siguientes: actos de enemigos públicos, incendios, actos o disposiciones gubernamentales, explosiones, accidentes, sabotajes, incapacidad para obtener combustibles, energía o materiales esenciales, guerras, inundaciones, huelgas y condiciones climáticas inusualmente severas.

8.1.5 Las partes acuerdan que la ejecución del presente Contrato deberá reanudarse, tan pronto como sea posible, una vez que el evento de caso fortuito o fuerza mayor haya cesado. Ambas partes acuerdan realizar todos los esfuerzos posibles para eliminar en el menor plazo posible cualquier causal que ocasione la suspensión de la ejecución del presente Contrato.

8.1.6 Si el caso fortuito o fuerza mayor se prolongara por más de 60 días desde que su ocurrencia fue notificada de conformidad con lo previsto en el numeral 8.1.2 cualquiera de las partes podrá resolver el Contrato, para lo cual se deberá seguir el procedimiento de resolución establecido.

\subsection{OBLIGACIONES Y RESPONSABILIDADES}

\subsection{DECLARACIONES Y OBLIGACIONES DE LA EMPRESA}

EN TESTIMONIO DE LO CUAL, las Partes firman el presente Contrato en el día, mes y año que se indica más abajo, pero que entra en vigencia en la fecha que primero se indica arriba. 
LA EMPRESA

Nombre:

Firma.....

Cargo: Representante Legal

Fecha....:
LA COMPAÑÍA

Nombre:

Firma....:

Cargo: Representante Legal

Fecha...: 


\section{Anexo 3.10: Orden De Compra Intech S.A. ORDEN DE COMPRA.............. 9-0096-PO}
Para :
Atn :
Fono :
Fax :
e-mail :

Fecha

Valor

Moneda

Comprador

Fono

Fax

\section{Descripción de la compra:}

Autorización del Comprador

Aceptación del Proveedor:

Sírvanse suministrar los Materiales, Equipos o Servicios que se encuentran descritos bajo "Descripción de

la Compra", sujeto a las condiciones establecidas en el presente documento, Términos y Condiciones Generales y a cualquier otro documento que se incluya, los cuales se consideran parte integral de esta Orden de Compra. 


\section{DEFINICIONES}

A. Donde se utilice en este documento las palabras "Propietario", "Comprador", "Adquirente", se entenderá el "CONTRATISTA"

B. Cuando se utilicen, en estos documentos, las palabras "Proponente", "Oferente", "Proveedor" o "Vendedor", significarán la "ENTIDAD" que ofrece o provee los Bienes y/o Servicios para el Proyecto.

\section{COMUNICACIONES}

Dirigir todas las comunicaciones a:

Atn.

Ref.

Fono

Fax

e-mail

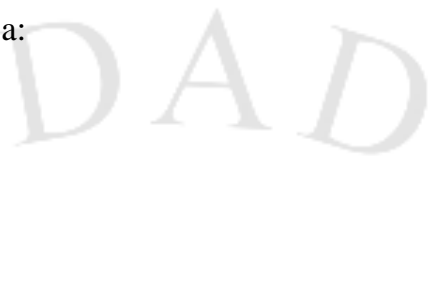

\section{NOTAS COMERCIALES}

A. Durante la vigencia de la Orden de Compra, los precios en Dólares USA son a firme y sin ningún tipo de reajuste.

B. El valor de esta Orden de Compra es:

C. Plazo de entrega:

D. Los precios están basados sobre la cotización Nro.

E. TERMINOS DE PAGO:

Los Términos de Pago son

40\% adelanto con la Orden de Compra contra presentación de Factura.

60\% Deposito en Cta. Cte. dentro de los 30 días calendario de la recepción de:

Comercial.

F. LUGAR Y CONDICION DE ENTRGA:

Los materiales de la presente Orden de Compra deberán entregase en:

Las guías y los materiales deberán identificados con la siguiente leyenda:

- Propietario:

- Requerimiento:

- Atn.:

- Ref.:

\section{CESIONES Y PRENDAS:}

El Proveedor no podrá ceder la presente Orden de Compra, otorgarla en prenda, ceder o transferir derechos bajo el mismo, realizar operaciones de factoring respecto de las facturas o cobros que pudieren generarse bajo la Orden de Compra ni dar esta en garantía. El Proveedor tampoco podrá otorgar mandatos a terceros para cobrar o percibir los montos que pudiere adeudarse al Proveedor de conformidad con esta Orden de Compra. Las operaciones señaladas no podrán ser realizadas ni aun condicionalmente. Tampoco podrá el Proveedor prometer a terceros la celebración de las operaciones mencionadas. La infracción de esta cláusula le dará al Propietario facultad a poner término inmediato a la Orden de Compra.

.....9-0096_PO - Nombre del material 


\section{INFORMACION DE FACTURACION}

Emita su factura a:

$\begin{array}{ll}\text { Giro } & \text { : } \\ \text { RUC } & : \\ \text { Dirección } & : \\ \text { Atención } & : \\ \text { Teléfono } & : \\ \text { Fax } & \text { : } \\ \text { Email } & \text { : }\end{array}$

El Proveedor deberá indicar la siguiente información en su factura.

- Número completo de la Orden de Compra.

- Descripción del bien o servicio motivo de esta Orden de Compra.

- Adjuntar las guías de remisión asociadas con esta Orden de Compra, visada por el Propietario.

- Adjuntar "Listado de materiales “o " Pedido de materiales " emitido por el Propietario (Cuando corresponda )

\section{PROGRAMA DE ENTREGA}

Fecha de Entrega :

Entrega en

Destino final

Recepción

Nota

: El número de la Orden de compra adjunta $\mathrm{N}^{\circ}$. 9-0096 PO, deberá venir identificada y/o destacada en la factura y Guía de Remisión.

\section{GARANTIA}

El Proveedor se compromete a reponer sin cargo para el comprador las mercaderías que sean recibidas defectuosas o en mal estado.

La Mercadería amparadas en esta Orden de Compra son garantizadas por el Proveedor por un tiempo de Un (1) año, a contar de la recepción.

\section{LISTADO DE MATERIALES}

Se adjunta detalle de los trabajos como parte integral de esta Orden de Compra.

\section{NO SE EFECTUARA NINGUN PAGO SIN CONTAR EN NUESTROS ARCHIVOS CON LA COPIA \\ DE ACEPTACION DEBIDAMENTE FIRMADA.}


Minera:

$\mathbf{N}^{\circ}$ Orden de Compra:

Listado de Materiales:

\begin{tabular}{|c||c|c|c||c|c||c|}
\hline LINEA \# & $\begin{array}{c}\text { DESCRIPCION DEL } \\
\text { MATERIAL }\end{array}$ & CANT & UOM & $\begin{array}{c}\text { PREC. } \\
\text { UNIT }\end{array}$ & $\begin{array}{c}\text { PREC. } \\
\text { ADIC. }\end{array}$ & PROGRAMA DE EMBARQUE \\
\hline & & & & & & \\
& & & & & & \\
& & & 2 & ea & & \\
\hline 1 & & & 1 & ea & & \\
\hline 2 & & & & & \\
\hline
\end{tabular}




\section{Anexo 3.11: Reporte Gastos De Viaje}

\begin{tabular}{|c|c|c|c|c|c|c|c|c|c|c|c|c|c|c|}
\hline \multicolumn{13}{|c|}{\begin{tabular}{|r|} 
EXPENSE REPORT \\
\end{tabular}} & \multicolumn{2}{|l|}{ No. } \\
\hline 1. NAME (LAST, FIRST, M.I.) & & & & & \multicolumn{5}{|c|}{$\begin{array}{l}\text { 2. TRAVELER ID NO./NENDOR NO. } \\
\text { SAP No. }\end{array}$} & \multicolumn{3}{|c|}{ 3. TELEPHONE } & \\
\hline \begin{tabular}{l|l} 
5. ORG. FLUOR & 6. ENT.
\end{tabular} & 7. POLICY NO. & & \multicolumn{4}{|c|}{$\begin{array}{ll}\text { 8. PURPOSE OF EXPENDITURE } \\
\end{array}$} & \multicolumn{8}{|c|}{ Business Trip - Project Set Up of PDDM to Site } \\
\hline 9. DESTINATION: CITY, STATE & & & 10. PRE & TRIP CLIENT AF & PROVAL & & & 11. CLLE & NT SIGN & ATURE & & & & DATE \\
\hline SANTIAGO - CHILE & & & $\mathrm{x}$ & YES & & NO & & & & & & & & \\
\hline 12. FORWARD REIMBURSEMENT TO: & & & DEPAR & URE DATE & & & & 13. TOT & & & & & 14. OFFICE ISSUING AD & DVANCE \\
\hline & & & RETUR & DATE & & & & ADVA & NCE \$: & & & & & \\
\hline & & ETIOI & NA-T & AVEL EXPEN & & & & & & & & & & \\
\hline DATE OF EXPENSE & MM & MM & DD & \begin{tabular}{l|l|l}
$M M$ & $D D$ \\
\end{tabular} & MM & DD & MM & $\mathrm{DD}$ & MM & DD & MM & DD & & \\
\hline 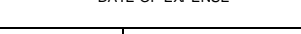 & 28-jun-11 & 29-ju & $n-11$ & 30-jun-11 & 01-jul - & $1-11$ & & ul-11 & $03-j \mathrm{j}$ & l1-11 & & $u-11$ & & \\
\hline PLACES & & & & & & & & & & & & & TOTALS FOR & FINANCE USE ONLY \\
\hline VISITED & & & + & + & & & & 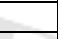 & & & & & THE WEEK & GST \\
\hline KILOMETRES DRIVEN & & & & & Z & & & & & & & & 0.00 & \\
\hline MILEAGE AMOUNT (\$0.50/KM) & & & & & & -5 & & & & & & & 0.00 & \\
\hline ACCOMMODATION & Q & & & 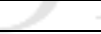 & & - & & & & & & & 0.00 & \\
\hline $\begin{array}{ll}\text { OTHER } & \text { Air Fare } \\
\end{array}$ & & & & & & & & & & & & + & 0.00 & \\
\hline & & CTION & B - M & & & & & & & & SUBT & DTALA A & 0.00 & \\
\hline MEALS - BUSINESS TRAVEL & & & & & & & & & & & 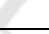 & & 0.00 & \\
\hline OTHER - (Lavandería) & & & & & & & & & & & + & + & 0.00 & \\
\hline 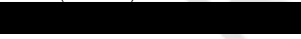 & SECTION C - E & XPENS & SES - $F$ & APPLICAB & & & & & & & SUBT & DTALB & 0.00 & \\
\hline PRIVATE - elect, telephone, HEC's etc & & & & & & & & & & & & & 0.00 & \\
\hline ENTERTAINMENT - employees \& relatives & & & & 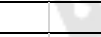 & & & & & & & & & 0.00 & \\
\hline GIFTS $>\$ 100.00$ & & & & +8 & + & & & & & & & & 0.00 & \\
\hline OTHER & & & & & & & & & & & & & $\$ 0.00$ & \\
\hline 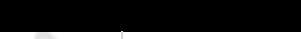 & ECTION D - EX & NSE & $S-N$ & TT APPLICA & & & & & & & SUBT & DTALC & $\$ 0.00$ & \\
\hline SUBSCRIPTIONS & & & & 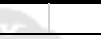 & & & & & & & & & 0.00 & \\
\hline TELEPHONE - Business & & & & 3 & & $1=$ & & & & & & & 0.00 & \\
\hline CAR PARKING / TAX - Business & & & & & & & & & & & & & 0.00 & \\
\hline ENTERTAINMENT - Business Guests & & Z & & & & & & & & & & & 0.00 & \\
\hline GIFTS $<\$ 100.00$ & & & & + & & & & & 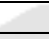 & 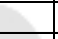 & & & 0.00 & \\
\hline FBT EXEMPT eg. Laptop computer & & & & & & & & & & & & & 0.00 & 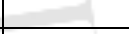 \\
\hline OTHER (*METRO) & & & & & & & & & & & & & 0.00 & \\
\hline 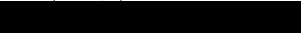 & & CTION & E-OT & & & & & & & & SUBT & DTAL D & 0.00 & \\
\hline PER DIEMS - PROVIDE FORM G8 & & & & & & & & & & & & & 0.00 & + \\
\hline CAR PACKAGED EXPENSES & & & & & & & & & & & 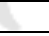 & & 0.00 & +2 \\
\hline RELOCATION EXPENSES & & & & & & & & & & & & & 0.00 & 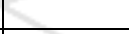 \\
\hline LAFHA / COLDA & & & & 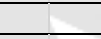 & & $\mathrm{B}$ & & & & & & & 0.00 & 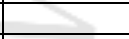 \\
\hline OTHER & & & & 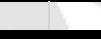 & & & & & & & & & 0.00 & \\
\hline . & SECTION F - E & XPENS & ES PA & BY COMPA & & & & & & & SUBT & DTALE & 0.00 & \\
\hline AIR FARES - BUSINESS & & & & & & & & & & & & & 0.00 & \\
\hline AIR FARES - PRIVATE ( $R$ \& R) & & & & $\bar{s}$ & - & & & & & & & & 0.00 & 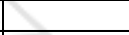 \\
\hline AIR FARES - HOME LEAVE (EXPATS ONLY) & & & & 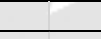 & & 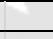 & & & 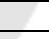 & & & & 0.00 & + \\
\hline AIR FARES - FLY IN FLY OUT & & & & & & & & 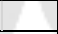 & & & & & 0.00 & \\
\hline OTHER & & & & & & & & & & & & & 0.00 & \\
\hline S & TION G - TOTA & S AND & CHAF & GING INFORN & ATION & & & & & & SUBT & TTALF & 0.00 & \\
\hline TOTALS BY DAY & & & & & & & 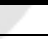 & & & & & & TOTAL: & \\
\hline OH/GL ACCT / PROJECT & & & & 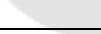 & & 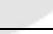 & & & & & & & TOTAL EXPENSES & \\
\hline SUBLEVEL COST CODE & & & & & & & & & & & & & $A+B+C+D+E+F$ & - \\
\hline REMARKS: & & & & & & & & & & & & & LESS: COMPANY & \\
\hline & & & & & & & & & & & & & PAID EXPENSES F & \\
\hline & & & & & & & & & & & & & LESS: & \\
\hline & 8 & & & & & & & & & & 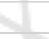 & & ADVANCES & \\
\hline 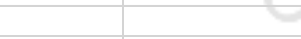 & $s$ & & & & & & & & & & & 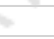 & AMOUNT & \\
\hline & & & & & & & & 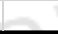 & ${ }^{2}$ & & 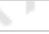 & & DUE USD to next ER & - \\
\hline & & TION & 4 & a्dNG DIST & BUTION & 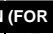 & DU & IING & E ON & & & & & \\
\hline$C / G$ & OVH ACCT/GE & LED & & PROJECT & + & SUBLE & UEL DET & ALL $/ \cos$ & CODE & $\%$ & NB & $\mathrm{BC}$ & o.c. CODE & AMOUNT \\
\hline & & & & 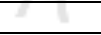 & 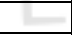 & 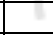 & & & & & & & & \\
\hline & & & & & & & & & & & & & & \\
\hline & & & & & & & & & & & & & & \\
\hline & & & & & & & & & & & & & & \\
\hline & & & & & & & & & & & & & & \\
\hline & & & & & & & & & & & & & & \\
\hline TRAVELER SIGNATURE & & & & & & DATE & & AUTHOF & IZED AF & PROVAL & SIGNA & & & DATE \\
\hline AUDITED BY & & & & & & DATE & & TYPE O & PRINT & & & & & \\
\hline
\end{tabular}




\section{Anexo 3.12: Documentación Para Presentación De}

\section{Valorizaciones Contratistas}

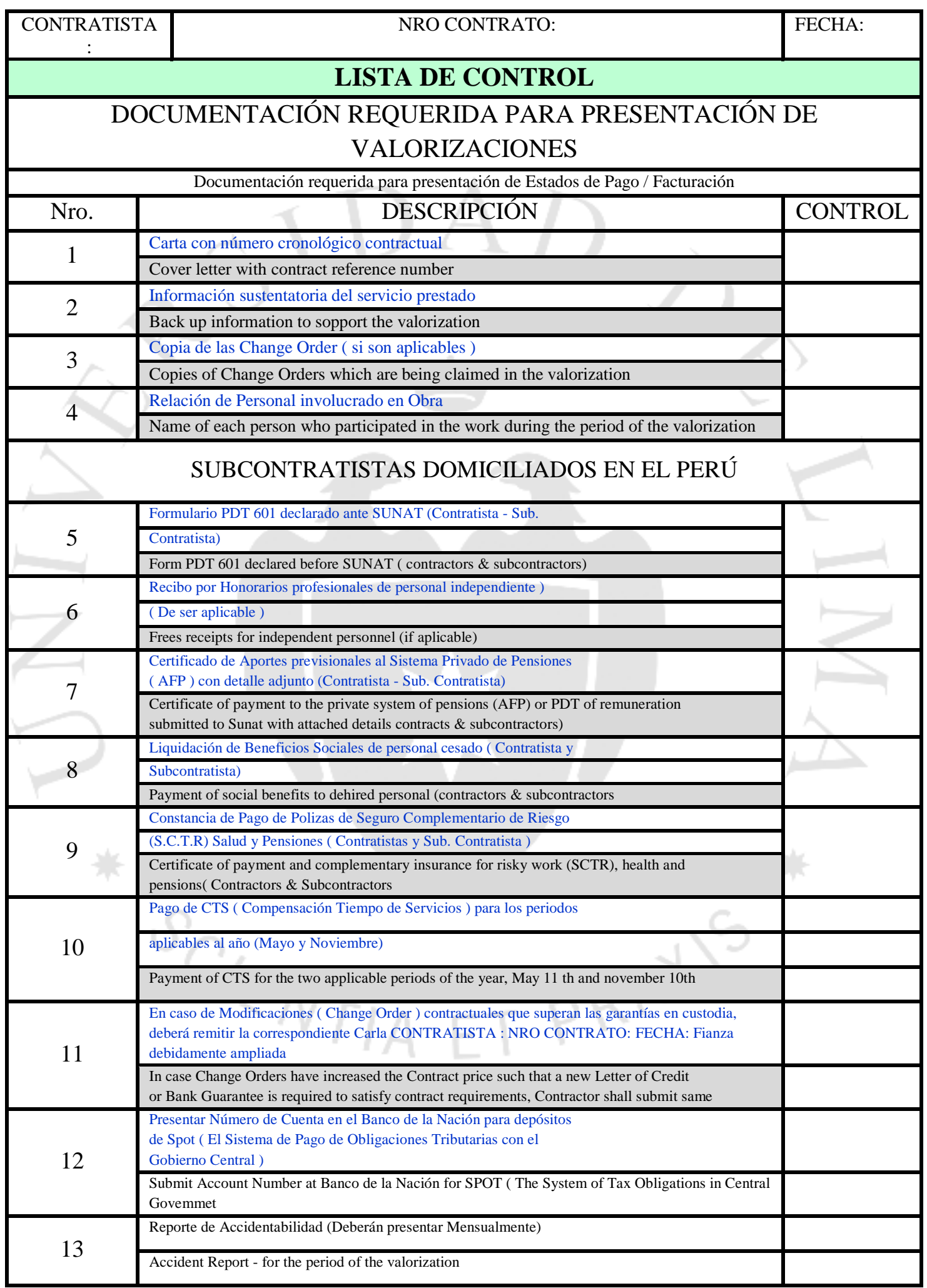

